\title{
Understanding Conduct Disorder: The ways in which mothers attempt to make sense of their children's behaviour.
}

\author{
by
}

\section{Rhiannon Lewis}

Submitted for the degree of Doctor of Psychology (Clinical Psychology)

Department of Psychology

School of Human Sciences

University of Surrey

July 2012

(C)Rhiannon Mae Peta Lewis 2012 
ProQuest Number: 27606687

All rights reserved

INFORMATION TO ALL USERS

The quality of this reproduction is dependent upon the quality of the copy submitted.

In the unlikely event that the author did not send a complete manuscript and there are missing pages, these will be noted. Also, if material had to be removed, a note will indicate the deletion.

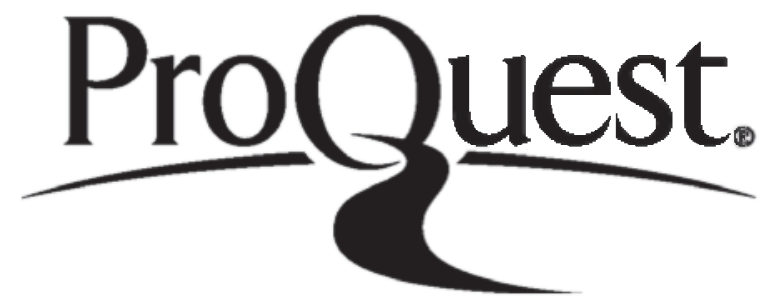

ProQuest 27606687

Published by ProQuest LLC (2019). Copyright of the Dissertation is held by the Author.

All rights reserved.

This work is protected against unauthorized copying under Title 17, United States Code Microform Edition (C) ProQuest LLC.

ProQuest LLC.

789 East Eisenhower Parkway

P.O. Box 1346

Ann Arbor, Ml $48106-1346$ 


\section{Acknowledgements}

I would like to thank all of my clinical and research supervisors who have offered me their support, guidance and encouragement during training. Special recognition goes to my clinical tutor Dr. Nan Holmes and my mentor Dr. Yasmin Mullick who have both helped me to reflect on my personal and professional development over the past three years.

I owe my eternal gratitude to my mother for helping to instil in me the personal qualities of determination and resilience that 1 needed to continue to pursue my ambitions in the face of personal struggles.

I am lucky to have met so many incredible people during this time and the support of my fellow trainees has been invaluable; extra special thanks goes to my amazing friend Kiki Atnas for always being there to help me find my way. Finally, thanks also to Dee for helping to bring me back down to earth when 1 needed it and reminding me that there is life outside of clinical training! 


\section{CONTENTS}

ACADEMIC DOSSIER

Page No.

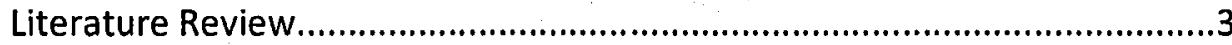

Problem Based Learning - Reflective Account (Yr 1) .................................26

Summary of Personal and Professional Learning and Development Group (PPLDG) Process Account (Yr 1)...........................................................35

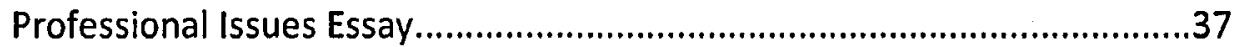

Problem Based Learning - Reflective Account (Yr 2).........................55

Summary of PPLDG Process Account (Yr 2) .............................................66

\section{CLINICAL DOSSIER}

Overview of Clinical Experience on Placement..........................................68

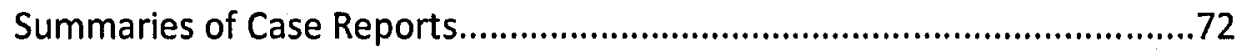

Summary of Oral Presentation of Clinical Activity.....................................8

\section{RESEARCH DOSSIER}

Service Related Research Project...........................................................83

Abstract of Qualitative Research Project...............................................120

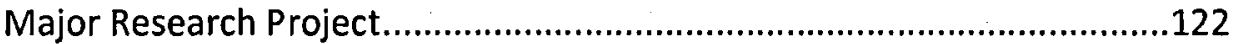

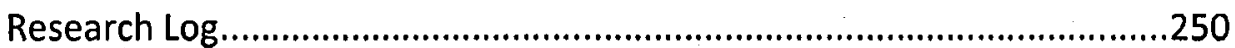




\section{Acceptance versus Change: Applications for Mindfulness based therapies in the treatment of psychological distress.}




\begin{abstract}
The so-called 'third wave' of behaviour therapies including Mindfulness Based Cognitive Therapy (MBCT) Dialectical Behaviour Therapy (DBT) and Acceptance and Commitment Therapy (ACT) have been gaining increasing attention as alternative approaches to traditional Cognitive Behavioural Therapy (CBT) in the treatment of various mental disorders, including anxiety, depression, psychosis, obsessive compulsive disorder and borderline personality disorder as well as substance misuse, pain management and eating disorders. The National Institute for Clinical and Health Excellence (NICE) currently only recommends the use of such therapies for the prevention of relapse in chronic depression and for the treatment of borderline personality disorder (NICE, 2009a, 2009b). The current review attempts to explore how the 'third wave' of therapies emerged from the existing models of behaviour therapy and examine the philosophical distinction between the different approaches. The current applications of mindfulness based approaches in the treatment of mental disorders and psychological distress are reviewed with specific reference given to the current recommendations for depression and borderline personality disorder. Finally the well as the emerging evidence for the treatment of anxiety disorders was reviewed and possible implications for clinical practise were discussed.
\end{abstract}




\section{INTRODUCTION}

\section{Question Formulation}

As a first year clinical psychology trainee $I$ am currently placed within a Primary Care Mental Health Team (PCMHT). The service operates a triage assessment process from which a range of primary and secondary treatment options are offered including computerised Cognitive Behavioural Therapy, self-help literature, care co-ordination, (including support around housing, medication management, occupational functioning, accessing education and referrals to local non-statutory services) as well as brief, medium and long-term psychological therapy.

As with many such services who strive to operate at the level of 'best practice' and within the National Institute for Clinical and Health Excellence (NICE) guidelines, the dominant model of psychological treatment offered is that of Cognitive Behavioural Therapy (CBT) and the service currently hosts two Improving Access to Psychological Therapy (IAPT) trainees. However the broader psychology team also aligns itself with many of the so-called 'third-wave' therapies and is involved in the provision of Dialectical Behaviour Therapy (DBT), Schema-focused therapy, Acceptance and Commitment Therapy (ACT) and Mindfulness Based Cognitive Therapy (MBCT). The most common presentations to be referred to the PCMHT include anxiety disorders (including generalised anxiety disorder, social phobia and panic disorder), obsessive compulsive disorder, post-traumatic stress disorder, specific phobias, bipolar affective disorder and depression as well as borderline personality disorder.

So how does the modern reflective practitioner operating within an evidence-based, protocol-driven service-paradigm choose a model to align oneself with? As an individual who is at a stage of training where problem formulation and treatment planning are often at the forefront of my mind 1 felt that this was an important question to ask myself. The introduction of 
IAPT has presented many service users with a choice beyond the prescription sheet that they may not previously have had access to, but is this a 'true' choice or are some service-users being confronted with a choice of CBT or nothing at all? When reflecting on this question I found myself querying whether the traditional CBT approach can stand up to the 'one therapy fits all' approach that the IAPT model may lead some to believe it to be.

As one model of therapy starts to become recognised as effective and economical, it would seem reasonable to assume there is often a narrowing of the evidence-base as alternative approaches receive less attention and therefore less funding. This raises the question as to whether as CBT has become the dominant model of psychological therapy it may have had the effect of excluding those who subscribe to a differing philosophy of the origins and treatment of psychological distress.

The Department of Health policy document New Horizons: A Shared Vision for Mental Health (DoH, 2009) emphasises the importance of personalized care and outlines strategy to offer a choice of treatments and extend research funding to other forms of psychological therapy. From the emerging literature it has been suggested that perhaps the 'third-wave' therapies can offer service-users an alternative way of viewing and approaching their difficulties. This is the position from which I started to explore the issue of acceptance versus change and in doing so start to examine my own therapeutic alignment and what it really means to be an 'integrative' practitioner.

\section{Methodology}

The literature review was conducted in four main stages. Firstly the National Institute for Health and Clinical Excellence (NICE) website (www.nice.org.uk) was used to access the current relevant guidelines for 
the treatment of anxiety, depression, OCD and psychosis. Secondly the National Health Service (NHS) Evidence website (www.evidence.nhs.uk) was searched using the keywords mindfulness, acceptance and commitment as a starting point for reviewing the current evidence base. Thirdly the following electronic databases were searched; Science Direct, PsycINFO, PsycARTICLES, PsycBOOKS and the Psychology and Behavioural Sciences Collection using the keywords: mindfulness; therapy; CBT; comparison; treatment; anxiety; depression; acceptance; commitment and 'third wave' in various combinations using the Boolean operators AND/OR. Finally the literature gathered thus far was used as a basis for identifying any previously omitted seminal pieces of work within the field.

\section{KEY CONSTRUCTS}

\section{The Emergence of the 'Third wave' of Behavioural Therapies}

The 'first wave' of behavioural therapies emerged in the 1950s from early work on operant and classical conditioning as well as learning theory. Therapies focused on changing observable and measurable maladaptive behaviours through techniques such as relaxation training and graded exposure to treat anxiety disorders and phobias and behavioural activation to treat depression. In the 1970 s the scope broadened to include a focus on the cognitive processes that accompanied and were underlying the observable maladaptive behaviours. This was based on the premise that for long-term change to occur there had to be a shift at the cognitive level of functioning and that individuals had strongly held, or 'core' beliefs were at the root of their current problems and would have to be challenged carefully through a process of logical analysis, Socratic questioning and examining the evidence for and against the emerging automatic thoughts and dysfunctional assumptions. This was the era of cognitive-behavioural therapy ( $C B T$ ) and there has emerged a vast evidence-base behind the 
theory-driven approach. The CBT paradigm is very much the dominant approach in use today and there have been countless protocols and treatment manuals produced for use with different clinical populations, as well as self-help books, websites and computerised CBT (CCBT) packages meaning that it has entered public as well as professional awareness. NICE currently recommends CBT for the treatment of a range of mental disorders including anxiety, depression, obsessive-compulsive disorder and post-traumatic stress disorder (NICE 2004, 2005a, 2005b, 2009a).

However in recent years there has emerged some research questioning the usefulness of the additional cognitive component of CBT (Hayes et al., 2006; Longmore \& Worrell, 2007). Critics suggest that it is not necessary to engage with the specific content of the unhelpful thoughts that occur at times of distress, but instead to move towards an understanding of the context in which they occur. The so-called 'third wave' of therapies takes a contextual and meta-cognitive approach to dealing with unhelpful thought processes and therapeutic techniques are based on developing skills in which it is possible to observe thoughts non-judgementally and move towards an understanding of the context in which they occur, therefore changing the relationship with the thoughts, rather than changing the specific form or content of the thoughts. Hayes gives the following explanation:

Grounded in an empirical, principle-focused approach, the third wave of behavioural and cognitive therapy is particularly sensitive to the context and functions of psychological phenomena, not just their form, and thus tends to emphasize contextual and experiential change strategies in addition to more direct and didactic ones. These treatments tend to seek the construction of broad, flexible and effective repertoires over an eliminative approach to narrowly defined problems, and to 
emphasize the relevance of the issues they examine for clinicians as well as clients. (Hayes, 2004 pp. 5-6)

\section{Mindfulness}

The literal translation of the word 'mindful' in the Oxford English Dictionary is to be "conscious or aware of something". The practise of mindful awareness has become familiar to many in the context of meditation as Eastern religious practices such as Yoga and Buddhism become increasingly familiar to a Western secular society searching for a way of reconnecting with a sense of spirituality or 'self' in the present moment.

However, there has been historically a tendency for psychology to try and distance itself from religious practise (Hathaway \& Tan, 2009) in an effort to be taken seriously by the natural sciences as a counterpart with grounded theoretical and evidence-based techniques. So although, arguably the CBT technique of 'decentering' or distancing the self from the content of negative thoughts and images in order to apply logical analysis and search for evidence for and against holds remarkable parallels with mindfulness, it was always seen as a means to an end and not just a useful practise in itself (Segal et al., 2002).

However in the last 15 years mindfulness as a distinct strategy has moved firmly into awareness in psychological literature as a technique for coping with distressing thoughts, images and feelings in a way that does not involve engaging with the content of the thoughts, but instead becoming aware of the context in which they occur. Guy Claxton has been at the forefront of the move towards acknowledging the impact of eastern religions on psychological theory and practise and described mindfulness as: 
...simply the knack of noticing without comment whatever is happening in your present experience. It involves just seeing from moment to moment what the mind is up to; the endless succession of ideas and feelings and perceptions and bodily sensations and memories and fantasies and moods and judgements arising and passing away. (Claxton, 1990 p.111 as cited in Still, 2005)

\section{MAIN TEXT}

\section{Current Applications for the 'Third Wave' Therapies}

Mindfulness Based Cognitive Therapy

In developing a maintenance therapy for depression Segal et al. (2002) became aware of the mindfulness as a strategy for stress reduction through the work of Jon Kabat-Zinn who described mindfulness as ...paying attention in a particular way: on purpose, in the present moment, and non-judgmentally' (Kabat-Zinn, 2003 p.145). The Mindfulness Based Stress Reduction (MBSR) programme consisted of group sessions in which participants were taught a series of strategies for coping with distressing thoughts, feelings and images including mindfulness of the breath and the body as well as using yoga stretches and mindful walking to develop a greater awareness of different feelings and sensations. These techniques were distinct from traditional relaxation strategies that are often taught as an anxiety management technique in the sense that they did not involve the participant actively trying to control or change the experience in any way, but instead encourage the individual to just notice the experience in a deliberate way, being grounded in the present moment and acknowledging any thoughts as they enter into conscious awareness. A central aspect of the programme was homework in the form of the daily practise of the techniques learnt. 
Segal et al. (2002) eventually incorporated these techniques into a Mindfulness-Based Cognitive Therapy (MBCT) for use with depression having theorised that in actual fact it was the process of decentering from unhelpful thoughts and becoming aware of the emergence of these thoughts, rather than thought challenging per se that was the essential component in preventing depressive relapse. There has been promising evidence to support the use of MBCT (Teasdale et al., 2000; Kenny \& Williams, 2007; Kuyken et al., 2008; Barnhofer et al., 2009) and it is currently recommended as an evidence-based treatment for depression in those who have experienced three or more previous episodes (NICE 2009a).

\section{Dialectical Behaviour Therapy}

Dialectical Behaviour Therapy (DBT) was initially developed through work with suicidal individuals (Linehan, 1987 cited in Robins et al., 2004) using traditional behavioural therapy techniques. It was proposed that these individuals were lacking in the appropriate skills to build and maintain a life 'worth living'. Strategies employed in these early stages included teaching problem solving, skills training, exposure and contingency management. However it soon became apparent that the focus on changing current behaviour led to participants experiencing the therapists as highly critical, and as these were individuals who had difficulties managing their emotions this perceived criticism led to disruptions to the therapeutic process including participants storming out of sessions, 'shutting down' or explicit attacks on the therapist (Robins et al., 2004). This meant that the attempts to teach the techniques which were at the core of the therapy in its current stage were being lost. However if the concept of change was not discussed, participants experienced therapists as invalidating and felt that their experience of suffering was not being sufficiently acknowledged. 
The framework of dialectics proposes that the process of change is constant and continually shifting and that every whole is made up of component parts that are entirely interrelated and inseparable. When these principles are applied to the therapeutic process the underlying philosophy means that any change cannot take place 'outside' the therapeutic relationship. Therefore this relationship is seen as the conduit for change, the context in which a more accurate view of the world can be nurtured through interactions between client and therapist and an ongoing and evaluative process of feedback.

In this context the core skill of Mindfulness is used as starting point in which to develop a clearer view of the world in the present moment, an acceptance of what 'is' without the distortions of judgments or delusions about what 'should' be. The current experience and distress of the individual is seen as an understandable consequence of the preceding events, rather than as a 'problem' to be solved, with this in mind participants are encouraged to move towards a position of radical acceptance. This does not mean labelling the current experience as inherently 'good' or 'bad' but being willing to accept that it exists in all its component parts rather than feel the need to escape, suppress or ignore it.

Participants are then encouraged to develop 'skilful means' of being and doing; that is to be aware of how ones' own actions and inactions shape the world and to be able to assimilate this information in order to respond appropriately, In essence participants are encouraged to develop a reflective stance about their own and others' behaviour. When this has started to be achieved the additional components of interpersonal effectiveness, emotion regulation and distress tolerance can be included.

Currently DBT is currently recommended as a treatment for borderline personality disorder (NICE 2009b). This population is commonly associated with high emotional reactivity and self-harm as well as interpersonal and attachment difficulties and so DBT has obvious application in developing 
alternative coping strategies for managing distress and improving interpersonal perspective taking and social problem solving (Bray et al., 2007). Evidence in support of DBT has indicated a reduction in deliberate self-injury and suicidal behaviour as well as a reduction in total number of days spent in hospital and increased social adjustment (Koons et al., 2001; Bohus et al., 2004; Robins et al., 2004). It has also been adapted for use with eating disorders and substance misuse and preliminary results appear promising (Telch et al., 2000; Dimeff et al., 2000).

Acceptance and Commitment Therapy

Acceptance and Commitment Therapy (Hayes, 2004)) has emerged from Rational Frame Theory (RFT) and has its roots in functional contextualism. This perspective assumes that it is only possible to predict and influence psychological events when viewed in context (historical and situational) rather than in isolation. RFT is primarily concerned with the acquisition and development of human language and cognition and surmises that a core part of the learning process is the ability to relate events to one another in various combinations and within a functional context (Ciarrochi et al., 2005).

When applying this to behavioural theory the implications are that since learning takes place within a context, and human cognition is a learned behaviour which holds an influence over other observable behaviours; then the context within which learning takes place holds an influence over the resulting behaviour and the subsequent function of that behaviour. From this perspective, rather than focus on specific features of cognitions and attempt to 'eliminate' maladaptive learning - it is instead possible to focus on the context in which they occur and their perceived function in order to reduce the impact of any negative cognitions (Hayes, 2004).

The general aim of ACT is to increase psychological flexibility in order to be more grounded in the present moment and more in contact with present 
experience rather than being consumed with an internal struggle in an attempt to understand, explain or suppress psychological events which usually results in experiential avoidance. From this perspective individuals are encouraged to identify a set of goal or values and identify ways in which they can work towards these goals, rather than persisting with behaviours that are intrinsically unhelpful or self-defeating. There are six core processes involved: acceptance; cognitive defusion; being present; self as context; values and committed action. Although all the core processes are seen to be interrelated, they are broadly separated into two categories 'mindfulness and acceptance' and 'commitment and behaviour change'.

ACT is not currently recommended by NICE as an evidence-based treatment for any mental disorders, however there is emerging evidence for use with depression, anxiety disorders, psychosis, chronic pain management, substance misuse, eating disorders, work related stress and smoking cessation (Hayes, 2004). Special attention is given in a review of the current evidence-base for use with anxiety disorders in the review of further applications for mindfulness-based therapies described below.

\section{Criticisms of the 'third wave' therapies}

In a systematic review and meta-analysis, (Öst, 2008) concluded that when the stringent American Psychological Association (APA) criteria for empirically supported therapies is applied, there are currently no third wave therapies that are implicated as viable alternatives to traditional cognitive behavioural therapy. Many of the criticisms of the existing studies were noted to be in the use of a relatively weak or poorly described methodology rather than the lack of a positive outcome.

However, it was noted by the authors that the APA criteria can be difficult for a relatively 'up and coming' therapy to fulfil, given that many of the treatment manuals are still under development and there are likely to be 
differences in the availability of funding when compared to established, empirically supported treatments such as CBT. It is noted that many of the studies included in the current review (see below) were published in 2009 and so could not have been included in the systematic review.

It is also noted that studies were matched for comparison with CBT studies published in the same (or a comparable) journal and within the same time period (plus or minus one year). However, other than excluding any studies conducted with children or adolescents, studies were not matched for diagnosis, gender, ethnicity, age or length of the treatment. For example, one of the criticisms of DBT highlighted by this review was the high attrition rate when compared to the CBT studies, however it is arguable that this difference is to be expected given the nature of the population that the DBT studies were conducted with (primarily individuals with borderline personality disorder who are often highly emotionally labile) and the length of treatment (five of the studies included lasted for one year) and that in order for studies to be truly comparable they should at least be matched for diagnosis and treatment length as well as year of publication.

Another criticism of the 'third wave' therapies is that the champions of the approach have based their arguments for an alternative approach on misplaced or misinterpreted critiques of the CBT model, such as its mechanistic and rigid approach and focus on symptom reduction (Hofmann \& Asmundson, 2008). There is some debate as to whether the proposed mechanisms of ACT and MBCT truly constitute a 'new' approach to the treatment of psychological distress, or are merely extensions of the existing cognitive behavioural approach. However the authors acknowledge that there is a significant philosophical distinction since CBT essentially shares its theoretical basis with the natural sciences and the idea of hypothesis testing and logical analysis whereas, as discussed 
previously $A C T$ is based on ideas from functional contextualism and DBT on dialectics.

\section{Further Applications of Mindfulness and Acceptance Based Therapies}

When publishing good practise guidelines, the National Institute for Clinical and Health Excellence (NICE) reviews potential efficacy for the treatment of mental disorders by individual diagnosis. Therefore for the current purposes it was felt that it would be appropriate to review potential further applications of mindfulness based therapies in terms of broad diagnostic categories. Particular attention here is given to recent evidence concerning the potential application to the treatment of anxiety since according to the Office of National Statistics mixed anxiety and depression is the most common form of mental distress in the UK, with generalized anxiety disorder being the second most prevalent (ONS, 2000) and thus perhaps has the most relevant in terms of applicability to a PCMHT.

There has been some promising evidence to support the use of an Acceptance-Based Behaviour Therapy (ABBT) for the use of Generalized Anxiety Disorder (GAD). Roemer and Orsillo (2007) reported significant reductions in symptom severity on measures of worry, anxiety, stress and depression following a 16 week intervention as well as significant improvements in quality of life. A follow-up at 3 months post-treatment indicated that these improvements had largely been maintained, though results on the two measures of depression used differed. It was noted that this study was limited by the absence of a control group and that this is essentially a treatment still in development, with revisions to the relapseprevention aspect of the treatment having been included by the authors since completion of the open trial.

A subsequent randomised control trial however (Roemer et al., 2008) produced similarly favourable results, however Hayes et al. (in press) highlighted that it is not yet entirely clear whether these positive results 
have truly been influenced by the mechanisms as suggested by the underlying theory of ACT, though increased acceptance was significantly correlated with an increase in the amount of time spent engaged in valued action and a decrease in reported worry.

Contrary evidence for the appropriateness of acceptance-based therapies in the treatment of anxiety comes from Hofmann et al. (2009). Brief reappraisal, acceptance and suppression techniques were compared in their effectiveness in reducing physiological and subjective experiences of anxiety during delivery of a 10 -minute speech under laboratory conditions. Re-appraisal was indicated as the most effective strategy whereas acceptance was not found to be significantly more effective in reducing subjective anxiety than suppression. It is worth noting however that acceptance was more efficacious than suppression in moderating physiological arousal (i.e. heart rate) and this finding supported earlier research by Campbell-Sills et al. (2006) who observed that acceptance was a superior strategy to suppression in managing both physiological arousal and subjective negative mood in a following exposure to an emotionprovoking film. However this earlier study was limited by the lack of a third control group to assess the apparent success of acceptance against any other recognised anxiety management strategies.

It is noted that the study by Hofmann et al. (2009) has several limitations which meaning that it is not appropriate to compare these results to the therapeutic gains of a full ACT-based treatment programme. Firstly the population (college students) was non-clinical and there were no differences observed in speech length and termination. The overall aim of both CBT and ACT based treatment for anxiety disorders in a clinical population should be to help individuals to overcome significant functional impairment associated with their difficulties and decrease maladaptive strategies such as experiential avoidance. Therefore it is questionable whether it is possible to compare effectiveness of the different strategies 
when there is no pre-existing impairment in functioning. Furthermore the strategies employed took the form of brief instructions - which clearly cannot be fully representative of all of the components in any given model of treatment. Notably the acceptance instructions did not include any mindfulness-based practise or any of the usual metaphors that are commonly used in ACT. Moreover the aim of the acceptance component of ACT is not to reduce or control any given experience, but simply to observe it fully in the present moment (Hayes et al., 2006). With this in mind a reduction in the experience of anxiety would not be predicted by the employment of such a strategy as participants are simply encouraged to engage with the experience and observe the outcome.

Further evidence in support of ACT for use with anxiety disorders comes from Eifert et al. (2009) who used a case-study design to describe a unified a treatment protocol for the use of Acceptance and Commitment Therapy with three differing sub-types of anxiety disorder: panic disorder; social phobia and OCD. The authors noted that the protocol was flexible enough to accommodate the different presentations and clinically significant reduction in symptom severity was observed for all three case studies as well as a subjective improvement in quality of life and achievement of identified goals. Obviously it is not possible to extrapolate results from this design but the evidence appears promising and a randomised control trial is currently underway. Additional support for the usefulness of acceptancebased techniques in the treatment of OCD comes from Twohig et al. (2006).

Finally some further promising support for an acceptance-based approach to the treatment of anxiety disorders comes from Kocovski et al. (2009) who observed significant reductions in symptoms of social anxiety, depression and rumination during an open trial of a mindfulness and acceptance-based group therapy. This study also offered preliminary support for mindfulness as a mediator of positive change. Once again, a 
randomised control trial comparing the approach with traditional CBT and a waiting list control group is underway by the authors.

\section{CONCLUSION}

\section{Discussion and Implications for Clinical Practise}

The current review has attempted to explore the emergence of the third wave' of behavioural therapies and their apparent philosophical distinction from the traditional model of CBT. Applications for the treatment of psychological distress were discussed both in reference to current guidelines for treatment recommended by NICE and potential further applications. Particular focus was given to the potential applications for the treatment of anxiety. Critics of the traditional CBT model argue that it has failed to live up to its perceived expectations in this area (Orsillo et al., 2004) and point out that generalized anxiety disorder remains difficult to treat successfully (Evans et al., 2008). Indeed many of the current implications for the use of mindfulness and acceptance-based therapies are in areas where the use of traditionally defined CBT has been viewed as insufficient, such as chronic depression, DBT and psychosis. In these cases it could be argued that the persistent, pervasive and subjectively uncontrollable nature of the maladaptive thought processes are such that individuals find it too stigmatising and challenging to engage with the specific form and content of their cognitions and therefore a metacognitive approach is more compatible with these client groups.

With specific reference to anxiety disorders there appears to be some promising emerging evidence with several further and more stringently controlled studies still in development. It is worth noting that in many cases the mindfulness and acceptance strategies have been added to a repertoire of existing and well-defined behavioural techniques for treating anxiety and as with CBT it has been questioned whether the 'third wave' 
therapies truly offer any additional 'added value'. However there has been some emerging evidence in support of the proposed mechanisms for change.

Finally, despite the apparent dominance of the CBT model is worth noting that although the NICE guidelines in the treatment of mental disorders are recommended as 'best practice' based on the current evidence. NICE also emphasises the importance of person-centred care and guidelines stipulate that 'treatment and care should take into account people's individual needs and preferences' and '...the guidance does not override the individual responsibility of healthcare professionals to make decisions appropriate to the circumstances of the individual patient' (NICE, 2009 p.2).

Therefore it would seem appropriate that clinical judgement, as well as national guidelines and local protocols should form the basis of any decision regarding the model of care which may be most appropriate in order to reach an integrative approach to tackling problems, rather than a rigid approach that does not offer individuals alternative ways of viewing their perceived problems. Indeed the major criticism of the IAPT model has been that it relies too heavily on this 'one-size-fits-all' approach to therapy and has led to misconceptions about the effectiveness and universal applicability of the CBT approach (Marzillier \& Hall, 2009).

\section{Personal Reflections}

As a trainee, I am currently still developing my own therapeutic style and attempting to incorporate new learning into my clinical practise. Although I had previously encountered some of the ideas discussed, I had not been in a position to incorporate specific techniques in my work with clients. With this in mind I approached the question of 'acceptance versus change' with curiosity and whilst engaging with the literature I have found myself adopting a favourable perspective, leading me to examine my own perspective about the nature and treatment of psychological distress. 
However, despite having found myself forming a generally positive and optimistic view of the emerging 'third wave' of therapies, it has not been the purpose of this review to suggest that mindfulness and acceptancebased techniques are in some way 'better than' traditional CBT strategies, but instead to explore whether there are realistic alternatives to viewing and treating a 'problem' that may offer a wider choice to service-users who might feel excluded, or indeed even stigmatised or invalidated by the emphasis on a wholly scientific perspective on the subjective experience of their distress. 


\section{References}

Barnhofer, T., Crane, C., Hargus, E., Amarasinghe, M., Winder, R. \& Williams, J. M. G. (2009). Mindfulness-based cognitive therapy as a treatment for chronic depression: A preliminary study. Behaviour Research and Therapy, 47, 366-373.

Bohus, M., Haaf, B., Simms, T., Limberger, M. F., Schmahl, C., Unckel, C. et al. (2004). Effectiveness of inpatient dialectical behavioral therapy for borderline personality disorder: a controlled trial. Behaviour Research and Therapy, 42, 487-499.

Bray, S., Barrowclough, C. \& Lobban, F. (2007). The social problem-solving abilities of people with borderline personality disorder. Behaviour Research and Therapy, 45, 1409-1417.

Campbell-Sills, L., Barlow, D. H., Brown, T. A. \& Hofmann, S. G. (2006). Effects of suppression and acceptance on emotional responses of individuals with anxiety and mood disorders. Behaviour Research and Therapy, 44, 1251-1263.

Ciarrochi, J., Robb, H. \& Godsell, C. (2005). Letting a little nonverbal air into the room: Insights from acceptance and commitment therapy: Part 1: Philosophical and theoretical underpinnings. Journal of RationalEmotive \& Cognitive Behavior Therapy, 23, 79-106.

Department of Health (2009). New Horizons: A Shared Vision for Mental Health. London: Department of Health

Dimeff, L., Rizvi, S. L., Brown, M. \& Linehan, M. M. (2000). Dialectical behavior therapy for substance abuse: A pilot application to methamphetamine-dependent women with borderline personality disorder. Cognitive and Behavioral Practice, 7, 457-468.

Eifert, G. H., Forsyth, J. P., Arch, J., Espejo, E., Keller, M. \& Langer, D. (2009). Acceptance and Commitment Therapy for Anxiety Disorders: Three Case Studies Exemplifying a Unified Treatment Protocol. Cognitive and Behavioral Practice, 16, 368-385.

Evans, S., Ferrando, S., Findler, M., Stowell, C., Smart, C. \& Haglin, D. (2008). Mindfulness-based cognitive therapy for generalized anxiety disorder. Journal of Anxiety Disorders, 22, 716-721.

Hathaway, W. \& Tan, E. (2009). Religiously oriented mindfulness-based cognitive therapy. Journal of Clinical Psychology, 65, 158-171. 
Hayes, S. A., Orsillo, S. M. \& Roemer, L. (in press). Changes in proposed mechanisms of action during an acceptance-based behavior therapy for generalized anxiety disorder. Behaviour Research and Therapy.

Hayes, S. C. (2004). Acceptance and Commitment Therapy and the New. Behavior Therapies: Mindfulness, Acceptance, and Relationship. In Hayes, S. C., Follette, V. M. \& Linehan, M. M. (eds.) Mindfulness and acceptance: Expanding the cognitive-behavioral tradition. (pp. 1-29) New York, NY US: Guilford Press.

Hayes, S. C., Luoma, J. B., Bond, F. W., Masuda, A. \& Lillis, J. (2006). Acceptance and Commitment Therapy: Model, processes and outcomes. Behaviour Research and Therapy, 44, 1-25.

Hofmann, S. G. \& Asmundson, G. J. G. (2008). Acceptance and mindfulnessbased therapy: New wave or old hat? Clinical Psychology Review, 28, 1-16.

Hofmann, S. G., Heering, S., Sawyer, A. T. \& Asnaani, A. (2009). How to handle anxiety: The effects of reappraisal, acceptance, and suppression strategies on anxious arousal. Behaviour Research and Therapy, 47, 389-394.

Kabat-Zinn, J. (2003). Mindfulness-based interventions in context: Past, present, and future. Clinical Psychology: Science and Practice, 10, 144-156.

Kenny, M. A. \& Williams, J. M. G. (2007). Treatment-resistant depressed patients show a good response to Mindfulness-based Cognitive Therapy. Behaviour Research and Therapy, 45, 617-625.

Kocovski, N. L., Fleming, J. E. \& Rector, N. A. (2009). Mindfulness and Acceptance-Based Group Therapy for Social Anxiety Disorder: An Open Trial. Cognitive and Behavioral Practice, 16, 276-289.

Koons, C. R., Robins, C. J., Lindsey Tweed, J., Lynch, T. R., Gonzalez, A. M., Morse, J. Q. et al. (2001). Efficacy of dialectical behavior therapy in women veterans with borderline personality disorder. Behavior Therapy, 32, 371-390.

Kuyken, W., Byford, S., Taylor, R. S., Watkins, E., Holden, E., White, K. et al. (2008). Mindfulness-Based Cognitive Therapy to Prevent Relapse in Recurrent Depression. Journal of Consulting and Clinical Psychology, 76, 966-978. 
Longmore, R. J. \& Worrell, M. (2007). Do we need to challenge thoughts in cognitive behavior therapy? Clinical Psychology Review, 27, 173187.

Marzillier, J. \& Hall, J. (2009). The challenge of the Layard Initiative. The Psychologist, 22 (5), 396-399.

National Institute for Health and Clinical Excellence (2004). Anxiety: management of anxiety (panic disorder, with or without agoraphobia, and generalised anxiety disorder) in adults in primary, secondary and community care. London: National Institute for Health and Clinical Excellence.

National Institute for Health and Clinical Excellence (2005a). Obsessivecompulsive disorder:

Core interventions in the treatment of obsessive compulsive disorder and body dysmorphic disorder. London: National Institute for Health and Clinical Excellence.

National Institute for Health and Clinical Excellence (2005b). Post-traumatic stress disorder

(PTSD): The management of PTSD in adults and children in primary and secondary care. London: National Institute for Health and Clinical Excellence.

National Institute for Health and Clinical Excellence (2009a). Depression: Treatment and management of depression in adults, including adults with chronich physical health problems. (Update). London: National Institute for Health and Clinical Excellence.

National Institute for Health and Clinical Excellence (2009b). Borderline personality disorder Treatment and management. London: National Institute for Health and Clinical Excellence.

Office of National Statistics (2000). Psychiatric Morbidity among Adults living in Private Households: A Summary Report. London: Office for National Statistics.

Orsillo, S. M., Roemer, L., Lerner, J. B. \& Tull, M. T. (2004). Acceptance, Mindfulness, and Cognitive-Behavioral Therapy: Comparisons, Contrasts, and Application to Anxiety. In Hayes, S. C., Follette, V. M. \& Linehan, M. M. (Eds.) Mindfulness and acceptance: Expanding the cognitive-behavioral tradition. (pp. 66-95) New York, NY US: Guilford Press. 
Öst, L.-G. (2008). Efficacy of the third wave of behavioral therapies: A systematic review and meta-analysis. Behaviour Research and Therapy, 46, 296-321.

Robins, C. J., Schmidt, H., III \& Linehan, M. M. (2004). Dialectical Behavior Therapy: Synthesizing Radical Acceptance with Skillful Means. In Hayes, S. C., Follette, V. M. \& Linehan, M. M. (Eds.) Mindfulness and acceptance: Expanding the cognitive-behavioral tradition. (pp. 3044) New York, NY US: Guilford Press.

Roemer, L. \& Orsillo, S. M. (2007). An Open Trial of an Acceptance-Based Behavior Therapy for Generalized Anxiety Disorder. Behavior Therapy, 38, 72-85.

Roemer, L., Orsillo, S. M. \& Salters-Pedneault, K. (2008). Efficacy of an Acceptance-Based Behavior Therapy for Generalized Anxiety Disorder: Evaluation in a Randomized Controlled Trial. Journal of Consulting and Clinical Psychology, 76, 1083-1089.

Segal, Z. V., Williams, J. M. G. \& Teasdale, J. D. (2002). Mindfulness-based cognitive therapy for depression: A new approach to preventing relapse, New York, NY US, Guilford Press.

Still, A. (2005). Introduction. Journal of Rational-Emotive \& Cognitive Behavior Therapy, 23, 275-280.

Teasdale, J. D., Segal, Z. V., Williams, J. M. G., Ridgeway, V. A., Soulsby, J. M. \& Lau, M. A. (2000). Prevention of relapse/recurrence in major depression by mindfulness-based cognitive therapy. Journal of Consulting and Clinical Psychology, 68, 615-623.

Telch, C. F., Agras, W. S. \& Linehan, M. M. (2000). Group dialectical behavior therapy for binge-eating disorder: A preliminary, uncontrolled trial. Behavior Therapy, 31, 569-582.

Twohig, M. P., Hayes, S. C. \& Masuda, A. (2006). Increasing Willingness to Experience Obsessions: Acceptance and Commitment Therapy as a Treatment for Obsessive-Compulsive Disorder. Behavior Therapy, 37, 3-13. 


\section{The Relationship to Change}

Problem Based Learning - Reflective Account 


\section{The Task}

The Problem Based Learning (PBL) task takes place within Personal and Professional Development (PPD) groups. We were given a task to prepare a presentation entitled 'The Relationship to Change' and advised that this could relate to clinical experiences of change and transition, theoretical models of change, as well as personal experiences and folk accounts of change. Although some initial reading and guidance was given, I found the ambiguity of the task and potentially broad scope of the subject somewhat frustrating. Perhaps this was reflective of my role as a new trainee and the desire to be given clear and specific guidance so that I could be assured that I was fulfilling the expectations of those who were potentially assessing me. I have since discussed in supervision that I often have a desire to get things right and that I sometimes find it difficult to express myself when I am worried this may not be the case. I have tried to balance this with the knowledge that it is often the process of 'wondering' about something that is important to facilitate learning rather than having the 'correct' answer. For me, this was one of the benefits of the PBL task, the ability to 'wonder' and explore a subject openly and in an environment in which there is not the immediate pressure of assessment.

\section{$\underline{\text { Initial Ideas }}$}

My initial reaction to the title 'The Relationship to Change' was to draw upon my previous clinical experience of working within Prochaska and DiClemente's (1982) transtheoretical model of change in a substancemisuse service. This prompted me to reflect in the group about the different relationship to change individuals may have depending on their individual experiences and attitudes. For example, whether change is viewed as elective or enforced will influence whether individuals go through an explicit 'decision' process which appears to be an important 
factor in order for change to be successfully maintained. I have since been able to relate this to my clinical practice; I have noticed the difficulties that individuals have in adjusting to major life events, such as loss or major illness when the change in these instances is clearly not elective. There appears to be a need to accept the change and make an explicit decision to integrate this into everyday experience, rather than struggle to return to a point before the event, which may be unrealistic.

I was aware that although topic felt quite familiar to me, I was in a sense disappointed by this as I felt that I would find it difficult to approach in an objective way. Although I initially struggled to leave my pre-conceived ideas behind me and take a different approach to the task, the group process helped me to reflect more on my own experiences of change and how it has impacted on my own personal and professional identity, roles and relationships.

\section{Group Process}

I found it helpful to view the group process in terms of Tuckman's (1965) stages of development in small groups, i.e. forming, storming, norming and performing. In the first week the group was mainly concerned with assigning roles such as chair and scribe, establishing boundaries or 'group rules' and discussing the role of the facilitator. As would be anticipated at this stage group members appeared somewhat cautious about how and what they contributed to discussions. I was aware that my own natural tendency at this stage is to be somewhat reserved and tentative in $\mathrm{my}$ suggestions. This resonated with my experience of having facilitated therapeutic groups and observations of the different roles that different group members feel most comfortable in at this stage. I noticed that some individuals initially appeared uncomfortable speaking in the group, whilst 
others were more confident in their contributions and some preferred to have a task-focused role (e.g. the scribe) at this stage.

I was also aware from previous experience that in the early stages of group development, expectations are often shaped by the presence of the facilitator and members may have a tendency to seek reassurance and attempt to please the facilitator with their contributions. I felt that this was also true of our own experience at this stage and we later reflected during the debrief process that the systemic ideas suggested by our facilitator were very quickly taken up by the group, which may have been due to a desire to please.

I felt as though there was an implicit need to have a decided approach to the problem in this initial meeting and to stay task-focused, but it soon appeared as though the subject was too broad to tackle in such a short space of time. Individual group members differed in their reactions to this, some were comfortable to go away and reflect on the problem and their own preferred approach in their own time and others appeared anxious to have a decision in the shortest possible time. These differences were also vocalised during the debrief process which appeared to be helpful in exploring the group dynamics.

Many different ideas were discussed at this stage, but there was quite a strong focus on exploring our own experiences of changes as a learning tool rather than taking the stance of 'othering' service-users and using purely clinical examples and theoretical models. There was also an early emphasis on exploring how changes to our roles (i.e. as trainees, partners, mothers and carers) may have impacted on others in our social network, which we coined 'the ripple effect'.

In the second week the group went through the process of rejecting and accepting ideas, this is often the time when the 'storming' phase takes place. However, I did not feel this was present at this stage. I was aware 
that during the debrief process some of the reflections on dynamics appeared to serve the process of relieving anxiety by using reassuring statements such as 'we worked well together' and 'everyone felt comfortable to contribute' rather than perhaps a true reflection of any dynamics at play. This would be indicative that the group was still in the 'forming' stage at this point.

The second week also highlighted differences in leadership style for me as the chair took the role of decision maker. At the time I felt uncomfortable with this, but I feel that this was reflective of my own leadership style. I also thought that assumptions were made about direction we were pursuing rather than an explicit decision making process and I felt it was important to note that not everyone's ideas had been taken up.

Between the second and third weeks, the group was tasked with exploring theories of multiple roles, role strain and social identity. During this time I went through a relationship break-up and became aware that the topic of change had become quite salient for me. I was exploring issues in the group such as social identity and self-concept (Turner, 1999) and was aware that this was related to my own desire to explore how my own identity had been impacted on by the process of change. I felt comfortable in disclosing my personal experience of change within the group but was aware that I found the concept of exploring change through a process of loss particularly difficult and reflected on whether this was similar to the experiences of my clients when asked to explore very salient issues early on in therapy before a safe environment has truly been established.

During the fourth week, group members discussed their personal experiences of loss and although this brought the group closer together, that there was a disparity in the amount of personal information that individuals were comfortable to bring at this stage. I initially felt frustrated by this but was also aware that there were certain aspects that I was not 
prepared to bring to this forum and reflected that this would certainly be true for service-users when entering a group for the first time.

The fifth week was very task focused and felt quite anxious at times. For me, it highlighted the difference in working styles as some members were very keen to get the presentation finished and take charge whilst others experienced this process as quite 'cut-throat'. It also highlighted that that individuals had different views about where the boundaries should be in terms of time and space given to the PPD group. This caused some friction and the end of the meeting was abrupt and left all feeling anxious about what the outcome would be. In terms of group process, I felt this was indicative of the 'storming' stage. In the final week finishing touches were made to the presentation and it seemed that group members had become quite tentative again in making suggestions to each other after the conflict in the previous week.

\section{The Presentation}

The final presentation focused on the impact of a forced change on the multiple roles and personal and professional relationships that we maintain. We drew on theories of role strain (Wheaton, 1990) and focused on the loss of a role through bereavement as the change in question in order to demonstrate the ideas we had discussed, but this change could have taken many different forms. We used an 'eco-map' to guide our thinking that was an amalgamation of our own experiences and this meant that the content had salience for each one of us.

\section{Personal and Professional Reflections}

The group process was an important learning tool in enabling me to reflect on how multi disciplinary teams (MDT) operate. I noted that in an MDT 
there is usually an explicit hierarchy and differing theoretical approaches which would often be the more obvious source of any dispute. However, within the PPD group I presumed that the environment would be relatively conflict-free because of assumptions that I made about the similarities of the group members.

I also felt that assumptions were made by all group members about the diversity present in the group in terms of background and experience, as well as what constitutes diversity. Change may have many different implications and meanings for different people depending on their experiences, background and culture. When I thought that other members of the group had made assumptions about the experiences I had, I was left feeling quite invalidated. These issues have wider implications for working in a team, as well as the therapeutic relationship and I feel it is important to try and note any assumptions that I make about others, and discuss these in supervision with an awareness that it is impossible to truly leave our pre-conceived ideas 'at the door'.

In terms of the applications to my clinical practice I feel I have become more aware of the impact that a loss of role can have on an individual and their wider network and have taken this into account when developing formulations, especially with regards to the maintenance of the problem. The feedback from the 'ripple effect' appears to be a reciprocal process, as when expectations about roles and relationships are not met from either side, this can result in conflict and frustration within the network.

I have been reminded of the importance of attitudes to change in determining how adaptable people may be to different circumstances. I have moved towards trying to foster acceptance of change with individuals who appear to be struggling to adapt, rather than move too swiftly towards tackling the 'problem' in a task-focused way whilst there is still ambivalence. 
Finally, I have been reminded that there are many different factors that come into play when someone decides whether or not to disclose, including their own assumptions about whether you as a therapist will be able to identify with and understand their loss. From my own experience of change during the task I recognised that it is difficult to reflect on a process when you are 'in' the process, things become more salient and it is tempting to steer clear of hot topics as a way of coping with this. 


\section{References}

Prochaska, J. O. \& DiClemente, C. C. (1982). Trans-theoretical therapy toward a more integrative model of change. Psychotherapy: Theory, Research and Practice, 19, 276-288.

Tuckman, B. W. (1965). Developmental sequence in small groups. Psychological Bulletin, 63, 384-399

Turner, J. C. (1999). Social identity, personality and the self-concept: A self categorizing perspective. In Tyler, T. R., Kramer, R. M. \& John, O. P. (Eds.) The psychology of the social self. (pp. 11-46) Mahwah, NJ, US: Lawrence Erlbaum Associates Publishers

Wheaton, B. (1990). Life Transitions, Role Histories and Mental Health. American Sociological Review, 55, 209-223 


\section{Personal and Professional Learning and Development Group (PPLDG) Process Account}




\section{Summary}

The Personal and Professional Learning and Development Group (PPLDG) is designed to 'promote reflection on clinical work, with reference to personal and professional learning, ethical dilemmas in our work, appreciation of diversity and the development of cultural attunement, and theory-practice linking' (University of Surrey, 2009). This account aims to give an overview of how my participation in the PPLDG process has contributed to my own personal and professional development during my first year of training.

Specific examples include potential applications to clinical practice, how my participation in the group has helped me to process feedback received from my supervisors and reflections on the cultural genogram exercise. Discussion is given to the organisation and structure of the group and how the individual roles and purpose of the group were defined during the early stages - including strengths and limitations of the approach taken by the group.

I have attempted to examine the wider issue of group processes and dynamics with reference to the PPLDG, group therapeutic processes and Multi-Disciplinary Team (MDT) working. I have also attempted to consider how my role within the group has been shaped and how it may have changed over time as well as how my contributions to the PPLDG process may have influenced others' learning. Finally discussion is given to the ending of the group and potential future directions. 
Moving beyond the distress/disability of the individual: how can clinical psychologists work with local communities to reduce the stigma and discrimination that lead to social exclusion?

Professional Issues Essay 


\section{Introduction}

The problem of social exclusion has become increasingly prominent over the past ten years and is now a hotly debated political issue, despite there being some ambiguity about what is actually meant by the term (Morgan et al., 2007). For the purpose of this essay I will be using the term social exclusion to refer to the marginalisation of a sector of the population by wider society, leading to inequalities in access to resources including education, employment, social occupation, adequate housing, financial resources and health and social care as well as restriction in social interaction and participation in political activities (Centre for Analysis of Social Exclusion, 2002). For the purpose of this essay I have focused on the stigma and discrimination faced by individuals experiencing mental health difficulties as it is in this area that the majority of my clinical experience has been based. However it is worth acknowledging that the many issues discussed can relate to any group that has historically been disenfranchised and disempowered by social inequalities.

From a personal perspective I was particularly interested in exploring the issue of mental health and social exclusion due to my own experiences of having facilitated psycho-education, relapse-prevention and recoveryoriented groups in various inpatient, forensic and community settings. I have found that during open discussions about stigma, discrimination and social exclusion, the perceived ability (or inability) to overcome these difficulties was often viewed by group members as being at least equally, if not more important in their recovery as the ability to cope with the actual 'symptoms' of their mental health difficulties. I was interested to move beyond my own anecdotal evidence and explore how these issues are currently being addressed, both by the government at a national level and by clinical psychology as a profession.

I aim to give a historical and political backdrop to the issue of social exclusion and mental health, before moving on to discuss some of the 
current initiatives being spearheaded to tackle the problem of social exclusion and the possible role for clinical psychology in moving these initiatives forward. I have chosen to focus primarily on the issue of service delivery as this stood out for me as an area in which the role of clinical psychology could be neglected if not for individuals within the field who have been key in ensuring that their voices are heard. During my own experience of training so far 1 have tended to focus on developing my individual clinical skills and I think that it is through involvement in wider issues such as tackling social exclusion that the leadership role of clinical psychology becomes more apparent.

\section{Background}

\section{Historical Context}

The physical exclusion from society of those suffering from mental distress can be said to date back to around the sixteenth century with the introduction of 'lunatic asylums' and although the institutions that exist now may be vastly different from their initial incarnations they still serve the purpose of keeping the distress of their occupants hidden from public view (Hinshaw et al., 2006). Many institutions during the nineteenth and early part of the twentieth century operated as self-sufficient communities, removing any need for their residents to access mainstream services - this only changed during the latter half of the twentieth century when reforms in health and social care meant that a new emphasis was placed on providing support within the community. This presented a dual challenge, not only did individuals who had spent years living in institutionalised-care have to adapt to community living - but the community would have to adapt to having mental health difficulties on the doorstep after years of having them hidden away behind closed doors. It has proved to be a

difficult challenge, Sayce (1998) describes some of the consequences of the 
public fears that arose during the 1990's, including a rise in media stories linking mental illness and violence and a spate of 'nimby' (not in my back yard) campaigns in opposition to community-based mental health services. It was against this backdrop that the issue of social exclusion and mental health started to emerge and started to become the subject of extensive research and government policy.

\section{Stigmatising Language}

The language used to describe mental illness has an extensive and complicated history. Valerie Sinason (1992) describes how language can hold an intrinsic role in our relationship with and comfort (or discomfort) in discussing an issue such as disability or mental illness. As terms which were once considered to be descriptive are used in a pejorative sense, they are replaced by new terms to describe the same concept. Sinason argues that this serves a function of allowing us to distance ourselves from the uncomfortable reminder of how society has dealt with the 'problem' of mental illness in the past and convince ourselves that by changing the language we use, we have by association changed our relationship with the problem. Despite these criticisms of the constant need to change the language associated will mental illness; there has been a strong move to establish a shift in the language used to describe individuals experiencing mental health difficulties, emphasising that challenging stigmatising language has played a major part in the success of other antidiscriminatory campaigns (Thompson \& Thompson, 1997 cited in Byrne, 2000). Shattell (2009) describes how referring to someone as 'schizophrenic' places the issue of illness before the person. She describes that using a description 'individual with schizophrenia' acknowledges that the individual comes first, not the illness. Others have gone further to suggest that the description 'individual with a diagnosis of schizophrenia' is preferable as it doesn't assume the label of 'illness' as a fact, merely the 
existence of a socially constructed label with which the individual may or may not be in agreement.

In the United States the National Alliance on Mental Illness (NAMI) has coined the term 'Brain Disorder' to emphasise a physiological or biological cause of mental illness (Shattell, 2009). However research suggests that public information campaigns that focus on a bio-medical model do little to promote a more positive attitude towards people with mental health difficulties (Sholl et al., 2010), and may actually contribute to an increase in negative viewpoints around dangerousness and treatability (Read \& Harre, 2001).

In the UK mental health services now encourage use of the term 'serviceuser' as a less medicalised term than the previously commonly used 'patient'. Throughout this essay I have mainly chosen to use the term 'individuals with mental health difficulties' I felt that the term 'serviceusers' can be inappropriate when discussing the issue of social exclusion as it does not acknowledge that many individuals experiencing mental health difficulties may never come to the attention of services and do not receive the appropriate support. In my own clinical experience I have often chosen to use the language preferred by the individual and have come across some strong opposition to the currently popular term 'service-user', one individual I worked with (who was at the time detained under the mental health act) told me they found the term patronising and inaccurate and stated "I'm not a service-user, I'm a patient! I don't have an option about whether I use this service or not." I found this to be a suitable reminder that sometimes our use of language serves the purpose of alleviating our own discomfort, and not the distress of those who it purports to describe.

\section{Moving into the Present - the Current Problem}

The Social Exclusion Unit (SEU) attributes the problem of social exclusion to ....a combination of linked problems such as unemployment, poor skills, 
low incomes, poor housing, high crime environments bad health and family breakdown' (SEU, 2004). Individuals with mental health problems have been identified as one of the most excluded groups in society, with strong links between homelessness and poor physical and mental health. Some groups have been identified as more vulnerable to the consequences of social exclusion, including women, asylum seekers and refugees and older people (National electronic Library for Health, 2004). As well as the direct consequences or 'symptoms' of mental illness, individuals often have to try and navigate potential loss of employment, relationship breakdowns and even homelessness. Combined with this is the impact of direct discrimination due to the label of mental illness and stigmatizing views from others, including mental health professionals (Berry et al., 2010). The true impact of stigma and discrimination is complex, multi-dimensional and difficult to measure fully since it takes many forms. Henderson and Thorncroft (2009) present a systemic model of stigma and discrimination demonstrating the multiple causes and consequences whilst Pinfold et al (2005) used focus groups to explore 'service-users' views and participants identified three main themes that resulted from stigmatisation: disempowerment, diminished credibility and avoidance by others.

The extent to which mental health difficulties are experienced as stigmatising by an individual will not simply depend on the dominant public view, but also the views held within the family and culture of origin. Different cultures hold different beliefs about the nature and origin of mental illness and there may be particular issues around shame in certain cultures that lead to mental health difficulties being hidden and individuals feeling excluded from family life (Knifton et al., 2010). As well as mental health difficulties themselves having a stigma attached, seeking help is often seen as stigmatising in itself. This can result in individuals not receiving help or support for their difficulties until a 'crisis' point, at which time consequences such as loss of employment or hospitalisation are more 
likely than if support had been provided at an earlier stage (Royal College of Psychiatrists Social Inclusion Scoping Group, 2009). This has led to a focus on early intervention services designed to work on a supportive and preventative capacity. Whether individuals decide to seek help is likely to be dependent on the extent to which they have internalised the stigmatising views of mental health difficulties, or 'self-stigma' combined with previously held views and ideas about seeking help. Research has indicated that the extent to which individuals hold self-stigmatizing beliefs is also likely to be related to cultural and gender norms and expectations about the ways in which people should deal with their problems (Vogel \& Wade, 2009).

\section{Current Policy and Political Context}

The need to address stigma and discrimination was identified as a priority for mental health service provision by the World Health Organisation (WHO, 2001). The 2001 World Health Report emphasised the importance of a multilevel approach incorporating public information campaigns as well as the education of health professionals and provision of communitybased mental health services, working alongside non-statutory services and supporting families to promote well-being, inclusion and recovery. It also emphasised the importance of effective legislation to protect the rights of individuals with mental health difficulties, e.g. in the workplace.

In the United Kingdom the issue of social exclusion has been a policy priority for over a decade. In 1999 the Department of Health (DoH) published the 'National Service Framework', a set of standards for the delivery of mental health services which set out specific guidance for combating discrimination and social exclusion. In 2004 the Social Exclusion Unit (SEU) was commissioned to consider what could be done to reduce social exclusion among adults with mental health problems (SEU, 2004). The study included consultation with mental health service-users and 
carers as well as service providers from health and social care, employment, housing and voluntary sectors. It highlighted stigma and discrimination as playing a large role in maintaining the problem of social exclusion, as well as low employment expectations for people with mental health difficulties and no clear responsibility for health and social care professionals to promote social and vocational opportunities. It also noted a lack of awareness amongst community services, such as education, arts, sports and leisure providers regarding how their services could be beneficial to those suffering from mental health difficulties and how they could make them more accessible. The SEU report also indicated that certain groups may face additional barriers to getting their needs met, such as those from black and ethnic minority (BME) backgrounds, young men with mental health problems (who may have dropped out of education and employment and become involved with crime), lone parents and adults with complex needs such as co-morbid substance misuse problems. Action points included a sustained programme to challenge stigma and discrimination, specifically targeting schools, the police force and Jobcentre staff as well as health and social care professionals. An emphasis was placed on the role of mental health services in promoting social inclusion as well as the responsibility of community resource providers to improve the accessibility of their services to people with mental health difficulties. The actions highlighted were carried forward and subsequently reviewed by the National Social Inclusion Programme (NSIP, 2009) who highlighted some successes in all areas, but emphasised that further work was needed.

Tackling mental health stigma and discrimination and delivering personcentred care was recognised as a priority for service provision and reform in the 'New Horizons' document (DoH, 2009a) and promoting wellbeing by taking into account an individuals' physical and mental health, social and emotional needs, personal relationships and daytime activity was included as an essential quality standard by the Care Quality Commission (CQC, 2010). Since 2009 The Inclusion Institute (part of the International School 
for Communities, Rights and Inclusion (ISCRI) at the University of Central Lancashire) has been tasked with taking forward the work of the NSIP as 'a centre of excellence for learning, evidence, innovation and practice on inclusion' (www.socialinclusion.org.uk/home/index.php accessed on 17 January 2011). It seems clear that the issue of social exclusion continues to be a service-priority - but it is sometimes less clear from the policy documents how this maps onto day-to-day service delivery.

\section{Service Delivery}

The funding and organisation of services may seem at first glance to be a separate issue to the problem of challenging stigma and discrimination with which this essay is primarily concerned. However one of the maintaining factors in the cycle of prejudice and discrimination is the lack of exposure that many people have to individuals with mental health difficulties in everyday environments and situations. With increased contact and experience comes greater understanding and a more positive attitude regarding what it means to experience mental health problems (Corrigan et al., 2001). The stigma of mental illness also impacts on confidence and self-esteem, this is all too often combined with an experience of hospitalisation and loss of involvement in everyday decision making. Individuals may also find decision making difficult or overwhelming as a direct result of their mental health difficulties and previously the tendency of mental health professionals was to attempt to help by taking the pressure away by simply doing tasks for the person rather than encouraging and empowering the individual to complete tasks for themselves. These factors can result in a loss of independent agency and a tendency to depend on others to make decisions, in extreme cases where individuals have spent long periods of time in inpatient care as a result of their mental health difficulties this process has been referred to as 
institutionalisation and a return to independent living in the community can feel overwhelming rather than liberating and welcoming.

One of the ways in which the government aims to address this is to deliver services in a way that provides greater choice, individual freedom and encourages more integration with mainstream services rather than a reliance on specialist mental health services which can restrict social engagement to other individuals with mental health difficulties and mental health professionals. This can be argued to help to empower the individual to take control over the way in which their care is provided, in essence becoming a consumer of health and social care services.

One of the initiatives introduced to try and encourage the use of mainstream services by people with mental health difficulties was the introduction of the 'Direct Payments' or 'Personal Budgets' scheme (DoH, 2009b) which aimed to give individuals more choice about the way in which they utilise community resources rather than feel restricted to the use of specialist mental health services.

However there are some criticisms of the Direct Payment programme, it is noted that there has been relatively poor uptake of the scheme and individuals need additional support from services to make the best use of the scheme. Some mental health day services have seen their funding withdrawn since the introduction of the scheme and critics argue that this has actually contributed to service-users feeling more isolated and excluded as these services had played a vital social role. There has been considerable opposition to the closure of day services from service-user and carer groups. For example, in response to the plan to close mental health day Services in Nottingham Peter Robinson, Chair of the Carers Council - Allies in Mental Health wrote:

\footnotetext{
"We understand the need for services to be designed to provide as much possible for mental health service users... to feel
} 
socially included. There is potential within self-directed support to improve support to some clients and increase choice of services. Day services need to respond to the challenge of personalisation, and provide value for money at a time of pressure on resources. However the closure of services without proper consideration of the benefits to clients of these services, and the current and future provision of community services, actually reduces choice and increases social isolation. Social inclusion actually requires more high value services, not less"

(www.pdteam.org.uk/blog/wordpress/?p=105 accessed on 19 January 2011). The letter goes on to describe concerns that the services provided by specialist day centres cannot be matched by mainstream services, which do not have the knowledge and resources to effectively support people with mental health difficulties and expresses fears that without these services, individuals will become increasingly isolated and vulnerable leading to an eventual deterioration in mental health. One service user who was asked by a local newspaper to express her views regarding the closure stated "They are trying to take away our day centre which is part of our lives. We will end up back in psychiatric wards." (www.thisisnottingham.co.uk/news/Consultation-closure-mental-healthday-centres-sham/article-2417584-detail/article.html accessed on 19 January 2011). There is also criticism that some people will not be able to manage their Personal Budgets effectively and that at best they will provide individuals with a few hours a week of support to access local services, which is no substitute to the social contact and flexibility provided by specialist day centres.

Whilst writing I found myself wondering why in the move to encourage greater integration into the community it has at times been constructed as a negative for individuals with mental health difficulties to spend time with others who have a shared experience and may offer a greater under- 
standing of their unique experiences. My own experience has been that when people come together as a group it can be highly normalising and reassuring. Whilst it is clear that services need to be provided in a way that offers individualised care and promotes social inclusion I wonder whether in this case the views of those who these decisions concern have been adequately taken into account. Berry et al. (2010) highlight that whilst service-user involvement is now an essential requirement in the planning and delivery of mental health services, it is often carried out in a way that is 'tokenistic' and that service-user views are subject to being routinely discredited or disregarded on grounds of limited resources.

I also wondered whether the approach to service re-organisation has attempted to produce a rapid uptake the use of mainstream services by, in a sense, removing the alternatives before the current obstacles to accessing services have been adequately addressed. Examining some of the policy documents draws attention to the fact that at the heart of the governments drive to promote mental health and wellbeing and reduce social exclusion there is an agenda of reducing the financial burden that individuals' with mental health problems place on the taxpayer. The role of a clinical psychologist extends beyond the therapy room and as mental health professionals, members of multi-disciplinary teams, researchers and leaders, clinical psychologists are in a position to be part of the consultation and decision making process to ensure that services are organised in a way that truly takes into account the needs and views of service-users and delivered thoughtfully with a long-term view.

As previously noted, individuals from black and ethnic minority backgrounds are at an increased risk of suffering the consequences of social exclusion due to mental health difficulties. Service providers need to ensure that they are targeting these communities effectively and delivering culturally sensitive care. Bowl (2007) highlights that whilst the previous government had made clear the intention to provide '... a safe and clinically 
effective, recovery-enhancing environment that respects their beliefs, culture, faith, spiritual needs and values' ( $\mathrm{DoH}, 2005)$ this would require a major cultural shift in a relatively short period of time. To ensure that services are responsive to the needs of their local communities there also needs to be effective local consultation and research processes in place which is where clinical psychologists can play a vital role in service-delivery.

Knifton et al. (2010) further points out that interventions to tackle public views of mental illness also need to be culturally sensitive in order to take into account the varying cultural views and explanations of mental illness and suggests that rather than a global public information campaign, carefully targeted community education programmes could provide a more effective route to tackling mental health stigma.

\section{Conclusion}

The problem of social exclusion is currently a major political issue and has contributed to a shift in the provision of services away from a focus on symptom reduction towards those that promote wellbeing, person-centred care and independence and support a holistic view of recovery that includes the ability to contribute to society through a valued and meaningful social role.

Services are under pressure to ensure that this is balanced with the availability of resources and the ability to demonstrate effective outcomes so as to satisfy key targets and performance indicators. I have attempted to consider some of the areas in which this presents a particular challenge and identify a potential role for clinical psychology in ensuring that serviceusers views are adequately represented in a meaningful way. This can be achieved by engaging locally with service-users and communities through research and consultation to ensure that the distinct needs and experiences of the local community are being adequately considered and 
responded to. Individuals frequently report experiencing stigmatizing views from mental health professionals (Berry et al., 2010) and without careful consideration, mental health services are at risk of remaining part of the problem by continuing to fail to respond to the issue of stigma and discrimination.

Clearly this represents just a small part of the challenge of tackling mental health stigma and discrimination and there are numerous other areas in which clinical psychologists can potentially play a key role both in local communities, e.g. by delivering targeted mental health promotion interventions in schools, colleges and workplaces, and at a national level, for example in publicly challenging discriminatory practices and negative stereotypes portrayed in the media (Sayce, 1998) and contributing to the growing evidence base around how to effectively target widely held stigmatizing views of mental illness through public information campaigns.

\section{Personal Reflections}

As a carer for a family member with complex health needs the issue of stigma, discrimination and social exclusion has been prominent issue in my personal life as well as my professional life for a number of years. Through my previous experience working as part of a substance-misuse treatment programme within the prison service I have been involved in delivering Harm Minimisation advice and education as well as providing training and information for prison staff. I have seen firsthand the importance of disputing myths and challenging prejudice and stereotypes and I believe that the responsibility for producing real social change lies within each individual in their daily lives as well as through their professional role. I hope that this is something that I can continue to be involved with throughout my career. Writing this essay has also reminded me that without proper and meaningful consultation with the people at whom they 
are directed, initiatives to promote social inclusion can appear tokenistic and at worst can perpetuate the cycle of exclusion that they seek to sever.

On a final note, in the time that I was preparing to write this essay there was extensive media coverage of the government's plan to replace the Strategic Health Authorities responsible for commissioning health services with GP commissioning consortiums. This for me raised questions about how the views of other professional groups and service-users would be represented in the commissioning process and how services whose primary role is early intervention, prevention and the promotion of social inclusion would fare in the current climate. 


\section{REFERENCES}

Berry, C., Gerry, L., Hayward, M. \& Chandler, R. (2010). Expectations and illusions: a position paper on the relationship between mental health practitioners and social exclusion. Journal of Psychiatric and Mental Health Nursing, 17, 411-421.

Bowl, R. (2007). The Need for Change in UK Mental Health Services: South Asian Service Users' Views. Ethnicity and Health, 12 (1), 1-19.

Byrne, P. (2000). Stigma of mental illness and ways of diminishing it. Advances in Psychiatric Treatment, 6, 65-72.

Care Quality Commission (2010). Guidance about Compliance: Essential Standards of Quality and Safety. London: CQC

Centre for Analysis of Social Exclusion (2002). Understanding Social Exclusion. London: London School of Economics.

Corrigan, P. W., River, L. P., Lundin, R. K., Penn, D. L., Uphoff-Wasowski, K., Campion, J. et al. (2001). Three strategies for Changing Attributions about Severe Mental Illness. Schizophrenia Bulletin, 27 (2), 187-195.

Department of Health (1999). A National Service Framework for Mental Health: Modern Standards and Service Models. London: Department of Health.

Department of Health (2005). Delivering Race Equality in Mental Health Care. London: Department of Health

Department of Health (2009a). New Horizons: A Shared Vision for Mental Health. London: Department of Health.

Department of Health (2009b). A guide to receiving direct payments from your local council: A route to independent living. London: Department of Health.

Henderson, C. \& Thorncroft, G. (2009). Stigma and discrimination in mental illness: Time to Change. The Lancet, 373, 1928-1930. 
Hinshaw, S.P., Cicchetti, D. \& Toth, S.L. (2006). Mark of Shame: Stigma of Mental Illness and an Agenda for Change. Cary, NC, USA: Oxford University Press.

Knifton, L., Gervais, M., Newbigging, K., Mirza, N., Quinn, N., Wilson, N. \& Hunkins-Hutchison, E. (2010). Community conversation: addressing mental health stigma with ethnic minority communities. Social Psychiatric Epidemiology, 45, 497-504.

Morgan, C., Burns, T., Fitzpatrick., Pinfold, V. \& Priebe, S. (2007). Social exclusion and mental health: Conceptual and methodological review. The British Journal of Psychiatry, 191, 477-483.

National electronic Library for Health (2004). Mental Health Promotion: Social Exclusion and Health. London: Mentality.

National Social Inclusion Programme (2009). Vision and Progress: Social Inclusion and Mental Health. London: NSIP.

Pinfold, V., Byrne, P. \& Toulmin, H. (2005). Challenging Stigma and Discrimination in Communities: A Focus Group Study Identifying UK Mental Health Service Users' Main Campaign Priorities. International Journal of Social Psychiatry, $51(2), 128-138$.

Read, J. \& Harre, N. (2001). The role of biological and genetic causal beliefs in the stigmatisation of 'mental patients'. Journal of Mental health, 10 (2), 223235.

Royal College of Psychiatrists Social Inclusion Scoping Group (2009). Mental Health and Social Inclusion: Making Psychiatry and Mental Health Services Fit for the $21^{\text {st }}$ Century. London: Royal College of Psychiatrists.

Sayce, L. (1998). Stigma, discrimination and social exclusion: What's in a word? Journal of Mental Health, 7 (4), 331-343.

Shattell, M.M. (Ed.) (2009). Stigmatizing Language with Unintended Meanings: "Persons with Mental Illness" or "Mentally III Persons"? Issues in Mental Health Nursing, 30, 199. 
Sinason, V. (1992). Mental Handicap and the Human Condition: New approaches from the Tavistock. London: Free Association Books.

Sholl, C., Korkie, J. \& Harper, D. (2010). Challenging teenagers' ideas about Mental Health. The Psychologist, 23(1), 26-27.

Social Exclusion Unit (2004). Mental Health and Social Exclusion Report. London: Office of the Deputy Prime Minister.

Vogel, D. L. \& Wade, N. G. (2009). Stigma and help-seeking. The Psychologist, 22 (1), 20-23.

World Health Organization (2001). World Health Report 2001. Mental Health: New Understanding, New Hope. Geneva: World Health Organization. 
Child Protection, Domestic Violence, Parenting, Attachment and Learning Disabilities.

Problem Based Learning - Reflective Account 


\section{The Task}

At the beginning of the second year we were presented with a Problem Based Learning (PBL) task entitled 'Child Protection, Domestic Violence, Parenting, Attachment and Learning Disabilities' in the form of a clinical vignette centred around the 'Staines' family. We were provided with a genogram depicting the family structure, an ecomap of the professional network, some background information and some prompt questions (Appendix A). Mrs Staines' was described as a forty year old white, English woman with a mild Learning Disability and $\mathrm{Mr}$ Staines as a white, English man in his early twenties whose family were members of a 'fundamentalist' evangelical Christian church. Their three year old twins, Sarah and Sally had been placed in short-term foster care due to allegations of emotional abuse and neglect and the Local Authority wished to move towards permanent adoption for the children in the belief that their parents would never be able to provide adequate care. It was explained that a referral had been made to psychology by the children's court-appointed Guardian for a full risk assessment and, if appropriate a rehabilitation plan. The end product of the PBL. task would be a twenty minute presentation and we were to work within our existing Personal and Professional Development Learning Groups (PPDLG).

I noticed at an early stage that my initial reaction to the vignette was quite a powerful one, I felt a strong desire to 'protect' the family from the forces that would seek to separate them. I noted that there were some aspects of the scenario that resonated with some of my own early experiences of having witnessed domestic violence and having spent time in foster care and in the care of my grandparents. I was aware that these factors contributed to my early reactions to the task, as well as the professional context that I held as a Trainee Clinical Psychologist placed within a Community Team for People with Learning Disabilities (CTPLD). I noticed that I felt inclined to align myself as an advocate for the parents' wishes to continue to care for their children. I was also influenced by my existing knowledge of some the historical failures by services to support parents with Learning Disabilities, with an emphasis being placed on inadequacy and failures rather than strengths and resources (James, 2004) and the impact of the eugenics movement, which had actively sought to prevent individuals with 
Learning Disabilities from becoming parents (Pfeiffer, 1994). The nature of the PBL task and this reflective account has given me the opportunity to reflect on these initial reactions and notice how my own personal and professional context influences my thinking around a particular piece of work. It is through experiences such as these that the importance of supervision and multi-disciplinary working is highlighted in order to give sufficient time and space to consider the different viewpoints and perspectives around a clinical case, rather than be overly swayed by initial 'gut' reactions.

I have since reflected on some of the difficulties that are inherent when working within a system that has previously played an active role in the disenfranchisement of the individuals for whom it now holds the responsibility to provide a person-centred service which aims to empower and enable. I have found this to be particularly the case when working in a Learning Disability service, since service-users in this context often rely on others to promote their independence and enable a degree of personal agency to a much greater extent than in Adult Mental Health services. I have found this particularly challenging in cases when it has felt as though some professionals have held seemingly oppositional views about where the responsibility of services lies. For me, this has emphasised the potential role for psychologists in providing multi-disciplinary training regarding the historical context and current priorities for service provision when working with socially excluded groups.

\section{The Group Process}

In contrast to the previous PBL exercise at the beginning of the first year which took place within allocated time slots, we were required to independently organise and allocate the amount of time we wished to dedicate to the current task. This meant that our initial meeting was mainly focused around the organisational tasks of allocating times and locations of the subsequent meetings and deciding how we wished to structure the group for the purpose of this task. We chose not to appoint a chair or scribe for the purpose of the task as the majority of the group wanted to discover how effectively we could work in a more unstructured environment. There was one member of the group who later 
reflected that they did not find this approach helpful, and chose to act as chair and scribe for one of the meetings. Upon reflection, I do think that the lack of explicit structure meant that some of our time was spent rather unproductively, but also the time felt a lot less pressurised than the previous PBL exercise which was a welcome change. Within our PPLDG we have since discussed some of the factors that led to a more relaxed working environment, including the natural process of becoming more comfortable with one another over time, being less worried about having to use the task to 'prove ourselves' than in the first year and having developed more confidence in our own professional identity and abilities. On a personal level $I$ also noted that the previous exercise had been quite ambiguous, whereas in this case the aims and expectations were clearer from the offset which led to me feeling much more relaxed and confident.

In the initial meeting we chose to use the prompt questions as a starting point and each took responsibility for researching a specific area so that we could share the information as a group in the next meeting and think further about where the focus of our presentation might lie. We were influenced by our prior experience of having found this to be a helpful approach and not wanting to be too hasty in deciding where our focus should lie, as we had previously found that our initial ideas had changed several times during this preliminary research stage.

The process of going through the preliminary research stage meant that when we returned to working together as a group we each brought a unique contribution to the task as well as our pre-existing diversity in knowledge, expertise and personal, as well as professional experiences. It also worth noting that as a group we were placed in a range of different services during the task - Child and Adolescent Mental Health Services (CAMHS), Older Adult Services and Learning Disability Services. During discussions we noted that these factors meant that we were positioned from different stakeholder perspectives at an early stage in our task. I think that this was helpful in enabling us to think more broadly around the wide-ranging issues that were inherent in the task, and perhaps made the experience more representative of multi-disciplinary working, though we noted that we still held the shared experience of being Trainee Clinical Psychologists at Surrey which undoubtedly influenced our thinking around the problem. 
We went through several early ideas about what form our final presentation should take, including considering a role-play in which we would represent various members of the professional network, and possibly Mr and Mrs Staines during a case conference or multi-disciplinary team meeting. We decided against this option as we did not want to make broad assumptions about the viewpoints of the different stakeholders and did not want to be implicit in the representation of any unhelpful stereotypes. We also considered presenting our ideas in the form of a piece of correspondence between the court-appointed Guardian and the Clinical Psychologist, but decided that this would be quite a 'dry' presentation and wanted to be able to engage more dynamically with the issues that were being raised.

\section{The Presentation}

I made the suggestion that we could deliver our presentation in the form of a debate, having been inspired by a similar exercise as part of the research module. This was quickly agreed and I think that this was partly due to the fact that we had all enjoyed the element of debating which meant that we could deliver quite a dramatic and impassioned argument, in an environment when often we are required to be relatively moderate, even cautious when representing our views.

$I$ also wondered whether the context of working within our PPLDG meant that some individuals were less concerned about their own ideas being represented in the final presentation, as there was more of a shared sense of responsibility and ownership, and also less of a competitive group environment than there had been during the previous task when we had been unfamiliar with one another.

The motion under debate was 'The Staines children should be adopted now', 1 chose to argue for the motion as I wanted to take a stance that would challenge my own initial viewpoint and thought that it would help me to be more objective in my consideration of the issues of risk that needed to be addressed. Much of my argument was based on the vast evidence of the potential detrimental effect to the children's ongoing development of continuing to be exposed to the risk of emotional abuse, in the form of being witness to domestic violence (Holt et al., 2008) and neglect as well as the compounding factors of poverty and maternal depression (Petterson and Albers, 2001). It brought to my attention that there 
was no doubt that a strong argument could be presented using this evidence and that in a case where an opposing argument may depend on the strength of resources available to the family it would seem that the outcome would be weighed heavily in favour of the Local Authority. This highlights another vital role for clinical psychology in bringing together the views, opinions and evidence from various sources to create a systemic formulation that attempts to represent a balanced viewpoint rather than a one-sided argument. I think that this was a considerable strength of the 'debate' format in that it allowed us to explicitly consider several opposing viewpoints and think about the counter-argument to our own positions. It also highlighted for me the importance of emphasising the strengths and resources within a system, rather than focusing wholly on 'the problem'.

When it came to presenting the arguments during the final presentation I was surprised at my own reactions, I felt quite uncomfortable making such strong, decisive statements without the time available to adequately qualify my argument. This was probably mainly due to the fact that I was representing an argument that was in direct opposition to my own initial reactions to the vignette. Upon reflection I also wondered whether talking about the overwhelmingly negative consequences that are indicated for children exposed to domestic violence also made me uncomfortable on a more personal level as I would probably consider myself to be an exception to the evidence. Throughout training and during this experience in particular, 1 have been aware of the need to be mindful of the influence that my own personal context can have on my ability to take certain perspectives. The PPLDG has been a helpful forum in which to consider these issues, as has the supervisory relationship.

\section{Further Learning}

When we were initially set the PBL task 1 was struck by the description of $\mathrm{Mr}$ Staines' family as being members of a 'fundamentalist' evangelical Christian church. 1 have since reflected on what the implicit and explicit meaning of this description, for me it appeared upon initial reading to have quite negative connotations and during the group discussions we considered $\mathrm{Mr}$ Staines' religious background to possibly account for his apparent strong feelings about 
gender roles within the family, evidenced by his resistance to using household appliances. However, I am aware that I come from the personal context of having rejected my own Christian upbringing and choosing to take an atheist position, and in this instance I wonder whether I was able to stop and question my initial opinions. This has made me consider the difficulties inherent in adequately addressing issues of diversity when there is a personal assumption made (rightly or wrongly) that we may understand something of what it means to be a certain faith, ethnicity or gender. Although as a group we did consider the strengths and resources of the family system, on reflection I do not feel that we adequately considered the faith community as part of the wider system and the potential support that this could have provided.

One particular area of clinical practise that was highlighted by the $\mathrm{PBL}$ is the way in which information is presented to individuals who are not able to read and write English. I was struck by the description of Mrand Mrs Staines being read the reports written by them "out loud... usually once, and sometimes on the morning of a Court hearing." (Appendix A). I have tried to be mindful of this during my current placement, by actively considering ways in which I can adapt information appropriately to service-users, using a range of methods, including visual prompts and an interpreter when necessary.

I was also interested in the description of Mr Staines' alcohol use and the apparent lack of involvement from the local drug and alcohol agency. Having had experience of working in substance misuse services within prison and forensic psychiatric settings, I was aware that community drug and alcohol services often have thresholds regarding what is considered to be 'problem' drinking and I have personally witnessed the frustration that can occur when individuals are refused treatment on the basis that it does not meet the threshold, regardless of what the personal cost may be to the individual. I strongly believe that there is a vast need for more specialist 'dual diagnosis' services to combat the difficulties that arise when services attempt to engage in issues of mental health, offending and substance misuse separately. In my current role I have taken the opportunity to deliver a substance-misuse training session within the team, in the hope that my colleagues will consider the issue of substance misuse as something that could potentially fall within their role, rather than a problem to be tackled elsewhere. 


\section{References}

James, H. (2004). Promoting Effective Working with Parents with Learning Disabilities. Child Abuse Review, 13, 31-41.

Pfeiffer, D. (1994). Eugenics and Disability Discrimination. Disability \& Society, 9(4), 481-499.

Holt, S., Buckley, H. \& Whelan, S. (2008). The impact of exposure to domestic violence on children and young people: A review of the literature. Child Abuse \& Neglect, 32, 797-810.

Petterson, S. M. \& Albers, A. B. (2001). Effects of Poverty and Maternal Deppression on Early Child Development. Child Development, 72, 17941813. 
Appendix A - The PBL Exercise

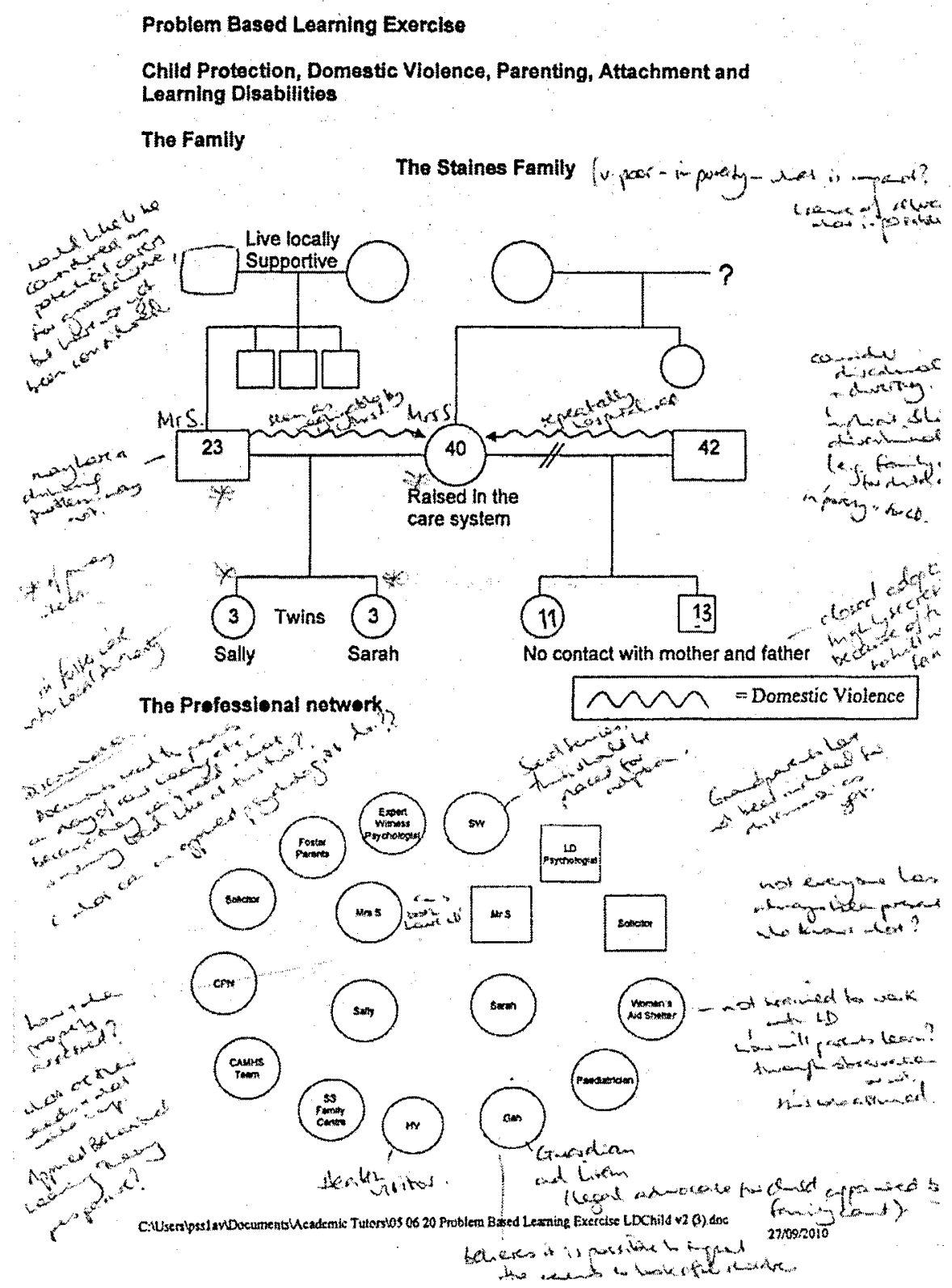




\section{The Problem}

The twins, Sally and Sarah Staines, were placed in short term foster care, following a recommendation of a full child protection case conference, and enacted at an initial Court hearing, that the children continued to be at risk in the care of their parents. The children were on the child protection register, under the categories of emotional abuse and neglect. The children's Guardian (Court Reporter) has approached you, and asked you to help the Court by conducting a full risk assessment, and if appropriate, to help the Court develop a rehabilitation plan for the children. This is a joint instruction by al parties to the proceedings. However the Local Authority wishes to place the children for adoption, before it is too late, in the belief that Mr and Mrs Staines will never be able to care adequately for their chlidren. Mr and Mrs Staines are passionate in their commitment to have the children retumed to their care.

Whose problem is it? Why?

Some Background Information.......

Mr and Mrs Staines are white English. They live on State benefits. Mrs Staines is described as a woman with learning disabilities, in the mild range. $\mathrm{Mr}$ Staines attended a school for children with special educational needs. His parents are members of a fundamentalist. evangelical Christian church. Social Services has not approached them as potential carers for the children, although they would welcome such an approach. Mr and Mrs Staines do not read and write English. It should be noted that many long reports have been written about them, their children, their care of their children and so on. Their solicitors read the reports out loud to them, usually once, and sometimes on the morning of a Court hearing.

Mrs Staines has two older children living with separate adoptive families. She is not able to have contact with them at the moment, as it was closed adoption. This is because her first husband was extremely violent to her, and threatened violence to the previous social workers. Social Services staff feared for the safely of the adapters if their whereabouts were known. Mrs Staines promised herself it would be different with this marriage and for these children.

Mr Staines has physically assaulted Mrs Staines, during disagreements, and apparently only when inebriated. She minimises his behaviour, saying it is nothing compared to what her prevlous husband used to do to her. The two children have witnessed these arguments and assaults. Mr Staines has not been offered a service from the local drugs and alcohol agency.

Mr Staines' parents are supportive. They buy clothes and toys for the children, and occasionally buy food shopping for the family. Apparently, they are willing to look after the children, despite Mr Staines mother suffering from a painful rheumatic condition. Mrs Staines was raised in the Looked After Children 
system, in a residential children's home, and has no contact with her family of origin.

Mr and Mrs Staines live in conditions of deep poverty. They do not have many household appliances that work, and it seems that Mrs Staines struggles to understand the workings of the second-hand appliances donated to them by family. It would seem that Mr Staines understands their workings, but is not prepared to use them. Social Services staff are most concerned about physical neglect of the chidren's needs. Family Centre staff say they have tried to engage both Mr and Mrs Staines in parenting classes, but the couple do not attend on a regular basis. The Family Centre appointed a family worker to visit the home, and show Mrs Staines 'how to keep house'. The family support worker has not been trained to work with parents with learning disabilities. The Social Worker says the Department has offered the family everything, and it makes no difference to the care of the children.

Mr and Mrs Staines are desperate about the loss of their children. They want them to come home. They fiercely resent the foster carers, and the supervisor of their contact with the children. The children's Guardian (Court Reporter) believes the parents can learn to be 'good enough' to satisfy Social Services requirements. Mrs Staines was referred to the local AMH service for help with feelings of despair and depression. She is taking anti-depressant medication. and is seeing a CPN for counselling.

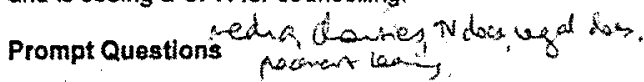
$X$....something about paying attention to the professional network (lialson,

$\chi$.....something about safety, risk assessment and risk management

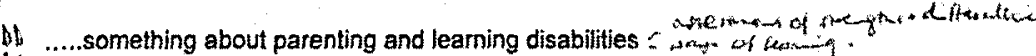

1 i. ... something about child witnesses to domestic violence and the intergenerational effects of domestic violence

ST .....something about the effects of poverty and class discrimination

16.....something about literacy and verbal comprehension (effects of anxiety and stress on memory and comprehension, and willingness/ability to express concerns, and say, 'I don't understand these reports')

HT.....something abolt resilience, adversity, depression ând coping .......something about problem drinking, and unaddressed need

If ....something about the role of grandparents in the care of children

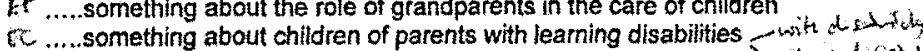

rf .....something about gender issues and gender scripts

$X$.....something about psychollogists, child protection and the legal system winges 


\section{Personal and Professional} Learning and Development Group

(PPLDG) Process Account 


\section{Summary}

The Personal and Professional Learning and Development Group (PPLDG) is designed to 'promote reflection on clinical work, with reference to personal and professional learning, ethical dilemmas in our work, appreciation of diversity and the development of cultural attunement, and theory-practice linking' (University of Surrey, 2009).

The reflective account aims to explore how the PPLDG process has contributed to my continuing personal and professional development during my second year of clinical training. One of the issues discussed in detail was the factors influencing group processes and dynamics, including the pressurised environment created by a task, the physical environment, the influence of the group facilitator and group members' individual differences and learning styles. I have explored the factors which led to a turning point being reached which enabled group members to take personal risks. I have also reflected on how my participation in the group has helped me to reflect on the issues of leadership and reflective practice as well as my own personal learning style and therapeutic stance.

Finally I have spent some time considering the ending of the group and implications for my future professional development. 


\section{Overview of Clinical Experience on Placement}

SEPTEMBER 2009 - SEPTEMBER 2012

YEARS 1-3 


\section{Year One: Adult Mental Health}

\section{Mole Valley Community Mental Health Team (CMHT)}

During this year long placement I carried out comprehensive psychological assessments and individual therapeutic interventions with working-age adults from a variety of backgrounds, presenting with a range of mental health difficulties and emotional distress. Particular difficulties included bipolar disorder, Post Traumatic Stress Disorder (PTSD), Obsessive Compulsive Disorder (OCD), depression and psycho-physiological insomnia. I utilised Cognitive Behavioural Therapy (CBT), mindfulness and schemafocussed techniques.

I worked within a Multi-Disciplinary Team (MDT) and liaised with my colleagues to co-ordinate a psycho-education/relapse prevention group for individuals with a diagnosis of bipolar disorder, including supervising a Support, Time and Recovery (STaR) worker. I also carried out a serviceevaluation to explore service-users' satisfaction with the service and the extent to which it had helped them to work towards their own recoverybased goals. The results of the evaluation were fed back to the MDT, along with recommendations for service development.

\section{The Gershwin Unit: Epsom General Hospital}

I also worked for one day a week at 'The Gershwin Unit' for the final six months of my placement, which provides therapeutic input to the attached acute and rehabilitation inpatient wards. I co-facilitated a recovery group for inpatients with a range of difficulties; including anxiety and depression as well as carrying out two neuropsychological assessments.

I also helped to develop an assessment protocol for the Dialectical Behaviour Therapy (DBT) skills group and carried out a structured personality assessment. 


\section{Year Two}

Richmond \& Kingston Psychology and Challenging Needs service for People with Learning Disabilities.

During this six-month placement I worked individually with people identified as having mild to moderate learning disabilities, as well as individuals diagnosed with Autistic Spectrum Disorder (ASD) with a range of concerns, including low mood, a history of loss and trauma and challenging behaviour. I had experience of utilising a wide range of therapeutic modalities, including CBT, narrative therapy and a brief psychodynamic informed intervention. I carried out two neuropsychological assessments, which included working with a signlanguage interpreter. I also worked closely with staff teams to inform a psychological understanding of behaviours that were deemed to be challenging. Additionally, I provided training to residential staff teams on understanding bereavement and worked as part of the systemic family therapy team.

Teddington, Twickenham \& Hampton Community Mental Health Team for Older People (CMHT-OP)

During this six-month placement I worked individually with older people with a range of mental health difficulties, including anxiety, depression and substance misuse utilizing CBT and mindfulness based techniques. I also carried out neuropsychological assessments with individuals referred due to concerns around memory difficulties and co-facilitated a Cognitive Stimulation Therapy (CST) group for individuals diagnosed with dementia and their carers. I also worked with staff to formulate appropriate interventions for individuals in residential care identified as presenting with challenging behaviours and used my previous experience to provide teaching and consultation on working with individuals with a history of substance-misuse using a Motivational Interviewing (MI) approach. 


\section{Year Three}

Merton Child and Adolescent Mental Health Services (CAMHS)

During this year-long placement I worked directly with young people and families with a range of presenting concerns, including anxiety-based disorders, OCD, depression/low mood and bereavement using CBT, systemic and narrative techniques. I utilized a range of assessment tools, including carrying out neuropsychological assessments and formal observations. I also worked as part of the Multisystemic Therapy (MST) team, who work intensively with families whose children are at risk of being placed in care or entering custody. My role involved working closely with other professionals within the MDT and liaising with other agencies, including schools, social care and voluntary sector organizations.

\section{The Shaftesbury Clinic: Springfield University Hospital}

The Shaftesbury clinic is a medium-secure inpatient service for adults with severe and enduring mental health difficulties and/or a diagnosis of Personality Disorder (PD) who have a forensic history. During this year-long I worked therapeutically with individuals utilising CBT and schema-focused approaches. I supervised the work of assistant and student psychologists and participated in aspects of service-development, including delivering information regarding outcome-measurement in a departmental meeting and liaising with the MDT to carry out an audit of ward atmosphere. I carried out several complex assessments, utilising information from a range of sources, including a variety of neuropsychological assessments and other standardized measures. I helped to co-ordinate and co-facilitate the psycho-educational 'Managing Mental Health' group and helped to develop a behavioural treatment plan for a service-user by working indirectly with their care team. 


\section{Assessment and Treatment within a Cognitive-Behavioural Framework of a Woman Presenting with Psycho-Physiological Insomnia.}

In order to protect confidentiality and preserve anonymity some details have been altered or omitted from this summary. Consent was gained from the client to use the report for the purpose of clinical training.

Case Report 1: Summary 
A white British woman in her mid-forties presented to her GP complaining of sleep disturbance, associated anxiety and low mood. Upon referral to the Primary Care Mental Health Team (PCMHT) she was assessed by a Mental Health Practitioner and referred to the psychology service.

The report outlines the referral and assessment process with discussion given to the role of diversity, risk assessment and the development of the therapeutic relationship. The initial formulation is outlined in the context of a cognitive model of psycho-physiological insomnia, as described by Broomfield et al (2008). A rationale is provided for the proposed plan of action taking into account the views of the service-user, the initial formulation, service-context and current evidence-base.

The intervention process and structure is summarised with discussion of the engagement difficulties encountered and an attempt is made to try and understand these processes by relating to and expanding upon the initial formulation. The outcome of the treatment is discussed and evaluated with reference to the original aims and personal reflection upon the factors that may have impacted on the therapeutic relationship. 


\section{Cognitive-Behavioural Assessment, Formulation and Treatment of a woman presenting with Obsessive Compulsive Disorder (OCD).}

In order to protect confidentiality and preserve anonymity some details have been altered or omitted from this summary. Consent was gained from the client to use the report for the purpose of clinical training.

Case Report 2: Summary 


\section{Summary}

A white British woman in her mid-thirties presented to her GP complaining of sleep disturbance and anxiety related to a persistent fear of being attacked at night. She was assessed by an Occupational Health Nurse who highlighted the impact on her employment and recommended further intervention, such as Cognitive Behavioural Therapy (CBT). Upon referral to the Primary Care Mental Health Team (PCMHT) she was assessed by a Mental Health Practitioner and referred to the psychology service.

This report outlines the referral and assessment process with discussion given to the role of diversity, assessment of risk and the development of the therapeutic relationship. The initial formulation is explained in the context of a cognitive model of Obsessive Compulsive Disorder (OCD) as described by Salkovskis (1985). The treatment plan, i.e. Cognitive Behavioural Therapy including Exposure and Response Prevention (ERP) is outlined with consideration given to the views of the service-user, the initial formulation, service-context and current evidence-base. The intervention process is summarised, including the development of the exposure hierarchy and specific techniques used to try and address responsibility appraisals and overestimation of risk. Discussion has been given to the reformulation of the initial problem to include emotional avoidance as a maintaining factor. The outcome of the treatment has been evaluated in light of the available evidence, objective measures and client report and additional factors that may have impacted on the therapeutic process. 


\section{A Narrative approach to working with a man referred for 'anger management' and unresolved bereavement.}

In order to protect confidentiality and preserve anonymity some details have been altered or omitted from this summary. Consent was gained from the client to use the report for the purpose of clinical training. 


\section{Summary}

A white British man in his early thirties, affected by a learning disability and epilepsy was referred to psychology following concerns from staff at his supported-living accommodation that he was refusing his medication and had been displaying aggressive behaviour.

The report outlines the referral and assessment process with discussion given to the role of diversity, risk and the development of the therapeutic relationship. The initial formulation is outlined in the context of an integrative model, with particular attention given to attachment theory and systemic processes. Discussion is also given to the role of therapeutic documents in co-constructing a narrative formulation and the conflict between a social constructionist approach and the use of empirical outcome measures.

The proposed intervention is discussed, taking into account the views of the client and his support network, the initial formulation and the evidence-base. The intervention process is described in light of the main themes and the outcome is discussed and evaluated with reference to the views of the client and his support network, the rationale for further intervention and consideration of alternative therapeutic approaches. 


\section{Assessment of a six year old girl with developmental delay referred to a Child and Adolescent Mental Health Service (CAMHS) for attention and concentration difficulties.}

In order to protect confidentiality and preserve anonymity some details have been altered or omitted from this report. Written consent was gained from the client's primary carer to use this report for the purpose of clinical training.

Summary of Neuropsychological Case Report: Child Placement 


\section{Summary}

A six year old girl with global developmental delay was referred to a Child and Adolescent Mental Health Service (CAMHS) with concerns regarding inattention and concentration following an assessment by an Educational Psychologist. Brief screening tools including information from parents and teachers appeared to suggest that a diagnosis of Attention Deficit Hyperactivity Disorder (ADHD) may be warranted.

The initial assessment is described, including personal, medical and educational history and observations of behaviour with the child in the clinic. An initial hypothesis was made that the observed inattention could be related to anxiety and task avoidance, in keeping with cognitive ability. Additionally it was suggested that difficulties in processing speed, possibly due to an early brain insult could also be contributing to the difficulties in accessing mainstream education.

An appropriate assessment of intellectual functioning, which included a measure of processing speed was used, in conjunction with structured observations in the school environment. The results of the assessment appeared to support the initial hypothesis and recommendations were made regarding the appropriateness of the educational setting in being able to support the child's individual learning needs. The assessment was critiqued in terms of potential limitations and avenues for further investigation. 


\section{Motivational Interviewing and Consultation with an Elderly Gentleman admitted to an acute inpatient setting with Alcohol Misuse and Anxiety}

In order to protect confidentiality and preserve anonymity some details have been altered or omitted from this report. All names used are fictitious and consent was gained from the client to use this report for the purpose of clinical training. 


\section{Summary}

Mr Brian Smith is a 72 year old, white British gentleman who is married with three grown-up children. He is currently retired but worked for many years as a Managing Director of a small business.

Mr Smith grew up in Wales, where he lived with his family for many years, but had recently moved to the Mediterranean and planned to retire there. Mr Smith's wife was diagnosed with dementia three years ago; she was initially cared for by her sister and later moved to a residential care home in the Mediterranean.

Mr Smith suffers from Chronic Obstructive Pulmonary Disease and had been using an oxygen cylinder to aid his breathing. However, following a house fire Mr Smith returned to England to live with his son and daughterin-law, later moving into his own flat nearby.

Mr Smith's son reported that his father had always been a heavy drinker, but in recent years seemed to be more in control of his drinking with help from Alcoholics Anonymous. However, this had worsened over the past few months as a consequence of him feeling highly anxious and depressed.

Mr Smith was initially referred to the Community Mental Health Team (CMHT) for Older People due to experiencing severe anxiety and panic attacks. During the initial assessment he described the anxiety as "coming out of nowhere" and did not find talking helpful. Mr Smith was admitted to an acute inpatient ward following an incident in which he was found intoxicated, highly anxious and expressing suicidal wishes.

When I initially met with Mr Smith he described feeling frustrated and upset because he felt as though his children blamed him for the situation he was in. Following discussions in supervision it was decided that it might be helpful for me to work with Mr Smith on an individual basis using a Motivational Interviewing (MI) style to help him to explore the relationship 
between his anxiety and his alcohol misuse, and at the same time provide consultation to the team so that the principles of MI could be utilised by others' involved in his care on an on-going basis. I met with Mr Smith for a total of ten sessions and on several occasions we were joined by a Community Psychiatric Nurse (CPN) from the CMHT. I also gave a brief presentation to the team regarding MI principles and techniques.

This presentation focuses on how the joint-working and consultation process helped both Mr Smith, and others involved in his care explore the factors needed to move towards making and maintaining positive change. 


\section{Evaluation of Service-User Satisfaction in a Primary Care Mental Health Team (PCMHT)}

In order to preserve anonymity some identifying details have been omitted from this report.

Service-Related Research Project 


\section{CONTENTS}

- Acknowledgements

- Abstract

- Introduction

- Background

- Rationale

- Aims and Objectives

- Method

- Participants

- Materials

- Procedure

- Analysis

- Results

- Initial contact with the team

- Satisfaction with specific aspects of service provision

- Communication

- Perceived benefits of the service

- Overall Satisfaction

- Discussion

- Recommendations

- References

- Appendices

- Appendix A - Service User Satisfaction Questionnaire

- Appendix B - Rationale

- Appendix C - Information leaflet for staff

- Appendix $D-V i s u a l$ representation of the data

- Appendix E-Additional Comments

- Appendix F-Acknowledgement from Service Manager 119.
Page No.

85.

86.

87.

87.

87.

89.

89.

89.

90.

90.

90.

91.

92.

92.

93.

93.

94.

96.

98.

100.

102.

102.

107.

109.

110.

115. 


\section{Acknowledgements}

I would like to thank the reception staff and all of the Mental Health Professionals at the PCMHT who helped to distribute the satisfaction questionnaires to service-users during this research project. Further gratitude goes to my research supervisor Dr. Sue Thorpe and my clinical supervisor Dr Emily Howard as well as the other regional psychologists, the service-user consultation group and team managers who gave their time, support and expertise to enable this project to go ahead. Finally I would like to give special recognition to all of the service-users who took the time to complete the satisfaction-questionnaire, without whom I would be unable to provide the valuable feedback to the team. 


\begin{abstract}
The Health and Social Care Act (2008) emphasises the responsibility of services to seek regular feedback from service-users to inform service development. The current study aimed to investigate how satisfied serviceusers were with the service provided by a Primary Care Mental Health Team (PCMHT). A questionnaire was designed in line with local and national policy documentation including ratings of overall satisfaction, initial assessment of needs, specific aspects of service provision and communication. Feedback was also sought on the impact of involvement with the service on various aspects of wellbeing including mood, confidence and independence as well as social and occupational functioning. This was in line with current emphasis placed on these aspects of service provision by the New Horizons document (DoH, 2009) and the recovery model as highlighted in the local operational policy (SABP, 2007). A total of 100 service-user satisfaction questionnaires were distributed by reception staff during routine appointments and during home visits by Mental Health Professionals (MHPs) over a period of seven weeks. Fortytwo questionnaires were returned and responses were entered into a database in order to analyse general trends.
\end{abstract}

Results indicated that overall participants were generally satisfied with service provision, with some possible areas for improvement identified, including care-planning, waiting times and copies of correspondence. Discussion was given to possible limitations of the study, including the possible impact of staff shortages and recommendations were made for service development. 


\section{Introduction}

\section{Background}

In 1999 the Department of Health (DoH) published 'A National Service Framework (NSF) for Mental Health', a ten year strategy outlining standards for the planning, delivery and monitoring of mental health services. It stated that services should:-

- Involve service-users and carers in the planning and delivery of care.

- Deliver high quality, effective treatment.

- Be non-discriminatory.

- Well-suited to those who use them.

- Easily accessible.

- Promote independence.

- Ensure continuity of care.

Progress in meeting these standards was reviewed in 'A National Service Framework for Mental Health - Five Years On' (DoH, 2004). It noted improvements in delivery of specialist services and stated that attention should be given to improving continuity of care between primary and secondary services and providing greater access to psychological therapies. The Primary Care Mental Health Team (PCMHT) model was devised to address this need and aimed to provide an 'accessible and flexible range of services' (SABP, 2007). This included the establishment of the current service in July 2004, replacing two existing Community Mental Health Teams (CMHTs) and providing links with GP surgeries.

\section{Rationale}

The Health and Social Care Act (2008) states that services must 'regularly seek the views (including the descriptions of care and treatment) of services users... to come to an informed view in relation to the standard of care and treatment provided'. Compliance with the essential standards of quality 
and safety is measured by the Care Quality Commission (CQC, 2010). Local policy guidelines developed to meet these standards (SABP, 2010) also highlight the importance of seeking regular feedback from service-users.

A previous service-evaluation was carried out in 2007 (Smith, 2007) and found that the majority of service-users were satisfied with the care they were receiving and found it beneficial ( $83 \%$ of respondents agreed with the statements 'I am satisfied with the care I am receiving from the service' and 'I have found/am finding the sessions beneficial').

Recommendations were made regarding the clear display of the complaints procedure in the waiting room $(23.8 \%$ of respondents disagreed with the statement 'I am aware of the procedure on how to comment on the care $($ am receiving'). In response to feedback from open-ended questions further recommendations were made regarding the clarity of professionals' titles on correspondence, the provision of emergency cover and continuity of care. Limitations discussed included the method of administration, since Mental Health Professionals (MHPs) had distributed questionnaires during appointments it was thought that participants may have felt obliged to give positive feedback. Furthermore, the questionnaire was relatively brief and the current study aimed to expand upon this to provide greater opportunity for specific feedback

In developing the current study, recommendations from the previous evaluation were taken into account, alongside relevant policy documents and recent guidance regarding priorities for service provision. A recent review of NSF in 'Mental Health Ten Years On: Progress on Mental Health Care Reform' (DoH, 2009) highlighted that future priorities should include reducing social exclusion, this was emphasised further in 'New Horizons: A shared vision for mental health' (DoH, 2009) which highlighted the 
importance of addressing stigma, promoting recovery and delivering personalised care.

\section{Aims and Objectives}

The aim of the current study was to provide the team with feedback regarding service-user satisfaction. Specifically whether service-users considered the service to be effective in providing person-centred care, communicating in a respectful and open manner, providing high-quality and up-to-date information and promoting independence and social inclusion.

The study also aimed to address the previous limitations in response bias and aimed to establish whether recommendations with regards to clear communication of roles and clear display of the complaints procedure had been effective.

\section{Method}

\section{Participants}

All of the participants were service-users currently attending appointments with a MHP at the PCMHT. A total of 100 questionnaires were distributed and 42 were returned. Sixteen participants were male and 25 were female (one participant did not specify) and all were between the ages of 18 to 65 . Ninety-one percent of participants identified themselves as White British; one participant did not specify and the remaining participants identified themselves as White European, Other White Background and Mixed White and Asian. Forty-two percent of participants had been accessing the service for longer than two years, $17 \%$ between one and two years, $11 \%$ for six months to a year and $17 \%$ for less than six months. 


\section{Materials}

A questionnaire was designed specifically for the purpose of this research project (Appendix A). It was broadly based on previous satisfaction surveys carried out locally and modified in line with local standards for involving people (SABP, 2010). Specifically questions were included to address standards regarding person-centred care, communication and information sharing. The service aims as outlined in the local Operational Policy (SABP, 2007) were also used as a guide; including items regarding quality of care, the provision of a flexible range of services based on individual needs and the promotion of social inclusion and independence. Demographic information, such as gender, age and ethnicity was included in order to gain a broad outline of the participant characteristics.

Items were rated using a series of 5-point Likert scales, ranging from 1 Totally Disagree/Very Dissatisfied/Very Negative to 5 - Totally Agree/Very Satisfied/Very Positive. An additional rating of ' $O$ ' or 'Does Not Apply' was included in questions related to specific aspects of service provision for items which were not considered relevant (i.e. have not used or not currently being provided) by individual participants. Open ended questions were included to provide participants with the opportunity to give additional feedback on helpful aspects of the service and areas for improvement.

\section{Procedure}

Prior to dissemination a draft version of the questionnaire and rationale (Appendix B) was distributed to the local management team for consultation purposes and presented in the team meeting. Suggestions were made for improvement and the questionnaire was amended in line with these. The questionnaire was also forwarded to a local service-user consultation group for review, though no feedback was received. Finally a leaflet was distributed to members of the team informing them of the 
purpose of the project (Appendix C), requesting their cooperation and thanking them for their assistance.

Questionnaires were placed in the waiting area and reception staff distributed them to service-users attending outpatient appointments at the PCMHT. A box was placed in clear view for participants to return the questionnaires anonymously. MHPs making home visits also distributed some additional questionnaires; this was felt necessary so as not to exclude participants who were unable to attend the outpatient clinic. A total of 100 questionnaires were distributed during a period of seven weeks.

\section{Analysis}

Responses were entered into a database using SPSS for Windows Version 17.0 and trends were analyzed by comparing frequencies. Responses to the open ended questions were collated and entered into a table so that common themes could be identified.

\section{Results}

For ease of reporting, results reported below reflect the main trends and percentages have been given to one decimal place. Missing values have not been included and further consideration is given to possible reasons for missing values in the discussion. Bar charts have been included in the appendices to visually represent the data. Results have been separated into five main areas reflecting the layout of the questionnaire:-

- Initial contact with the team

- Satisfaction with specific aspects of service provision

- Communication

- Perceived benefits of the service

- Overall Satisfaction 


\section{Initial contact with the team}

The majority (64.3\%) of participants reported having been seen by a member of the PCMHT within one month of referral from their GP, $26.2 \%$ were seen within one week and $23.8 \%$ reported waiting for more than six weeks. The remaining participants did not respond or stated that they could not remember.

There were strong levels of agreement with the statements 'I was aware of the nature and purpose of the appointment' (97.6\% of participants agreed strongly/somewhat), 'I was aware of the name of the healthcare professional and their role among the team' (97.5\%), 'I was advised about issues of confidentiality' (87.2\%), 'I was advised about emergency procedures and the crisis line' (82\%) and 'I felt my strengths, interests and values were taken into account as well as the 'problem' for which I had been referred' (85.3\%). There was a tendency to agree with the statements 'I was provided with information about the different services available' (70.7\% of participants agreed strongly/somewhat), 'The information was clear and concise' (76.2\%) and 'I was offered the choice to receive a copy of any correspondence about me' (72.5\%). Lower levels of agreement were reported for the statements ' felt I had a choice about the kind of service I could expect to receive' (65.8\% of participants agreed strongly/somewhat) and 'My personal and cultural background was taken into account when considering suitable services' (63.5\%). See Figures 1-10 Appendix D.

\section{Satisfaction with specific aspects of service provision}

Participants were, asked to rate their satisfaction with specific aspects of the service. Scores have been excluded for participants who ticked the 'Does not apply' column in order to make clear comparisons. Highest ratings were given for advice/help with social needs, education/training, housing and/or employment ( $88.4 \%$ of participants were very/somewhat satisfied), carer support (85.2\%) and sessions with a care-coordinator 
(84.8\%). Relatively high satisfaction was reported for the other aspects of service provision, including crisis support $(79.4 \%)$, medication management (79.4\%), sessions with MHPs at the GP surgery $(77.4 \%)$, care-planning $(75.7 \%)$ and psychological therapy (71\%). See Figures $11-18$ Appendix D.

\section{Communication}

There were strong levels of agreement with the statement 'I feel I am treated with respect when communicating with a member of the team' (92.1\% of participants agreed strongly/somewhat), "I am treated as an individual' (97.2\%), 'reception staff are polite and courteous' (94.7\%), 'written communication is clear and concise and avoids unnecessary jargon' (82.4\%) and 'written communication clearly indicates the name and role of the healthcare professional who is writing to me' (83.8\%). Although there was also a tendency to agree with the statements 'I receive copies of correspondence written about $m e^{\prime}(69 \%)$ and 'I am aware of the procedure I would need to follow if I wished to communicate a problem or complaint about the service (64.1\%) this was less pronounced. See Figs. 19-25 Appendix D.

\section{Perceived benefits of the service}

Participants were asked to rate whether they felt the service had impacted (positively or negatively) on different areas of their life. The areas in which participants felt they had benefitted most were mood $183.7 \%$ of participants reported a very/somewhat positive impact), medication management $(79.4 \%)$, independence $(74.2 \%)$ and confidence $(72.8 \%)$. There were also reports of a positive impact on access to community services and social network (54.9\% and $54.8 \%$ respectively) although $9.7 \%$ of participants reported a negative impact in these areas. Finally there were some reports of a positive impact on education/training opportunities and employment $(48.3 \%$ and $48.2 \%$ respectively); however 
$10.3 \%$ of participants reported a negative impact in these areas. See Figures 26-33 Appendix D.

\section{Additional Comments}

Participants were asked to comment further if they felt they had experienced a significant impact on particular areas of their life. One participant reported that the support and encouragement from the team had helped to improve housing, employment and self-esteem. Praise was also given for the carer support service and drop-in centre. One participant stated that although it had been identified that they may benefit from CBT (cognitive behavioural therapy) this had not yet begun. This could suggest that prolonged periods of time spent waiting for services may have a negative impact on wellbeing. See Appendix D for a full list of comments.

\section{Overall Satisfaction}

Overall $57.5 \%$ of participants reported that they were very satisfied with the service and $37 \%$ reported that they were somewhat satisfied. Of the remaining participants $2.5 \%$ stated that they were neither satisfied nor dissatisfied and $2.5 \%$ reported that they were somewhat dissatisfied (See Figure 34). 


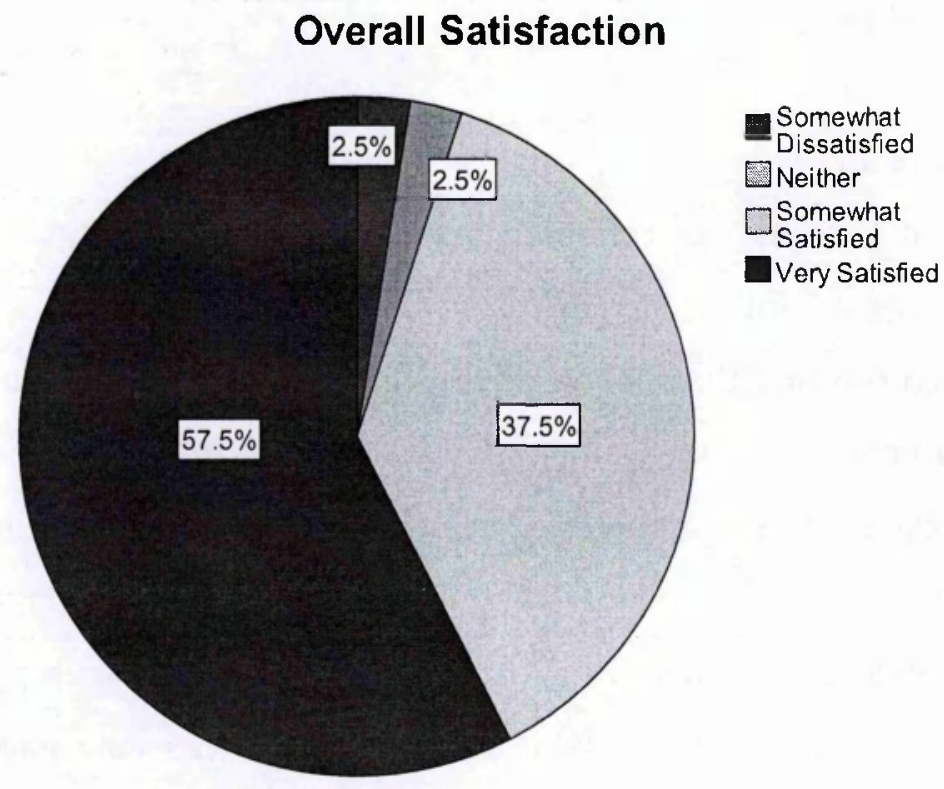

Figure 34 - Overall satisfaction (in percentages \%) with the service provided bv the PCMHT.

\section{Additional Comments}

Participants were also asked to provide feedback regarding aspects of the service that had been particularly helpful and areas for improvement (Appendix E).

\section{Helpful Aspects of the Service}

There were several positive comments regarding the service as a whole and particular praise was given for the professionalism and friendliness of the staff. Participants reported experiencing team members as knowledgeable, well-trained, well-informed, positive, caring, calming and supportive. Other aspects of the service highlighted as particularly helpful included crisis support, medication management and cognitive behavioural therapy. 


\section{Areas for improvement}

There were particular comments made regarding access to additional support services, one participant suggested that it would be helpful for counselling to be available within the PCMHT and another stated that they would benefit from 'advice and help in coping instead of just tablet talk'. Other participants highlighted the need for easier access to support from a CPN (community psychiatric nurse) and a social 'drop-in' for service-users. There were also comments regarding a perceived lack of consistency caused by changes in staff, delays in receiving services and potential improvements in the transparency of procedures. One participant stated that complaints made had elicited no response.

\section{Discussion}

There were high levels of overall satisfaction with almost all participants reporting that they were somewhat or very satisfied with the service they had received.

Levels of satisfaction with the initial contact (triage assessment) were also generally high, with possible areas for improvement regarding the amount of choice that participants felt they were offered regarding their treatment and the extent to which their personal and cultural background was taken into consideration. It is noted that participants tended to neither agree nor disagree with these statements suggesting some ambivalence about how relevant these aspects were considered to be to the provision of care. It is also recognised that choice is limited within a stepped care framework which poses difficulties when striving towards person-centred care.

High levels of satisfaction were reported with specific aspects of service provision, including advice/help with social and occupational needs, carer support and sessions with a care-coordinator. Nearly a fifth of participants reported some dissatisfaction with the care-planning process. Some 
explanations from the feedback provided were a perceived lack of consistency and the availability and choice of support available, possibly related to staff shortages and limited availability of resources. Over ten percent of participants reported some dissatisfaction with the provision of psychological therapy, whilst a further $16.1 \%$ stated that they were neither satisfied nor dissatisfied. Additional feedback suggested that this could be related to the time spent waiting for therapy from the initial referral and the perceived availability.

There appeared to be generally positive experiences of communicating with the team, and improvements had been made from the previous evaluation in terms of names and roles of MHPs being clearly indicated. However $20 \%$ of participants indicated that they did not receive copies of correspondence written about them. Finally $17.9 \%$ of participants reported that they were not aware of the complaints procedure, although this was an improvement from the previous study.

Participants reported that involvement in the service had a positive impact on mood, medication management, independence and confidence. There is evidence to suggest that service-users' views of success in terms of treatment outcome is more tied up with social needs and self-efficacy than symptom reduction (Perkins, 2001) and that these views should be taken into consideration when measuring outcomes. Some participants reported a negative impact on areas such as education, employment, social network and access to community services suggesting further need to address social exclusion.

There have been criticisms of the validity of service-user satisfaction questionnaires in terms of the response bias (Williams, 1994). Taking this into account it is likely that despite attempts to reduce any response bias by distributing questionnaires in the waiting room rather than the 
consulting room, this may remain a factor. However Edwards et al (2004) suggest that actively seeking constructive criticism can go some way towards addressing this further.

It is noted that there were significant amounts of missing data which could have affected the results. This may be due to participant fatigue, difficulties understanding questions or as a result of participants being called into appointments whilst they were filling in the questionnaire - as was observed by one team member.

\section{Recommendations}

From the results discussed the following recommendations were made. These have been presented to the team and are to be taken forward by the service manager (Appendix F)

- When service users have expressed a preference, ensure copies of correspondence are sent.

- In first meeting, ensure that there is a clear discussion regarding issues of confidentiality including instances when this might need to be broken (i.e. when there is a risk to self or others).

- Wherever possible, emphasise the choices available throughout the care pathway and review the care-plan at regular intervals. This may include signposting where additional support is available within the service and as well as referrals to non-statutory and specialist services.

- When a change in allocation of staff has taken place, try to ensure sufficient handover/transfer of information. This could take the form of a summary sheet identifying current relevant issues in collaboration with service-users. 
- It may be useful to conduct further research to investigate which specific aspects of the care-planning process and the provision of psychological therapies service-users are dissatisfied with.

- Addressing social exclusion should continue to be a priority. Including maintaining links with community agencies, such as education, leisure and employment services. 


\section{References}

Care Quality Commission (2010). Guidance about Compliance: Essential Standards of Quality and Safety. London: CQC

Department of Health (1999). A National Service Framework for Mental Health: Modern Standards and Service Models. London: Department of Health

Department of Health (2004). A National Service Framework for Mental Health - Five Years On. London: Department of Health

Department of Health (2009a). National Service Framework for Mental Health Ten Years On: Progress on Mental Health Care Reform. London: Department of Health

Department of Health (2009b). New Horizons: A Shared Vision for Mental Health. London: Department of Health

Edwards, C., Staniszweska, S. \& Chrichton, N. (2004). Investigation of the ways in which patients' reports of their satisfaction with healthcare are constructed. Sociology of health and illness, 26(2), 159-183.

Perkins, R. (2001). What constitutes success? The relative priority of service users' and clinicians' view of mental health services. The British Journal of Psychiatry, 179, 67-72.

Surrey and Borders Partnership NHS Foundation Trust (2007). Operational Policy for Primary Care Mental Health Teams (Draft 4). Surrey: SABP 
Surrey and Borders Partnership NHS Foundation Trust (2009). Standards for Involving People. Surrey: SABP

Smith, M. (2007) Service User Satisfaction Questionnaire. Unpublished manuscript.

Williams, B. (1994) Patient Satisfaction: A valid concept? Social Science and Medicine, 38(4) 509-516. 


\title{
Appendix A - Service-User Satisfaction Questionnaire
}

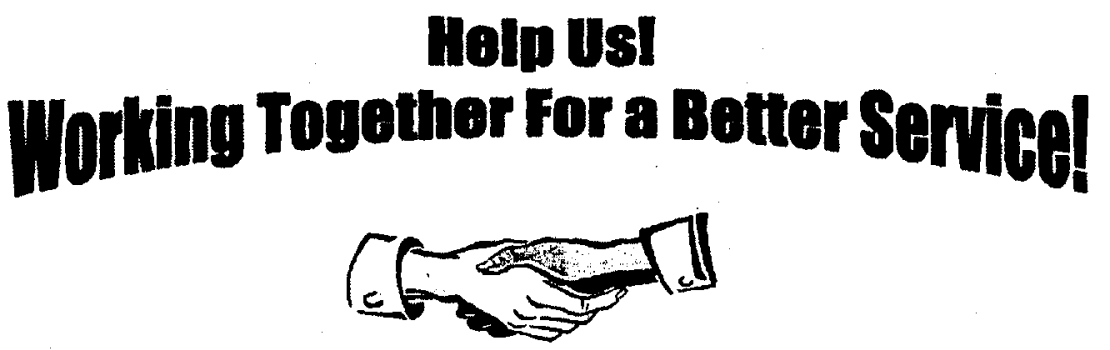

\author{
Service-User Satisfaction Questionnaire - \\ Primary Care Mental Health \\ Team (PCMHT)
}

What is this questionnaire about?

This questionnaire is about the service you have received from Primary Care Mental Health Team (PCMHT). This might have included appointments with a Mental Health Practitioner at your GP surgery, home visits or appointments with a Mental Health professional at

By participating in this survey you will be providing us with valuable feedback which will help us to discover what we are doing well and where we could improve our services. You may have been asked to complete a similar questionnaire as part of a national survey recently. We hope that you will also be able to take the time to answer our questions as they will directly inform the team here about our service-users views and experiences.

Completing the questionnaire

Please answer as honestly and openly as possible. Participation is entirely voluntary and your responses will remain completely anonymous. Your choice about whether or not to participate in this' survey and the feedback you give us will not affect the service you receive. We will be distributing the results of this survey when all the data has been collected.

For each question please tick the box which best represents your view. There are also some empty boxes in which you can provide us with additional feedback/comments if you wish. Please do 50 , as this often provides the most helpful information.

When you have finished please return the questionnaire to reception staff or the member of the team that handed it to you. 
Section 1 - About you

Thls section will help us to discover who is using our service and whether we are providing a fair service to all members of the community.

1. Are you $\square$ Male or $\square$ Female?

2. Age $\square 18-25 \square 26-35 \square 36-49 \square 50-65 \square 65$ or over

3. Ethnicity - please tick the box which best describes your ethnic background

a. White

$\square$ White British $\quad \square$ White Irish $\quad \square$ White European

$\square$ Any other White background (please indicate)

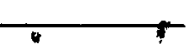

b. Mixed

$\square$ Mixed White and Black Caribbean $\square$ Mixed White and Black African $\square$ Mixed White and Asian

$\square$ Mixed White and Chinese $\square$ Any other mixed background (please indicate)

c. Black / Black Brittsh

$\square$ Caribbean $\square$ African $\square$ Any other Black background (please indicate)

d. Aslan / Aslan British

$\square$ Indian D Dakistani $\square$ Bangladeshi

$\square$ Any, other Asian background (please indicate)

e. Other

$\square$ Chinese $\square$ Middle Eastern $\square$ Any other ethnic background (please Indicate)

4. How long have you been accessing services at CMHT?

$\square$ Less than six months $\square$ six months to a year $\square 1-2$ years

$\square$ longer than 2 years 


\begin{tabular}{|c|c|c|c|c|c|c|}
\hline \multicolumn{7}{|c|}{$\begin{array}{l}\text { Section } 2 \text { - Your first contact with } \\
\text { 5. How long did you have to wait from being referred to being offered an initial appointment? This would most } \\
\text { likely have been a meeting with a Mental Health Practitioner at your GP surgery. }\end{array}$} \\
\hline D One week or less & \multicolumn{3}{|c|}{$\square$ One week to one month } & \multicolumn{3}{|c|}{$\square$ more than six weeks } \\
\hline \multicolumn{7}{|c|}{$\begin{array}{l}\text { 6. Please rate the extent to which you agree with the following statements about your first contact with a member } \\
\text { of the team. }\end{array}$} \\
\hline & & $\begin{array}{l}\text { Totally } \\
\text { Disagree }\end{array}$ & $\begin{array}{c}\text { Disagree } \\
\text { Somewhat }\end{array}$ & $\begin{array}{l}\text { Neither } \\
\text { Agree nor } \\
\text { Disagree }\end{array}$ & $\begin{array}{c}\text { Agree } \\
\text { Somewhat }\end{array}$ & $\begin{array}{l}\text { Totally } \\
\text { Agree }\end{array}$ \\
\hline \multirow{3}{*}{\multicolumn{2}{|c|}{$\begin{array}{l}\text { I was aware of the nature and purpose of the } \\
\text { appointment. } \\
\text { I was aware of the name of the heatthcare } \\
\text { professional and their role within the team? } \\
\text { I was advised about Issues of confidentiality? }\end{array}$}} & $\square$ & $\square$ & $\square$ & $\square$ & $\square$ \\
\hline & & $\square$ & $\square$ & $\square$ & $\square$ & $\square$ \\
\hline & & $\square$ & $\square$ & $\square$ & $\square$ & $\square$ \\
\hline \multicolumn{2}{|c|}{$\begin{array}{l}\text { I was advised about emergency procedures and } \\
\text { the crisis line? }\end{array}$} & 口 & $\square$ & [ & $\square$ & $\square$ \\
\hline \multicolumn{2}{|c|}{$\begin{array}{l}\text { I was provided with information about the } \\
\text { different service avallable. }\end{array}$} & $\square$ & $\square$ & $\square$ & 口 & $\square$ \\
\hline \multicolumn{2}{|c|}{ The information given was clear and concise. } & $\square$ & $\square$ & $\square$ & $\square$ & $\square$ \\
\hline \multicolumn{2}{|c|}{$\begin{array}{l}\text { I felt I had a choice about the kind of service I } \\
\text { could expect to receive. }\end{array}$} & $\square$ & $\square$ & $\square$ & 口 & $\square$ \\
\hline \multicolumn{2}{|c|}{$\begin{array}{l}\text { I was offered the choice to receive a copy of any } \\
\text { correspondence about me. }\end{array}$} & $\square$ & 口 & $\square$ & $\square$ & $\square$ \\
\hline \multicolumn{2}{|c|}{$\begin{array}{l}\text { If felt my strengths, interests, values and } \\
\text { potential were taken into account as well as the } \\
\text { 'problem' for which I had been referred. }\end{array}$} & $\square$ & $\square$ & $\square$ & 口 & $\square$ \\
\hline \multicolumn{2}{|c|}{$\begin{array}{l}\text { My personal and cultural background was taken } \\
\text { into account when considering suitable services }\end{array}$} & $\square$ & 口 & $\square$ & $\square$ & 口 \\
\hline \multicolumn{7}{|c|}{$\begin{array}{l}\text { Section } 3 \text { - The services you have received from PCMHT } \\
\text { 7. Please indicate how satisfied you have been with the help/advice you have received from the service? Tick as } \\
\text { many as apply. }\end{array}$} \\
\hline & $\begin{array}{l}\text { Does Not } \\
\text { Apply to } \\
\text { me }\end{array}$ & $\begin{array}{l}\text { Very } \\
\text { Dissatisfied }\end{array}$ & $\begin{array}{l}\text { Somewhat } \\
\text { Dissatisfied }\end{array}$ & $\begin{array}{l}\text { Neither . } \\
\text { Satisfied } \\
\text { nor }\end{array}$ & $\begin{array}{l}\text { Somewhat } \\
\text { Satisfied }\end{array}$ & $\begin{array}{l}\text { Very } \\
\text { Satisfied }\end{array}$ \\
\hline $\begin{array}{l}\text { Involvement in your care plan } \\
\text { including regular reviews. }\end{array}$ & $\square$ & $\square$ & 口 & $\begin{array}{l}\text { Dissatisfled } \\
\square\end{array}$ & 口 & D \\
\hline $\begin{array}{l}\text { Sessions with your care- } \\
\text { coordinator }\end{array}$ & $\square$ & $\square$ & 口 & $\square$ & $\square$ & [ \\
\hline $\begin{array}{l}\text { Advice/help with social needs, } \\
\text { education/training, housing } \\
\text { and/or employment }\end{array}$ & $\square$ & $\square$ & $\square$ & 口 & $\square$ & प \\
\hline $\begin{array}{l}\text { Support /advice from a Mental } \\
\text { Health Practitioner at GP surgery }\end{array}$ & $\square$ & $\square$ & $\square$ & $\square$ & $\square$ & ㅁ. \\
\hline Carer Support & $\square$ & $\square$ & $\square$ & $\square$ & $\square$ & $\square$ \\
\hline Emergency/crisis support & $\square$ & $\square$ & $\square$ & $\square$ & $\square$ & 口 \\
\hline Medication management & $\square$ & $\square$ & $\square$ & $\square$ & $\square$ & $\square$ \\
\hline Psychological therapy & $\square$ & $\square$ & $\square$ & $\square$ & $\square$ & D \\
\hline
\end{tabular}


Section 4-Communicating with the team

8. Please Indicate the extent to which you agree with the following statements about your experience of communleating with the team.

$\begin{array}{ccccc}\begin{array}{c}\text { Totally } \\ \text { Disagree }\end{array} & \begin{array}{c}\text { Disagree } \\ \text { Somewhat }\end{array} & \begin{array}{c}\text { Neither } \\ \text { Agree nor } \\ \text { Disagree }\end{array} & \begin{array}{c}\text { Agree } \\ \text { Somewhat }\end{array} & \begin{array}{c}\text { Totally } \\ \text { Agree }\end{array} \\ \square & \square & \square & \square & \square \\ \square & \square & \square & \square & \square \\ \square & \square & \square & \square & \square \\ \square & \square & \square & \square & \square \\ \square & \square & \square & \square & \square \\ \square & \square & \square & \square & \square \\ \square & \square & \square & \square & \square \\ & \square & & & \square\end{array}$

I feel I am treated with respect when

communicating with a member of the team I am treated as an indlvidual.

Reception staff are polite and courteous.

1 recelve coples of correspondence wpitten about

me (lf you have ind cated that you wish to do sol.

Written communication is clear and concise and

avolds unnecessary jargon.

Written communication clearly indicates the name

and role of the healthcare professional who is

writing to me.

I am aware of the procedure 1 would need to

follow if I wished to communicate a problem or complaint about the service.

Section 5- Benefits of the service

9. Please Indicate whether you feel the sevice you have received from of the following areas of your life?

Mood

Medication management

Education/training opportunlties

Employment

Social network

Accessing community services

Confidence

Independence

$\begin{array}{ccc}\begin{array}{c}\text { A very } \\ \text { negative } \\ \text { impact }\end{array} & \begin{array}{c}\text { A somewhat } \\ \text { negative } \\ \text { impact }\end{array} & \begin{array}{c}\text { No } \\ \text { in } \\ \text { dir }\end{array} \\ \square & \square \\ \square & \square \\ \square & \square \\ \square & \square \\ \square & \square \\ \square & \square \\ \square & \square \\ \square & \square\end{array}$

PCMHT has had an impact on any

10. If the service you have received from

PCMHT has had a significant impact on any of the above areas of your life we would like to know more. Please add any specific information below. 
Section 6-Overall Satisfaction

11. Overall, how would you rate your satisfaction with the service provided by

Very Dissatisfled

$\square$

Somewhat Dissatisfied

口
Neither Satisfied

nor Dissatisfied
Somewhat

Satisfied

PCMHT?

Very Satisfied

$\square$

12. What are we doing well? Please tell us if there any aspects of the service you have found particularly helpful that have not been covered by this questionnaire.

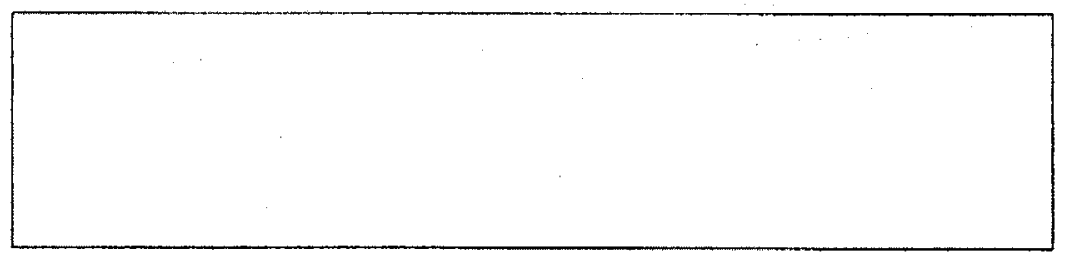

13. What could we be doing better? Please tell us If there are any areas where we could improve our services?

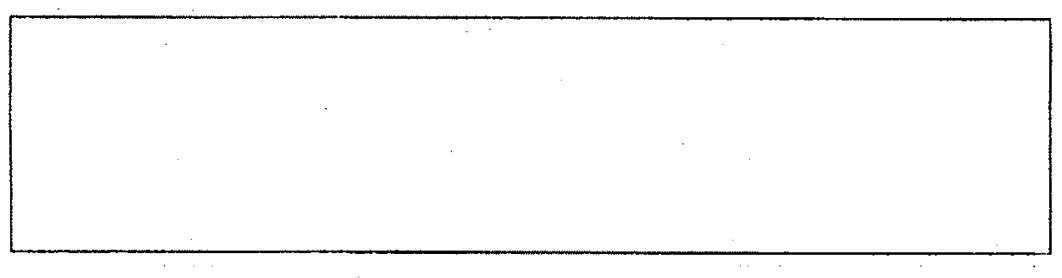

Thank you

Your views and opinions are very important to us. Thank you for your participation. 


\section{Appendix B - Rationale}

\section{Service-User Satisfaction Questionnaire}

\section{Additional Rationale}

The service user satisfaction questionnaire has been designed to address issues raised from the following sources and guidelines:-

\section{SABP Standards for Involving people:}

Standard 5 addresses the monitoring and evaluation of services and states that:-

- Service users and carers have regular and routine opportunities to comment on services and are given feedback.

- All services and teams actively seek regular feedback from service users and carers through such things as satisfaction questionnaires, comments cards and regular meetings in community settings. A collation of comments and the services or team response is published.

Furthermore Standards 1 and 2 regarding person-centered care and appropriate communication have been used in the development of specific items within the questionnaire (see below).

Standard 1: Service Users and Carers are actively involved in personcentred care

A) Service users and carers are given full information about all relevant services and processes.

Has been used to guide questions in Section 2 regarding provision and quality of information.

B) All assessments focus on the whole person including preferences, circumstances, strengths and needs.

Has been used to guide questions in Section 2 regarding choice of services and consideration of strengths, interests and diverse needs.

C) Care Plans are developed in negotiation with the named person. and

D) The named person is involved in reviewing and revising the care plan and measuring its success

Have been used to guide questions in Section 3 regarding care-planning and reviewing

Standard 2: There is effective and appropriate communication and information sharing

A) Information about the Trust, its services and the role of partner organisations is readily available and accessible 
Has been used to guide questions in Sections 2 and 4 regarding the provision of information and correspondence.

B) The trust communicates with and responds to service users are carers in respectful and appropriate ways

Has been used to guide questions in Section 4 regarding the quality of communication.

2. National Service Framework for Mental health - Ten Years On: Progress on Mental Health Care Reform

This report specifically highlights the importance of social inclusion, i.e. "improving quality of life for people with mental illness, linking better mental health care to opportunities for employment and training, and opposing stigma."

This has been used as to guide questions in Section 5 regarding benefits of the service to quality of life and wellbeing.

\section{Operational Policy for primary Care Mental Health Teams (SABP)}

The questionnaire has been designed to address service aims including:-

- To provide high quality, community focused treatment and holistic care based on individual needs and in keeping with best practise.

- To provide accessible and flexible range of services to meet the needs of service users and carers within the local community regardless of race, gender, ethnicity, sexual orientation or religious beliefs and in keeping with fair access to service.

- To provide assessment, treatment and monitoring to service users in a primary care setting where possible, to reduce the impact of their mental health difficulties on other aspects of their life and enable them to continue functioning at their optimum level.

- To provide a needs-led, person centred approach to service users, carers and their families in line with the NSF which promotes social inclusion and acknowledges social issues.

- To promote independence and health promotion to service users in line with the Recover Model.

- To work in partnership with carers and service users, voluntary and statutory agencies/organisations, to enable service users to remain part of their local community and engage in community facilities. 


\section{Appendix C - Information Leaflet for Staff}

\section{Holp UsI Worting Togethor For a Better Servicel

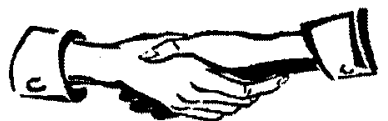 \\ Service-User Satisfaction Questionnaire - \\ Mental Health Team (PCMHT)}

\section{Information for Staff}

We are currently carrying out a survey amongst service-users about the services we provide at Primary Care Mental Health Team (PCMHT)

Questionnaires will be handed out at reception, but for those service-users who attend appointments at other locations (e.g. home visits or at a GP surgery) they will need to be distributed and collected by the relevant Mental Health Professional.

Please could you provide service-users with a copy of the questionnaire and ask them to complete it either during the appointment, or in their own time to be returned during the following session (if applicable).

In order to encourage open and honest feedback it may be important to advise serviceusers that participation is on a voluntary basis and responses will remain completely anonymous. It may also be helpful to offer reassurance that the choice about whether or not to participate in the survey and the nature of the feedback given will not affect the service that is provided.

Thank you for your assistance in facilitating the completion of this survey.

Regards, 


\section{Appendix D - A Series of Bar Charts used to Visuallv Represent the Results}
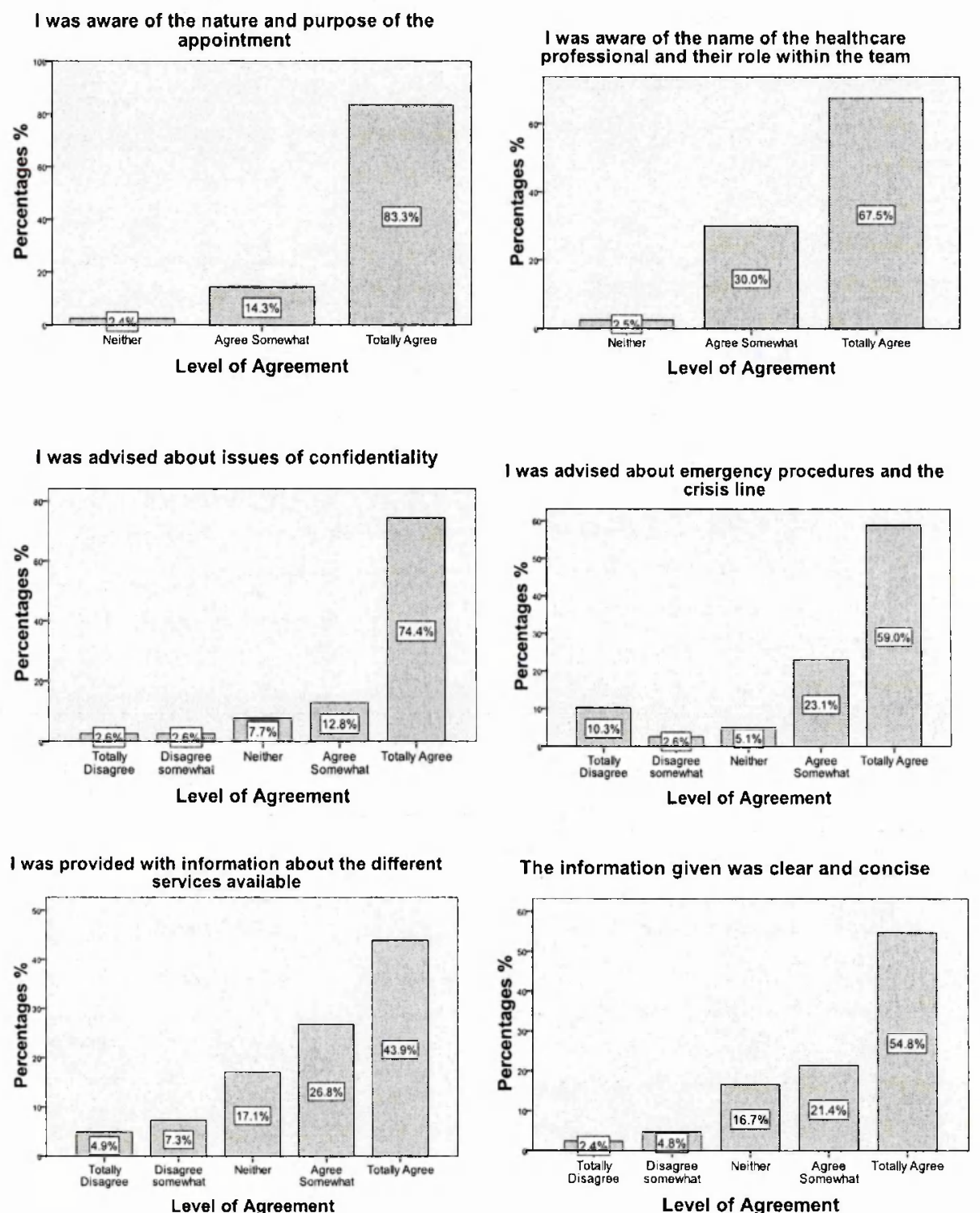

I felt I had a choice about the kind of service I could expect to receive

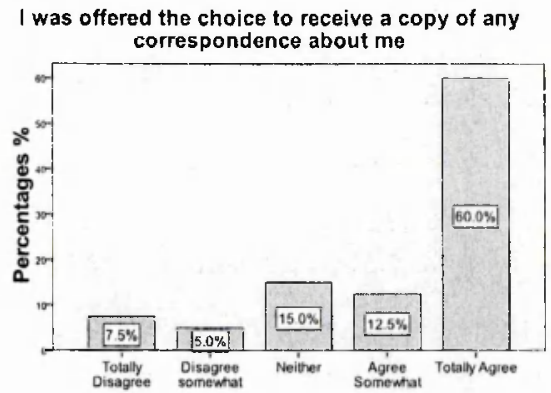

Level of Agreement 
I felt my strengths, interests, values and potential were taken into account as well as the 'problem' for

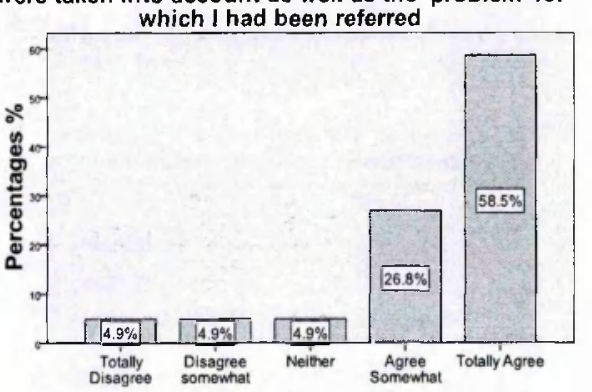

Level of Agreemen

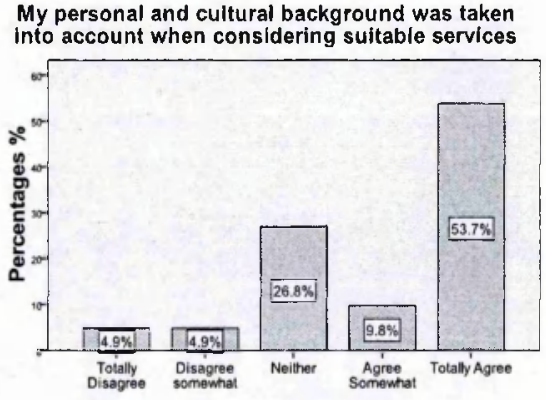

Level of Agreement

Figures 1-10 - Levels of agreement (in percentages \%) with statements regarding participants' experiences of initial contact (triage assessment) with the PCMHT

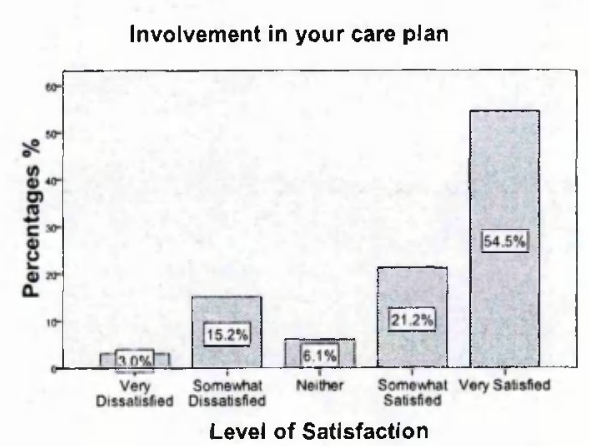

Advice/help with social needs, education/training, housing and/or employment

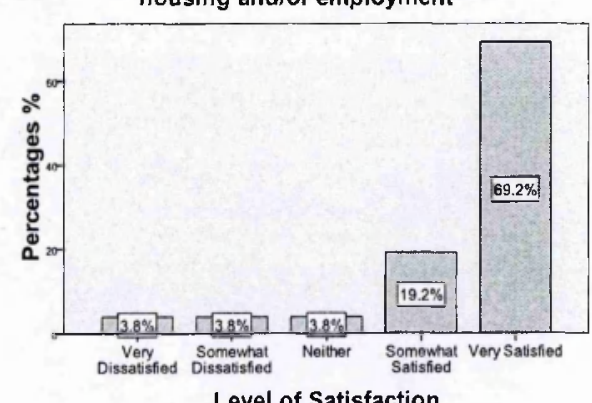

Sessions with your care-coordinator

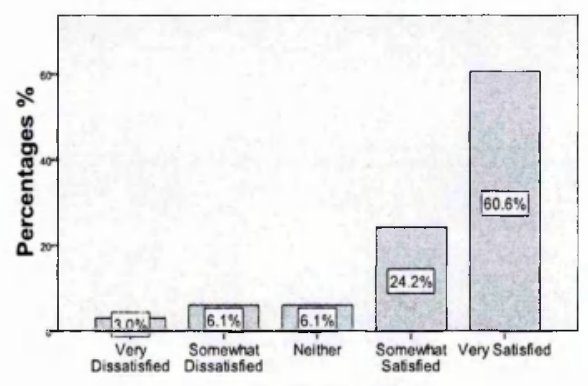

Level of Satisfaction

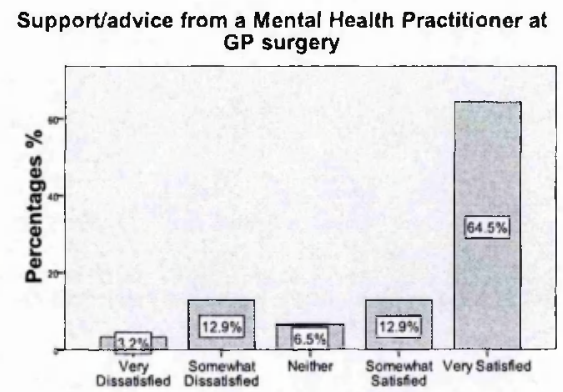

Level of Satisfaction 

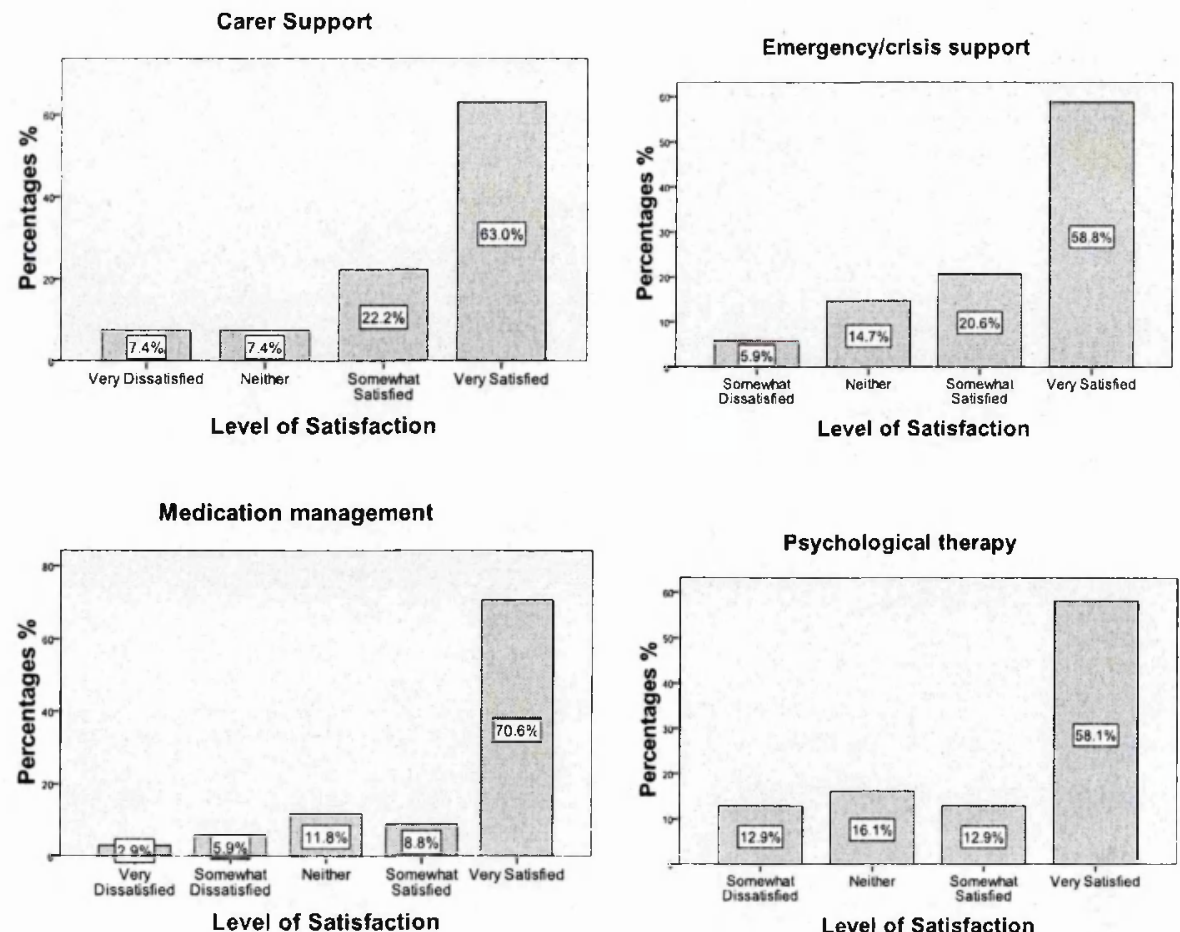

Figures 11-18 - Levels of satisfaction (in percentages \%) with specific aspects of service provision
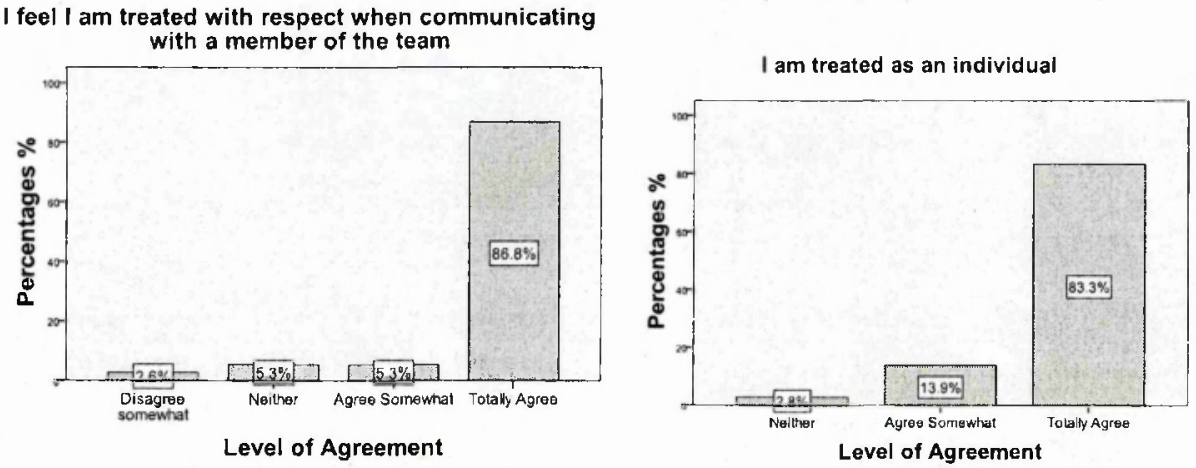

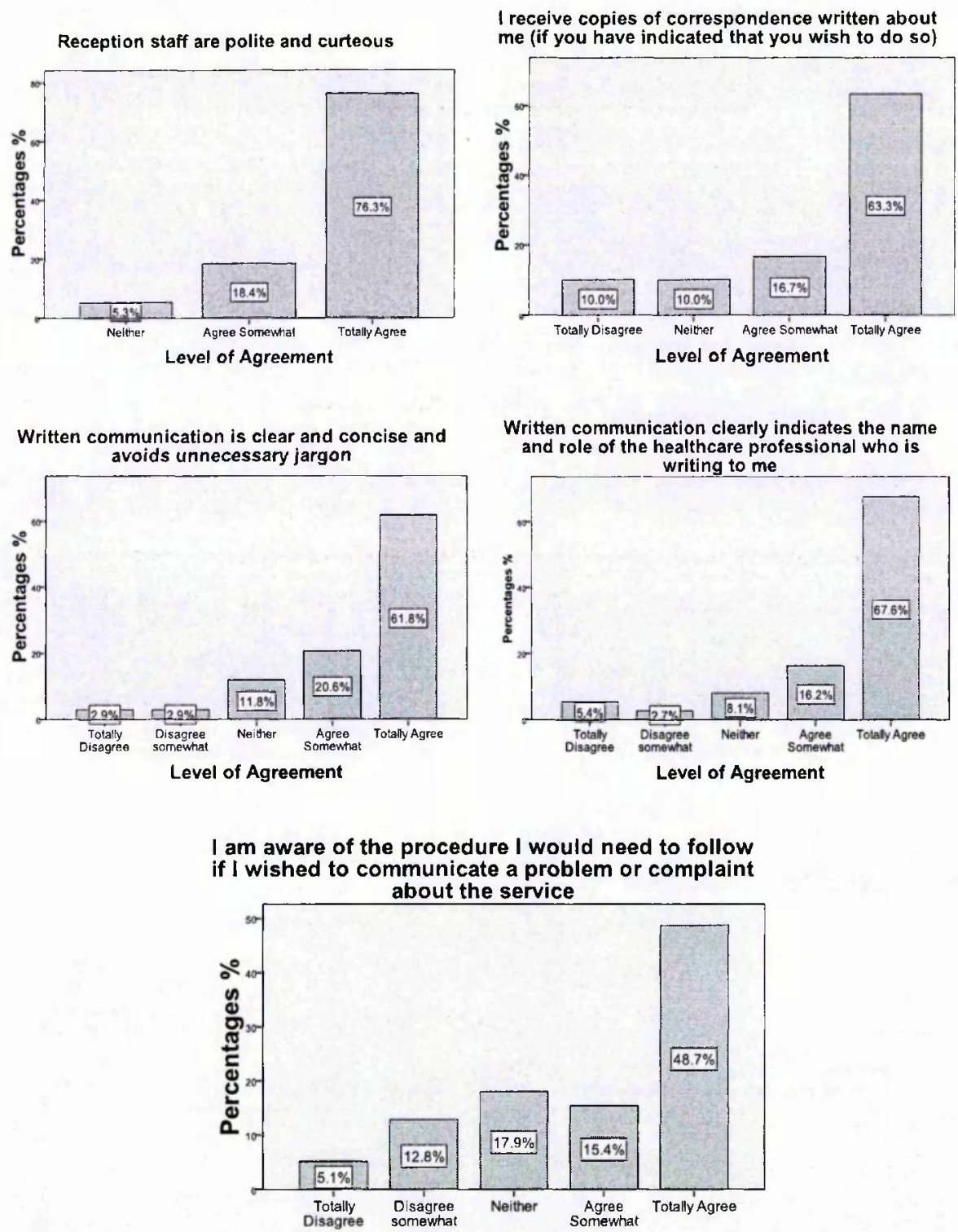

Level of Agreement

Figures 19-25 - Levels of agreement (in percentages \%) with statements regarding participants' experiences of communicating with the PCMHT. 

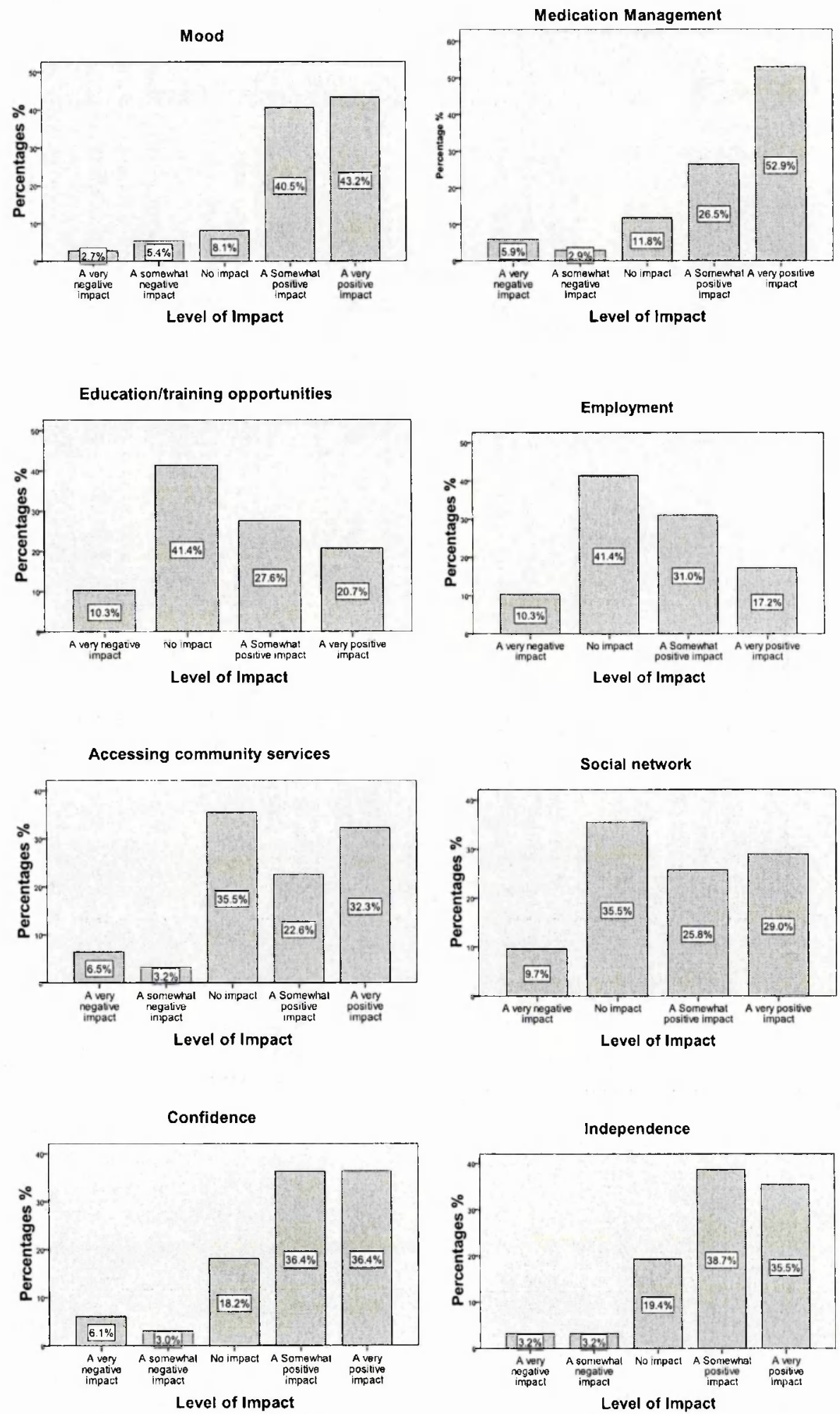

Figures 26-33-Participants' views on the level of impact (in percentages \%) that involvement with the PCMHT has had on various aspects of wellbeing. 


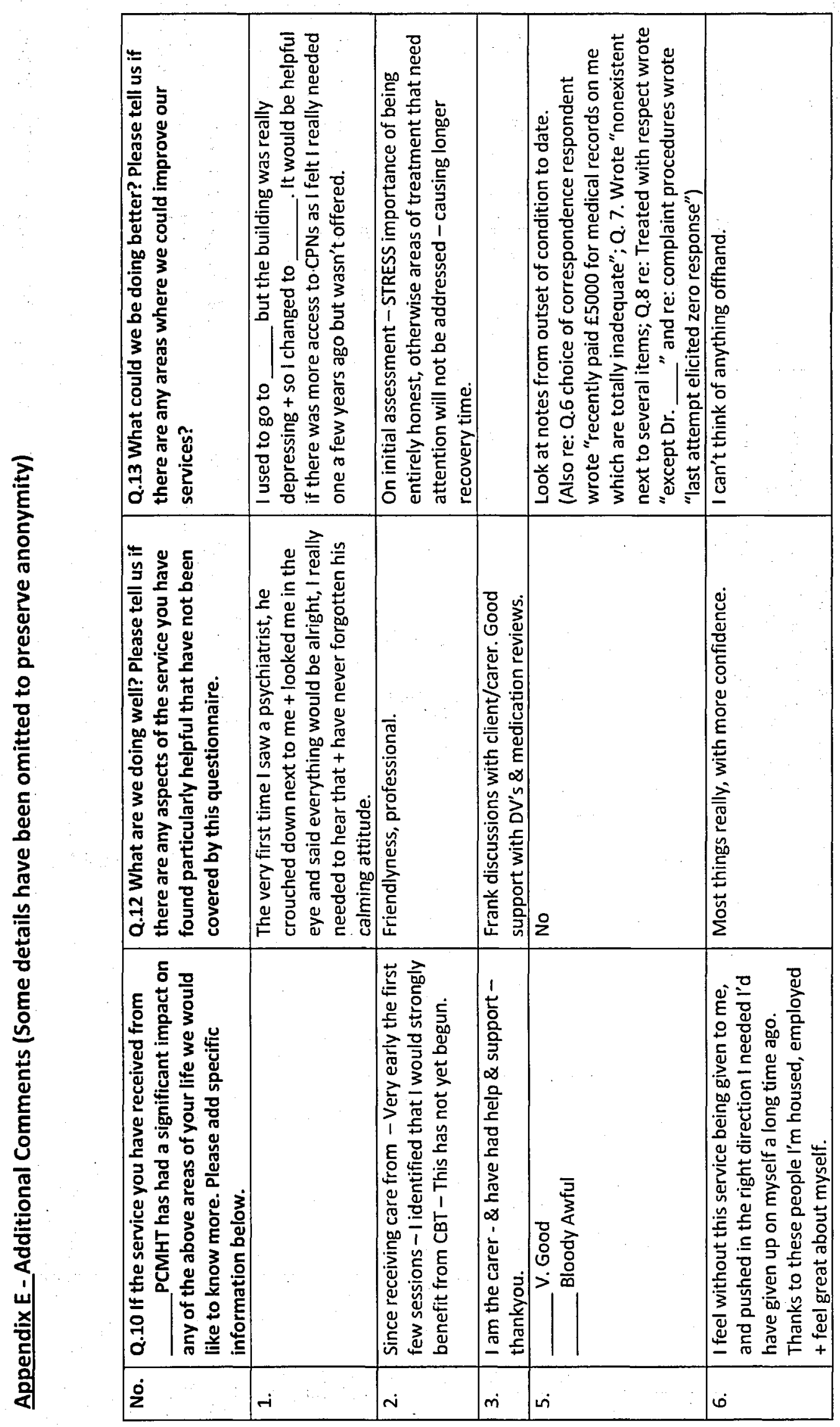




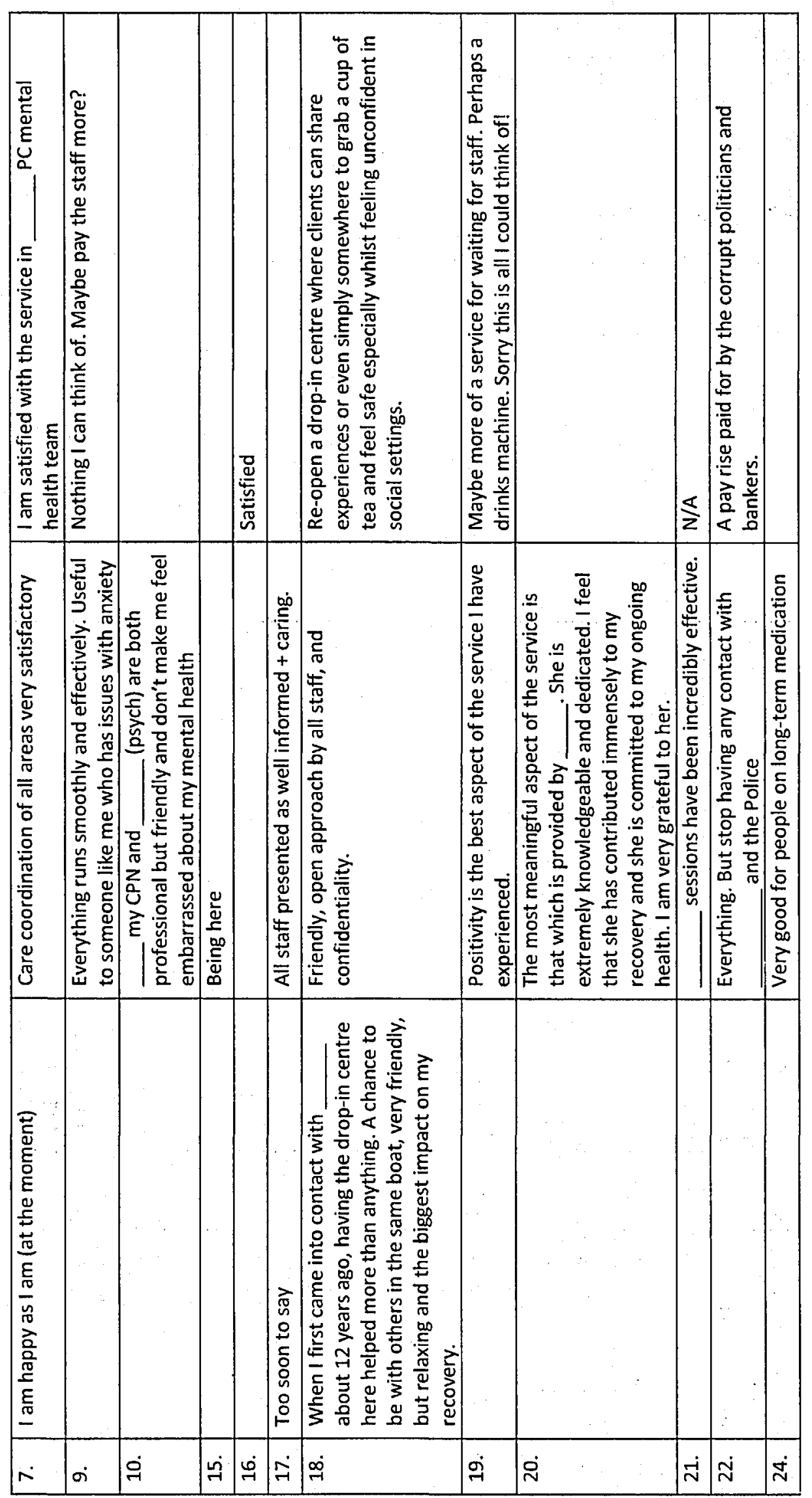




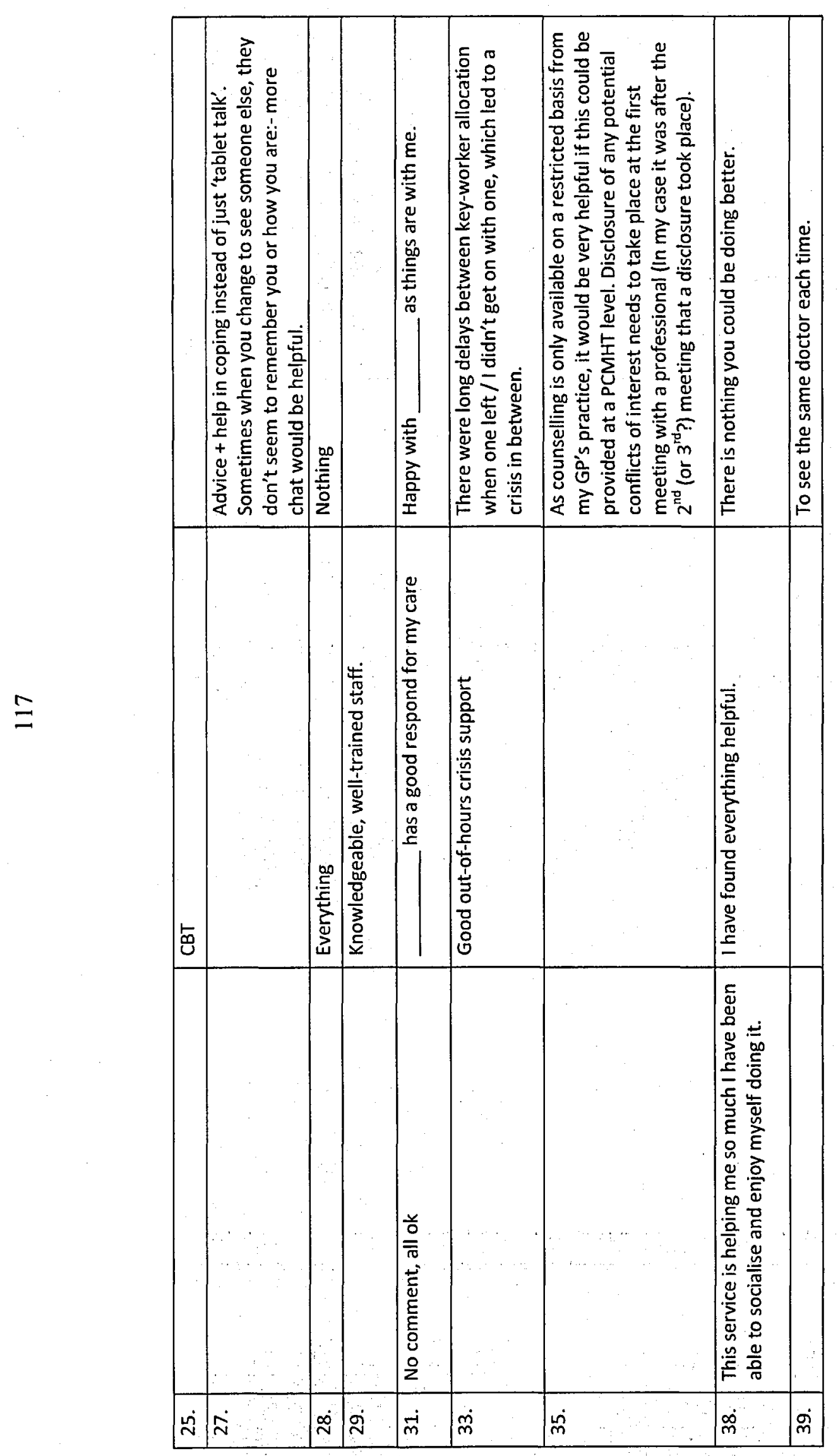




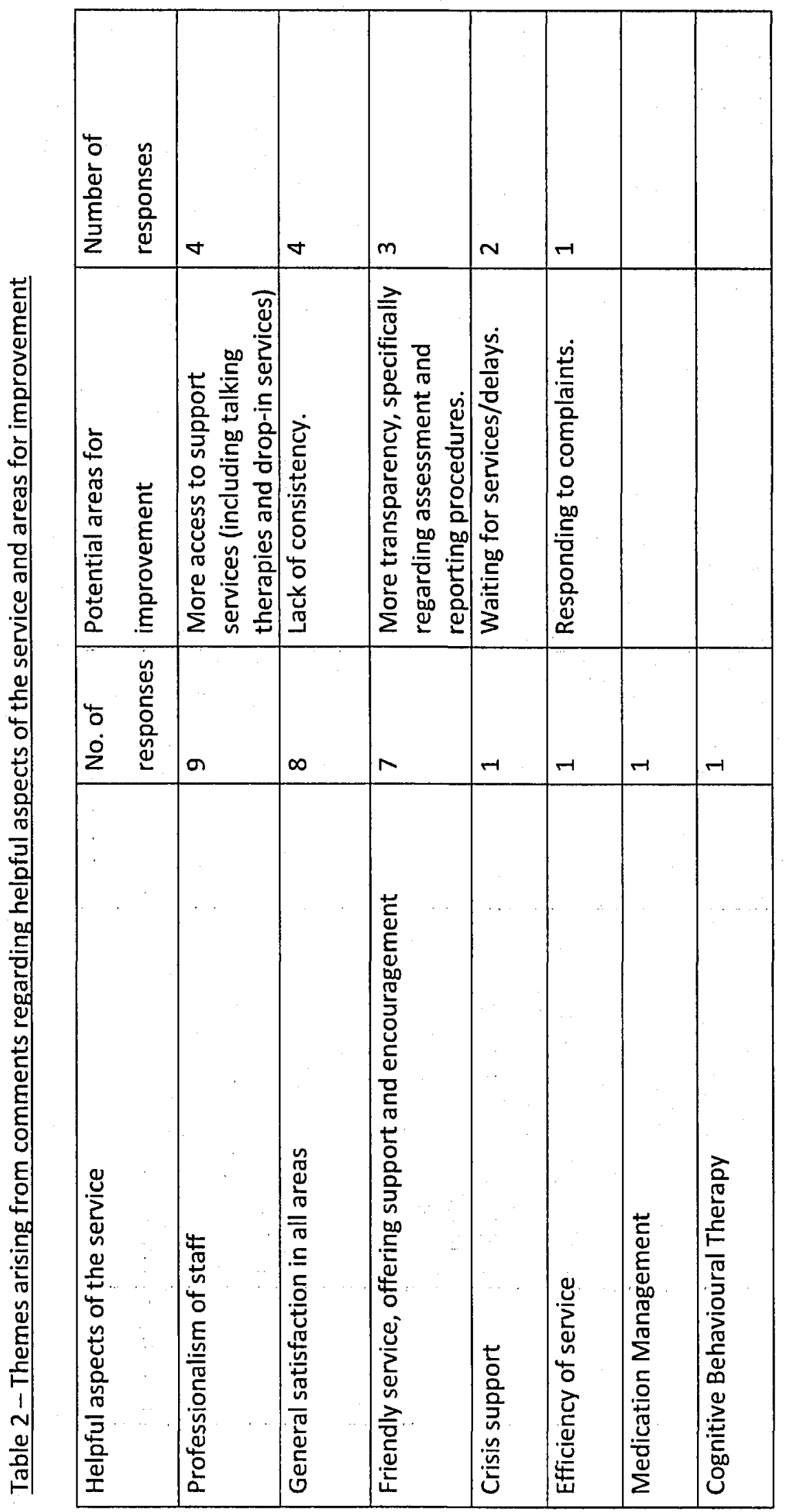




\section{Appendix F - Acknowledgements from Service manager}

(Some details have been omitted to preserve anonymity)

From:

Sent:

To:

Cc: Senior Team Members

Subject: RE: Presentations

Dear

On behalf of the team I would like to thank you for presenting us with the outcome of your service- user study - aimed to investigate how satisfied service-users were with the service provided by a Primary Care Mental Health Team (PCMHT).

It was heartening to have reports of high levels of overall satisfaction with almost all participants reporting that they were somewhat or very satisfied with the service they had received.

I have noted your recommendations and will take these forward through the seniors and our team meeting to ensure we address the concerns raised.

Many Thanks again for your very valuable study.

\section{Regards}

Service Manager PCMHT 
Trainee Clinical Psychologists' Perceptions of Working with Clients: An Interpretative Phenomenological Analysis

Qualitative Research Project: Abstract 


\begin{abstract}
This study aimed to explore trainee clinical psychologists' perceptions of working with clients. Semi-structured interviews were conducted with five female first-year trainee clinical psychologists and transcripts were subjected to the qualitative analysis of Interpretative Phenomenological Analysis (IPA). The interview schedule included questions relating to the therapeutic alliance, clinician factors that may impact upon alliance, the learning facilitated by existing clinical and personal experiences, and the impact of this learning on clinical practice.
\end{abstract}

Five superordinate themes were generated from the data: (a) variability of experiences; (b) confidence and competence; (c) engagement issues; (d) past experiences and personality; (e) learning as an ongoing process. Reflections are presented relating to the shared identity of the researchers and participants as trainee clinical psychologists, and the potential implications of this shared identity on levels of objectivity when interpreting participants' accounts. Limitations associated with the ambiguous nature of certain interview questions are acknowledged, and suggestions for future research offered. Implications for clinical practice are discussed, including the importance of professional development and learning support systems to enable clinicians to develop confidence and competence, to manage their own emotions, and to promote ongoing learning. 


\section{Understanding Conduct Disorder: The ways in which mothers attempt to make sense of their children's behaviour.}

Major Research Project 


\section{CONTENTS}

Page No.

- Abstract

126.

- Acknowledgements

128.

1. Introduction

129.

1.1. Historical Context 129.

1.2. Diagnostic Criteria 130.

1.3. Prevalence 132.

1.4. Co-morbidity 134.

1.5. Long-term Prognosis 134.

1.6. Building an Integrative Formulation 135.

1.6.1. Individual Factors 135.

1.6.2. Parenting and Attachment 136.

1.6.3. Social and Cultural Factors 138.

1.7. Treatment Considerations 139.

1.7.1. Parents Attributions 142.

1.7.2. Help-seeking 145.

1.8. Summary and Rationale 146.

1.9. Theoretical Assumptions 147.

2. Methodology 149.

2.1. Ethical Approval 149.

2.2. Design 149.

2.3. Participants 149.

2.3.1. Inclusion and Exclusion Criteria 149.

2.3.2. Sampling 151.

2.4. Procedure 151.

2.4.1. Recruitment $\quad 151$.

2.4.2. Data Collection 152.

2.5. Ethical Considerations 152.

2.5.1. Informed Consent 152.

2.5.2. Confidentiality 153. 
2.5.3. Management of Risk 153.

2.5.4. Potential for Additional Burden 154.

2.5.5. Reimbursement 154 .

2.5.6. Service User and Carer Input 154.

2.6. Materials 155.

2.6.1. Information and Consent Forms 155.

2.6.2. Contact Form 155.

2.6.3. Interview Schedule 156.

2.6.4. Debrief Information Form 156.

2.7. Contextualising the Data 157.

2.8. Data Analysis 158.

2.8.1. Procedure 158.

2.8.2. Validity and Reliability 161.

2.8.3. Researcher's own Perspective 163.

3. Results 166.

3.1. Looking for an answer... 166.

3.2. The emotional experience of being a parent 174.

3.3. Trying to get help 180.

3.4. '... a long, long road...' 186.

4. Discussion 190.

4.1. Research Findings 190.

4.2. Strengths and Limitations 195.

4.3. Clinical Implications 197.

4.4. Future Research 199.

4.5. Final reflections 200.

- References 202

- Appendices 214

A. Outcome letter from NHS Research Ethics Committee 214.

B. Evidence of compliance with approval conditions 218.

C. NHS R\&D approval 219.

D. Approval from Uni of Surrey's FAHS Ethics Committee 221. 
E. Participant Information form 222.

F. Professionals' information form 225.

G. Contact form 229.

H. Risk Assessment 232.

I. Participant consent form 234.

J. Interview schedule 236.

K. Debrief information sheet 239.

L. Example of analysed transcript 241.

M. Excerpt from table showing themes \& relevant quotes 245.

N. Process showing emergence of master themes 248. 


\begin{abstract}
The most common reason for referral to Child and Adolescent Mental Health Services (CAMHS) is often cited as being so-called disruptive behaviour disorders' (Puckering, 2009). Current treatment guidelines focus on family interventions, especially parent training programmes (NICE, 2006) and these have recently been included in the implementation of 'Children and Young People's Improving Access to Psychological Therapies' project (CYP IAPT, 2012).
\end{abstract}

There have been significant difficulties reported in engaging families, with parental attributions and attitudes towards help-seeking being proposed as factors influencing engagement (Morrissey-Kane \& Prinz, 1999; Kane et al., 2007). However, much of the previous research has tended to privilege pre-existing frameworks of understanding. The current study utilised qualitative methods in order to add to the current understanding of parents' experiences. Specifically, the ways in which parents attempt to make sense of their children's behaviour.

Participants were recruited through CAMHS and semi-structured interviews were carried out with six mothers. Interpretative Phenomenological Analysis (IPA) revealed four master themes: 'Looking for an answer', 'The emotional experience of being a parent', 'Trying to get help' and '...a long, long road...' Participants used a variety of frameworks in order to try and make sense of their children's behaviour, including emphasising difficulties in processing complex emotions and the impact of loss and trauma. Participants appeared to struggle to integrate opposing views of their children and the emotional impact of parenting and the wider family context was found to be vital in understanding mothers' experiences. 
Participants described feelings of shame associated with help-seeking and services were often viewed as inconsistent, invalidating and stigmatizing. In contrast, positive experiences were those which were characterised as being non-judgemental, normalising and took into account the wider family context, including mothers' own emotional needs. These findings were discussed in relation to existing research and implications for clinical practice. 


\section{Acknowledgements}

I would like to thank my supervisors, Dr. Victoria Petch, Dr. Naomi Wilson and Dr. Simone Fox for all of their support and guidance throughout this process. Thanks also to all of the professionals at the Child and Adolescent Mental Health Services who helped me to identify and recruit potential participants and to the parents who kindly agreed to take part and share their experiences with me.

Thanks also to my friends and family whose support and encouragement has helped me to get through this process. 


\section{Introduction}

\subsection{Historical context}

$\therefore$ there is nothing new about debates concerning young people's behaviour.' (Hendrick, 2006, p.14)

In his chapter 'Histories of Youth Crime and Justice' Hendrick (2006) describes the historical pre-occupation that each new generation is somehow more 'delinquent' than the previous, and discusses the sociopolitical origins of this discourse. There have clearly been long-standing concerns regarding behavioural problems among children and adolescents; indeed, Costello and Angold (2001) cite examples of 'bad behaviour' in young people in religious texts dating back to $7^{\text {th }}$ Century BC. However, the way in which these problems have been conceptualised and dealt with at a familial and societal level has changed considerably (Costello \& Angold, 2001). Mallett (2006) describes how the practise of labelling 'abnormal' or 'socially undesirable' behaviour in youth in terms of a psychiatric diagnosis, and therefore the concern of mental health professionals was legitimised during the first half of the $20^{\text {th }}$ Century, with the emergence and development of psychiatric classification systems. The diagnosis of 'conduct disturbance' first appeared in the $8^{\text {th }}$ Edition of The Statistical Manual for the Use of Hospitals for Mental Diseases (United States Census Bureau, 1918 - 1942, cited in Mallett, 2006), a predecessor of the now commonly used Diagnostic and Statistical Manual of Mental Disorders (DSM).

Currently, the issue of 'delinquent youth' continues to be focus of much debate in the media, with young people commonly being portrayed as dangerous 'hoodies' and 'yobs' (Gardner, 2009). The issue has also become a key political agenda and targeting the most 'troubled' families through 
Family Intervention Projects (FIP) was identified as a policy priority for the current UK government following the nationwide rioting in 2011 ('Trouble shooters scheme to tackle 'troubled families'; BBC News, 2011).

\subsection{Diagnostic Criteria}

The most recent edition of the Diagnostic and Statistical Manual of Mental Disorders (DSM-IV-TR; American Psychiatric Association (APA) 2000) places Conduct Disorder and Oppositional Defiant Disorder (ODD) under the overarching category of 'Disruptive Behaviour Disorders', along with Disruptive Behaviour Disorder Not Otherwise Specified which is used in cases where there are significant concerns about behaviour but which do not meet the diagnostic threshold for ODD or Conduct Disorder. Conduct disorder is defined as 'a repetitive and persistent pattern of behaviour in which the basic rights of others and major age-appropriate societal norms or rules are violated' leading to 'significant impairments in social academic or occupational functioning'. In order for diagnostic criteria to be met at least one of the behaviours must have been present for a minimum of six months (APA, 2000). The DSM-IV-TR also indicates a range in severity, from mild to moderate and severe and a distinction is made between childhood onset (before aged 10 years) and adolescent onset. Current evidence suggests that the causal factors for adolescent-onset may differ somewhat (Sainsbury Centre for Mental Health, 2009) and this is less likely to lead to subsequent offending in adulthood leading some to suggest that there should be an 'adolescent limited' subtype (Moffitt, 2003).

Possible revisions proposed for the fifth edition of the Diagnostic and Statistical Manual (DSM-V) include an additional specifier of 'Callous and Unemotional Traits' including 'lack of remorse or guilt, lack of empathy; lack of concern about performance and shallow or deficient affect' (APA, 2012). This suggestion has been highly controversial due to the similarities 
to so-called psychopathic traits in adulthood and the possible implications for those labelled as such in childhood. It has been noted that if present, these traits are likely to apply only to a specific sub-set of individuals and the links are by no means clear-cut (Loeber et al., 2009).

Oppositional Defiant Disorder (ODD) is defined by the DSM-IV-TR as 'an ongoing pattern of anger guided disobedience, hostilely defiant behaviour toward authority figures which goes beyond the bounds of normal childhood behaviour' which 'causes considerable distress for the family and/or interferes significantly with academic or social functioning'. Similarly, the behaviours must have been present for at least six months to reach the threshold for diagnosis and must be considered to go beyond what would be considered 'normal' childhood disobedience. It has been estimated that up to $52 \%$ of children diagnosed with ODD will later go on to be diagnosed with Conduct Disorder (Lahey et al., 1992). This has led some to call into question the validity of the distinction between the two diagnostic categories (Mallett, 2006).

Although the DSM-IV-TR is one of the most commonly used and widely accepted diagnostic tools, it is not without criticism. Mallett (2006) highlights a number of concerns regarding the validity of the diagnoses and states that the 'recent exponential expansion (1969-2000) of these youth psychiatric disorders, without any clear empirical support, is testimony to the excessive influence of noted individuals and the American Psychiatric Association... although the aetiology was actually propelled forward by rhetoric and promises, but it was receptively received by a very biologicallydeterminative medical community and lay public.' (p.15)

Critics also argue that the diagnostic labels are too broad and over-simplify. the complex interplay between the multiple factors that are thought to contribute to the development of externalising behaviours. The concerns. 
about the usefulness of a diagnostic system which places the 'problem' within the child and downplays the importance of adverse environmental conditions are long-standing. In 1965 Anna Freud wrote 'Some children run away from home because they are maltreated, or because they are not tied to their families by the usual emotional bonds.... Here, the cause of the deviant behaviour is rooted in the external conditions of the child's life and is removed with improvement of the latter.' (p.111, cited in Wakefield et al., 2002). Richters and Cicchetti (1993) also draw attention to the oversimplicity of the diagnostic criteria which, they argue broadly ignores information about the child's development, comparative strengths, family circumstances and environment.

These criticisms can be seen as part of the wider discussion regarding the usefulness of accepting psychiatric diagnoses as an unequivocal 'truth' and the implications this has with regards to reinforcing social and political hierarchies (Harwood, 2006; Miller \& McClelland, 2006). Proponents of a formulation based approach as an alternative to psychiatric diagnosis suggest that a person-centred, integrative formulation that includes contextual, social and cultural factors can provide a more comprehensive, useful and sensitive account of an individual's particular difficulties (British Psychological Society, 2011).

\subsection{Prevalence}

Conduct disorders and related disruptive externalizing behaviours are commonly cited as the most common reason for referral to Child and Adolescent Mental Health Services (CAMHS; Renk, 2008; Baker, 2008). In 1999, The Audit Commission for Local Authorities and the National Health Service in England and Wales found that over $60 \%$ of children being seen by CAMHS presented with disruptive anti-social or aggressive behaviour in some form (Audit Commission, 1999). Finch et al., (2006) propose that the 
reasons for such high rates of referral are that the aggressive behaviours often associated with conduct disorders are easily observed by others, often cause difficulties in educational settings and bring the young person into contact with the criminal justice system and social services.

Estimates of prevalence vary somewhat with figures in the USA and Canada ranging from between 6 to $16 \%$ of adolescent boys and 2 to $9 \%$ of adolescent girls (Murray \& Farrington, 2010). A review of mental health amongst children and young people in the UK placed the prevalence of disruptive behaviour disorders at $6.9 \%$ for boys and $2.8 \%$ for girls aged between 5 and 10 years old and $8.1 \%$ for boys and $5.1 \%$ for girls aged 11 to 16 (Green et al., 2005). Lahey at al. (1999) noted that much of the observed variance could be accounted for by variations in methodology, for example differences in terminology and requirement of a formal diagnosis.

Canino and Alegria (2008) have highlighted cross-cultural differences in estimates of prevalence and treatment outcomes and discussed the influence of culturally protective factors present in different communities, such as family and community cohesiveness as well as the impact of environmental risk factors in the development of externalizing behaviours. This impact of environmental factors raises the question of how 'pathology' is defined cross-culturally, since behaviours which might be considered disruptive in one environment could be considered adaptive in another. However, some researchers have found that there are no significant cross-cultural differences in prevalence when rates are adjusted for socio-economic and other demographic differences (Roberts \& Roberts, 2007). However, there is a research bias in operation with the majority of evidence originating from Western countries and a dearth of literature regarding prevalence of childhood behavioural disorders in developing countries. It is worth noting that there are clear methodological difficulties 
involved in measuring prevalence in countries where there may be wider issues such as political instability and a lack of available resources impacting upon the provision of child and adolescent mental health services, and therefore the priority given to the identification and treatment of childhood behavioural disorders.

\subsection{Co-morbidity}

There have been high rates of co-morbidity with Attention Deficit Hyperactivity Disorder (ADHD) observed among children diagnosed with Conduct Disorder and ODD (Renk, 2008; Maughan et al., 2004) which for some adds to concerns about the validity of the diagnoses. There have also been reports of significantly elevated rates of anxiety and depression observed in children diagnosed with disruptive behaviour disorders (Maughan et al., 2004). Although Angold et al. (1999) suggested that this may represent a more complex picture of co-morbidity in this group since when they controlled for other co-morbidities (including ADHD), there was no independent association observed between ODD and anxiety and the association between conduct disorder and anxiety appeared to be largely accounted for by their links with depression. Bassarath (2001) describes a number of links between conduct disorder and substance-misuse, with the rate of co-morbidity being reported in one study up to $91 \%$ (DeMilio, 1989, cited in Bassarath, 2001).

\subsection{Long-term Prognosis}

There are poor long-term outcomes associated with a childhood diagnosis of conduct disorder; it is associated with a diagnosis of Antisocial Personality Disorder in adulthood (NICE, 2006), poor educational attainment, criminality, substance misuse, employment problems and interpersonal difficulties (Baker, 2008). There have been differential 
outcomes proposed for girls such as early pregnancy and increased risk of becoming the victim of partner-violence (Baker, 2008). Keenan et al. (1999) highlight that girls with conduct problems are at a higher risk of developing co-morbid internalizing disorders, such as depression and anxiety and it has also been suggested that girls with a diagnosis of conduct disorder in childhood are at higher risk of developing symptoms associated with Borderline Personality Disorder (BPD) in late adolescence and adulthood (Stepp et al., 2012).

\subsection{Building an Integrative Formulation}

There has been a great deal of research into the roles of the various different biological, parental and social factors that have been suggested as interacting in the development and maintenance of conduct problems. Farrington (2005) provides a comprehensive review and some of the key factors are discussed in more detail below with reference to the dominant psychological models which can be used to develop an integrative understanding of the origins of these difficulties.

\subsubsection{Individual factors}

One of the most consistently reported findings is the significantly higher prevalence of conduct disorder in boys (Maughan et al., 2004) with some studies reporting a ratio of up to 5:1 (Bassarath, 2001). Although some studies report similar findings for ODD, the evidence for this is markedly less consistent (Lahey et al., 1999 and Maughan et al., 2004). Meier et al. (2011) also suggest that the stability of antisocial behaviour from childhood to adulthood may be greater for males than for females.

Many researchers also describe significant differences in the way that conduct problems are expressed in girls compared to boys, with 'indirect. aggression' (e.g. spreading rumours and ostracizing peers) and 'status 
offences' (i.e. truancy, prostitution, underage drinking etc.) more often observed than direct violence and physical aggression. Furthermore, when physical aggression is observed it is more likely to be expressed towards a close relative than a stranger (Bassarath, 2001). This raises clear questions regarding the role that social and cultural gender expectations may play in terms of the acceptability of displays of aggression in girls versus boys.

Baker (2008) and Farrington (2005) both highlight a range of underlying cognitive deficits often observed in children diagnosed with conduct disorder, including poor verbal skills, impulsivity and social cognition. If these underlying problems are not identified at an early stage in development then the young person is likely to experience feelings of frustration and frequently be met with failure, particularly in an educational setting and with little support, they may not be equipped with the skills to deal with these feelings effectively resulting in externalizing behaviours.

There has also been much focus on the role of individual differences in temperament that may contribute to a cycle of negative responding from parents, which then serves to reinforce non-compliant or aggressive responses in the child (Baker, 2008).

\subsubsection{Parenting and Attachment}

One of the most influential theories in understanding the development of antisocial behaviour has been that of Social Learning Theory (SLT) as described by Patterson in 1982 (cited in Snyder et al., 2003) in which behaviour is thought to be shaped by a combination of positive and negative reinforcement, coercive interactional styles and modelling by antisocial peers and role-models (Snyder et al., 2003). Support for SLT comes from the consistent finding that parenting style plays a key role in the development of antisocial and oppositional behaviour. In a review of 
key findings from several longitudinal studies, Murray and Farrington (2010) found that in terms of parenting style, poor parental supervision was the strongest and most replicable predictor of delinquent behaviour. Other risk factors highlighted included harsh and inconsistent parenting, an authoritarian (highly punitive) parenting style, parental conflict and exposure to physical abuse. There was also strong evidence to suggest that conduct disorders are more prevalent in families where there has been parental separation. However, it has been stressed that this is highly likely to be related to the additional financial and social stressors that single. parent families might face and that it is important to take into account the impact of multiple stressors over the life-course.

In terms of the suggested role of parental psychopathology in the development of conduct problems, findings have been mixed. Frick et al. (1992) found a strong association with maternal parenting style (poor supervision and lack of consistency in discipline) and paternal anti-social personality disorder and substance misuse and suggested that whilst maternal depression is often associated with difficulties in childhood, it is not more highly associated with externalising behaviours per se. More recently Marmorstein and lacono (2004) found a strong association with high parent-child conflict and maternal depression and Chronis et al. (2007) found that in children with ADHD, maternal depression did predict later conduct problems. Additionally they found that early positive parenting (i.e. praise and positive affect) predicted fewer conduct problems later on in life.

The mixed picture highlights the complex interplay between individual and familial risk factors in the development of such behaviours and the inherent difficulties in teasing out the relevant factors from those that are just co-occurring due to similar underlying difficulties. For example, whilst some researchers maintain that parent psychopathology (especially 
paternal anti-social behaviour) is in itself is a risk factor due to the suggested heritability of such traits (Bornovalova et al., 2010) others have argued that it is more likely that there are generally higher levels of parentchild conflict and inconsistent parenting seen in these families. These intergenerational patterns can also be understood in terms of disorganised attachment relationships (Lyons-Ruth, 1996) in which unpredictable and inconsistent responding by the care-giver in infancy is associated with later externalising behaviours and hostility.

Scott and Dadds (2009) highlight that whilst SLT may be a helpful starting point in understanding how parent-child interactions influence the development of conduct problems, and indeed is the basis of many of the existing parent-training interventions, this understanding must be extended in order to fully account for the complex nature of these difficulties. They point to attachment theory and systems theory as two ways in which the current understanding can be extended, and help to point towards further possible interventions, especially in cases when the standard approaches have not been sufficient. Scaramella and Leve (2004) provide an integrative understanding of parent-child interactions in their 'Early Childhood Coercion Model' in which the quality of attachment relationships is core to understanding the development of emotional regulation and externalising behaviours in children. Walton and Flouri (2010) have also highlighted the role of maternal warmth and emotion regulation in the development of conduct problems.

\subsubsection{Social and Cultural Factors}

Conduct problems are consistently reported as occurring more frequently in families with lower socioeconomic status (Baker, 2008; Bassarath, 2001; Farrington, 2005; Murray \& Farrington, 2010). The higher prevalence amongst these groups is generally seen as being a result of the combined impact of factors such as poor housing, poor access to health and 
education services, unemployment, social isolation, family breakdown, anti-social peer relations and poverty.

Furthermore rates of crime and delinquency amongst young people are commonly reported to be significantly higher amongst inner-city populations than other urban or rural populations, emphasizing the role of social exclusion and peer group relations in the development of anti-social behaviour (Murray \& Farrington, 2010). Pearce et al. (2003) also highlight the role of exposure to violence within the community in the development of externalizing behaviours. Findings suggest that positive parenting involvement and several dimensions of religiousness served as protective factors amongst youth exposed to mild and moderate (but not high) levels of violence within their community.

\subsection{Treatment Considerations}

Given the strong evidence for the role of parenting style in the development of disruptive behaviour disorders, current treatment focuses mainly around parenting interventions which have their foundations in SLT. Whilst there are a range of parent training and education programmes, the most influential have been the Webster-Stratton 'Incredible Years' parenting group (Webster-Stratton, 2010) and the Triple-P positive parenting Programme (Sanders et al., 2000). However, the effectiveness of these approaches in everyday practice has been called into question by those who call attention to the fact that the participants in the original research trials volunteered to take part in the programme. It is argued that these participants therefore represent a very small proportion of parents, who already have positive views regarding seeking and receiving help with parenting. They are likely to hold a causal hypothesis regarding their children's behaviour that includes their role as a parent as a contributory factor (Puckering, 2007). The situations that services face in trying to 
deliver the programmes are likely to be quite different, and as such results cannot be generalised. Indeed, parents who did not complete research trials were more likely to be young, of low Socio Economic Status (SES), have less social support, higher levels of stress, be less educated and have higher levels of depression and anxiety (Puckering, 2009). Given that these parental characteristics have all been cited as risk factors for the development of conduct problems in children, services are tasked with the challenge of targeting interventions towards the most difficult to engage group. However, despite significant difficulties reported in engaging parents in training programmes, evidence from research-trials in more naturalistic settings has still shown promising results (Gardner et al., 2007; Hutchings et al., 2007; Scott et al., 2001).

Additionally Webster-Stratton and Hammond (1990) have made some specific recommendations for ways to overcome the perceived barriers to engagement. These include targeting additional family and systemic needs such as parental mental health, budgeting, problem-solving and couples therapy. They also suggest providing practical solutions to overcome financial barriers, such as incentives for attendance and access to childcare and transport as well as holding groups in easy to access community locations outside of working hours. Finally, they highlighted the importance of actively fostering a supportive group environment.

Nix et al. (2009) found that even when particular attention is paid to overcoming barriers in attendance at parenting groups, quality of participation (as measured by group facilitators) remains predictive of treatment response. Factors found to be related to quality of participation included parents' level of education and employment. The authors hypothesise that the educational format of these training groups may mean that by their very nature they are less accessible to some parents who may be struggling with severe hardships. These parents may have 
previous experiences of poor educational attainment and therefore feelings of failure and shame associated with a formal teaching environment.

Parent training groups have consistently been shown to be highly costefficient (NICE, 2006) and as such are popular with commissioning groups and have been included in the roll out of the Children and Young Persons Improving Access to Psychological Therapies (CYP IAPT) pilot in the UK. Given that many of the social risk factors for the development of behavioural problems later in childhood, such as poverty and social isolation are relatively easy to identify (Puckering 2009), there has been a recent shift in focus towards early intervention and community based approaches designed to promote wellbeing in vulnerable groups (Department of Health, 2009). However, despite support for early intervention (Sainsbury Centre for Mental Health, 2009; Broadhead et al., 2009), in the current financial climate with a focus on short-term outcome measures and payment by results, it has been difficult to secure ongoing funding for these projects as it is difficult to evidence effectiveness in the short-term.

For more complex cases or when there have been significant engagement difficulties, more intensive interventions such as Functional Family Therapy, Multi-dimensional treatment foster care and Multisystemic Therapy (MST) are suggested as an alternative to parenting groups (Baker, 2008; Carr, 2009) which draw heavily from attachment and systems theory. Although these interventions have been criticised for being resource-heavy and expensive, proponents of these approaches argue that the immediate cost is far outweighed by the potential long-term savings in health and social care and criminal justice proceedings and that existing interventions fail to take account the multiple determinants of anti-social behaviour in children (Henggeler et al., 2009). The Sainsbury Centre for Mental Health 
estimated the overall lifetime cost of adverse outcomes (with the biggest proportion being the cost of crime) among those diagnosed with conduct disorder at around $£ 225,000$ per case (Sainsbury Centre for Mental Health, 2009). There have been good long-term outcomes reported for MST in reducing rates of offending and need for out-of-home placements (Henggeler et al., 2009).

One factor suggested as playing a key role in engagement and treatment outcome are parental views regarding the need or relevance of intervention (Baker, 2008) which is discussed further below.

\subsubsection{Parental Attributions}

Heider (1958, cited in Snarr et al., 2009) theorised that in order to understand, predict and respond to their environments, people form causal explanations, or 'attributions' regarding other people's actions. These attributions are said to be influenced by an individual's perceptions regarding the characteristics of the other person and the intentionality of their actions. Miller (1995) suggested that the attributions that parents make regarding their children's behaviour may influence the way in which they respond. There has been strong support for an association between 'child-centred' responsibility attributions that assume behaviour is purposeful with a negative intent and harsh parenting practices (Grusec et al., 1997; Snarr et al., 2009;).

There has been a lot of investigation into the role that parental attributions have on parent feelings of self-efficacy in particular clinical samples, such as parents of children diagnosed with ADHD and some comparisons have been made between groups. Saltmarsh et al. (2005) found that compared to a sample of parents whose children had been diagnosed with ADHD; parents whose children had behavioural difficulties but had not been given a diagnosis were more likely to view negative behaviours as intentional and 
under the child's control, which led to an increase in feelings of anger. Maniadaki et al. (2006) highlighted that these differences in parents' perceptions of their children's behaviour meant that mothers of children with conduct problems were likely to employ more strict parenting practices than mothers of children with ADHD.

There is clearly strong support for the idea that parental attributions regarding children's behaviour will influence parents' affect and subsequently, their reactions to the behaviour. However, this is not believed to be a linear process and there is also evidence for the idea that ineffective responses to behaviour and subsequent perceived failure further reinforces the attributions. This would further support the case for preventative interventions which target risk factors and can help parents to develop positive parenting styles before unhelpful attributions about the origins of disruptive behaviours have been formed.

Dix and Lochman (1990) proposed a three stage models of parental attributions in which the parent considers factors such as the child's perceived understanding, ability and the potential influence of others during their interpretation of their child's behaviour. However, this linear model is applied to each situation in isolation and it could be criticised for paying little attention to the potential impact of cultural, familial and environmental factors in influencing these attributions over an extended period of time.

Wilson et al. (2006) demonstrated that maternal attributions regarding globality and internality of conduct problems are not static, and change over time. They found that whilst early conduct behaviours were predictive of later maternal attributions (i.e. higher levels of oppositional behaviour at age three predicted maternal attributions regarding internality and 
globality of behaviours at age four), early maternal attributions were not predictive of later conduct problems.

Parental cognitions and attributions regarding the origins of the challenging behaviour and self-efficacy have been suggested as mediating factors to engagement and treatment outcome (Morrissey-Kane \& Prinz, 1999) with strategies that target these cognitions having been suggested as a pre-treatment intervention (Mah \& Johnson, 2008). However, Peters et al. (2005) found that whilst parents who made child-responsibility attributions regarding the origin of their child's behaviour were no less likely to complete a Parent Management Training programme, parents who believed that they were responsible for their child's behaviour were more likely to complete the programme. This presents a mixed picture as whilst it suggests that child-responsibility attributions are not necessarily a barrier to engagement, making more parent-responsibility attributions is related to positive engagement. However, socioeconomic status was predictive of attendance, further supporting the rationale for providing practical solutions to overcoming socioeconomic barriers to attendance. Furthermore, parents of children who had received a formal diagnosis in the written/electronic records were seven times less likely to complete the programme and families who completed therapy were more likely to have been referred from clinical psychology than psychiatry or other sources. The authors tentatively suggested that the way in which clinicians present an explanation and rationale for treatment can influence parental adherence to a treatment programme (especially if treatment appears to contradict the existing causal explanation). It is worth noting however that the study did not investigate the relationship between these factors and the overall effectiveness of the intervention.

There is a mixed picture regarding the potential role of parental attributions in the development and treatment of conduct problems. It is 
worth noting that research studies regarding the impact of parental attributions differ considerably in their methodology, i.e. the way in which parent attributions and conduct problems are measured, including using a variety of self-report measures, observation and clinical interview as well as age at assessment and whether a previous diagnosis of conduct disorder is required, or assessed as part of the research process. All of these variables mean that it is difficult to compare results.

\subsubsection{Help-seeking}

In situations where referrals to mental health services have been precipitated by problems within the school environment or involvement with the criminal justice system, there is likely to be an immediate barrier to engagement as services may be seen as imposing themselves upon families who have not initiated the process. In a review of parents' experiences of taking part in parenting programmes, Kane et al. (2007) highlighted that feelings of self-blame, stigma and social isolation may further impede help-seeking. A range of factors have been suggested as influencing formal and informal support seeking in parents, including socioeconomic status and educational level (Redmond et al., 2002). It has been suggested that parents with low-incomes tend to utilise resources such as social networks and publicly available media, rather than health and social services when seeking help with parenting. Services should therefore seek to provide information utilising a range of creative methods (Keller \& McDade, 2000).

In order for services to continue to work towards positive methods of engagement, including providing sufficient information, support and education for care-givers, it is important to explore the processes and methods that parents' utilise to try and make sense of their children's behaviour. 


\subsection{Summary and Rationale}

The development of conduct problems and related externalising behaviours in childhood is associated with a range of individual, familial and social factors. Social learning, attachment and systemic theories provide an integrative understanding of these difficulties and appropriate interventions.

Previous research has indicated that parental attributions regarding their children's behaviour may influence parental affect and subsequent responding, as well as potentially influencing parental engagement with treatment. However, it is suggested that parental attributions are not fixed and there is an interactional process, whereby repeated experiences of failure lead to low self-efficacy and appraisals which emphasise internality and globality.

In addition, there are a range of other factors which are likely to impact upon parents' engagement with services, including associated feelings of shame, stigma and previous experiences of failure.

Previous research studies into parental attributions have tended to utilise quantitative methods in which parents are asked to make causality and responsibility appraisals regarding hypothetical situations. The current study aims to add to the existing literature by exploring the ways in which parents attempt to make sense of their children's behaviour from their own perspective rather than imposing a pre-existing framework of understanding onto their experiences. As Gergen et al. (2004) state, qualitative research allows for the possibility of new theory, methods and clinical practice by 'shifting the lens of understanding'. 
The specific research question under investigation is 'how do parents make sense of their children's behaviour over time'.

\subsection{Theoretical Assumptions}

The current study is informed by a phenomenological approach (Husserl, 1927 cited in Shinebourne, 2011) whereby in order to try and understand individuals' experiences and the meaning they attach to them it is necessary to engage in a process of 'systematically and attentively reflecting on everyday lived experience' (Smith, 2009, p.33).

The approach used in this case was that of Interpretative Phenomenological Analysis (IPA) which takes a relativist position (Willig, 2008) in which there is not an assumption of an 'absolute truth', but rather multiple realities which are seen as being embodied within a social and cultural context.

IPA is also grounded in the process of interpretation, or hermeneutics (Heidegger, 1962 cited in Shinebourne, 2011) in which the role of the researcher is central to the process of making sense of participants' experiences. Smith (2004) refers to this process as 'double hermeneutics' in which 'the researcher is trying to make sense of the participant trying to make sense of their personal and social world' (p.40).

IPA uses an ideographic approach, in which the aim is to gain in-depth and detailed accounts of a small number of participants. By doing this the researcher is able to engage with the data in a way which takes into account the fine detail of each case and can move towards developing an understanding of the similarities and differences across individual experiences (Smith, 2009). 
By examining data in a way that allows for a deeper engagement with individuals' experiences, it was hoped that this study would help to contribute towards a more in-depth understanding of the ways in which parents' make sense of their children's behaviour. Taking a non-directive, curious stance allows for a more open discussion and avoids privileging pre-determined frameworks of understanding about individuals' experiences. There are a number of possible outcomes when undertaking qualitative research, such as uncovering issues for further research and implications for service development and clinical practice (Smith, et al., 2009). It was hoped that this study might help to inform the development of services and resources in way that meets parents' needs, including helping to address potential barriers to engagement. 


\section{Methodology}

\subsection{Ethical Approval}

The study received a favourable opinion from the London - East NHS Research Ethics Committee in September 2011 (Appendices A \& B) and the University of Surrey, Faculty of Arts and Human Sciences (FAHS) Research Ethics Committee in January 2012 (Appendix D).

Additionally the study received approval from South West London and St. George's Mental Health NHS Trust Research and Development Committee to recruit participants from three Child and Adolescent Mental Health Services (CAMHS) within the trust (Appendix C).

\subsection{Design}

As discussed previously, the research question is primarily concerned with exploring the ways in which parents try and make sense of their children's behaviour over time and therefore a qualitative design was thought to be the most appropriate methodology since this allows the researcher to gain an in-depth account of participants' experiences from their own perspective. Specifically, Interpretative Phenomenological Analysis (IPA) was used since the aim of this approach is to 'explore in detail how participants are making sense of their personal and social world' (Smith \& Osborn, 2008, p.53).

\subsection{Participants}

\subsubsection{Inclusion/exclusion criteria}

Parents whose children had been identified as displaying 'significant conduct problems' by a Mental Health Professional (MHP) within one of 
the three identified CAMHS teams were eligible for inclusion in the study. The age range was specified as being between eight and thirteen and 'significant conduct problems' were defined as those which would meet the diagnostic criteria for Conduct Disorder or Oppositional Defiant Disorder (as defined by the DSM-IV-TR). Since the actual number of formally diagnosed cases of Conduct Disorder or Oppositional Defiant Disorder was thought to be relatively small compared to numbers of cases in which there may be a 'working hypothesis', the child in question did not need to have received a formal diagnosis. Also, due to the high rate of comorbidity typically observed in this population, children who might have additional difficulties were not excluded from the study; however, it was emphasised that any behavioural difficulties being displayed should not be wholly attributable to a separate developmental disorder (such as Autistic Spectrum Disorder) or mood disorder (such as generalised anxiety). The family did not need to be currently receiving formal input from the CAMHS service.

Due to the potentially sensitive nature of the material, families were excluded from the study if there were potential factors indicating that participation would cause undue or unnecessary additional stress due to current difficulties coping with major life stressors (such as recent bereavement or significant loss, serious mental or physical illness that required hospitalisation or homelessness in the last six months). To try and ensure the safety and welfare of participants and the researcher, families were also excluded if there were currently significant risk factors within the family (such as domestic violence, abuse or neglect) and/or if there were any children within the family who were currently subject to a child protection order or custody procedures.

Additionally parents needed to be informally assessed as having capacity to consent to participation and able to adequately understand the issues 
around consent and participation, i.e. possessing sufficient written English and verbal literacy skills.

\subsubsection{Sampling}

Potential participants were recruited through the means of purposive sampling, as described by Smith et al. (2009); specifically, suitable individuals were identified via referral from Mental Health Professionals (MHPs) including Consultant Psychiatrists, Clinical Psychologists and colleagues from Nursing and Social Work backgrounds. Through this method, the sample was not intended aim to be 'representative' of a particular population, but instead provides an opportunity to gain an indepth understanding of a particular set of experiences.

The sample was homogeneous in that all participants were the primary carers (mothers) of children aged between eight and thirteen who had been identified as having significant conduct problems and had received input from CAMHS regarding their child's behaviour. Furthermore, all the participants lived in the suburbs of a large city in the South of England.

\subsection{Procedure}

\subsubsection{Recruitment}

Relevant professionals within the three Child and Adolescent Mental Health Services were approached by the field supervisor and lead researcher to ascertain whether they considered their services to be suitable sites for recruitment. Once the study had been given a favourable opinion by the NHS and University Research Ethics Committees and had been approved by the NHS Trust's Research and Development Board, information forms (Appendix F) were disseminated to all team members outlining the purpose of the study, inclusion and exclusion criteria and contact details for the lead researcher and academic supervisors. The lead 
researcher also attended team meetings and liaised with relevant professionals to promote the research further.

\subsubsection{Data Collection}

Once potential participants had been identified by the CAMHS team members and verbal consent had been obtained, the lead researcher contacted participants by phone to arrange interviews. At this stage participants were once again assured that they were under no obligation to take part and if they had not already been provided with an information form (Appendix E), these were sent by post along with consent forms (Appendix I).

A total of eight parents (all mothers) were approached by MHPs from the CAMHS services about the research and gave verbal consent to be contacted by the researcher. Of these eight parents, six consented to take part in the study and two parents declined to take part at the present time due to family commitments. A further four potential participants had been identified by clinicians as eligible to take part in the study; two were excluded due to current risk factors within the family, one parent was excluded due to clinicians being concerned about their ability to be able to adequately give informed consent and it was decided that the final parent would not be approached at the current time due to concerns that they would find the research distressing due to issues currently being raised during treatment. All of the interviews took place at participants' homes and were recorded using a digital recording device.

\subsection{Ethical Considerations}

\subsubsection{Informed Consent}

Participants were provided with an information sheet (Appendix E), which outlined the nature of the study and what participation would involve. It 
was recognised that participants may feel obliged to take part in the study due to the researcher's status as a Trainee Clinical Psychologist and association with the CAMHS service. Additionally it was likely that this could also impact on the interview process. In order to try and minimise the likelihood of these effects occurring, care was taken to assure participants throughout the research process that their participation was entirely voluntary and that their participation would not impact on any input they were currently receiving from the CAMHS team. It was also emphasised that the content of the interviews would not be routinely fed back to the professionals involved their child's care (except in exceptional circumstances, as discussed below). Participants were sent consent forms (appendix 1 ) in the post in advance of taking part in the research and prior to giving written consent, participants were once again given the opportunity to ask the researcher any questions or raise any concerns they might have about taking part. At the point of interview, participants were informed by the researcher that they could choose to withdraw their data from the study up until the point of submission to the university.

\subsubsection{Confidentiality}

Participants were informed that their names and any other personally identifiable information would be altered or omitted from the final study to ensure anonymity. It was explained that some excerpts from research interviews may be published in the final document, but that these would not render participants identifiable.

\subsubsection{Management of Risk}

A brief risk assessment was included in the Participant Contact Form (Appendix G) in order to help MHPs identify any potential risk factors to be discussed further with the researcher. In cases when it was determined that a home visit would not be appropriate it was agreed that interviews could be conducted on site at the CAMHS office; in the case of home visits 
local NHS lone working guidelines were followed. Participants were also informed both verbally by the researcher and in the information sheet that if they disclosed any information during the interview that indicated a risk to themselves, their child or others; then confidentiality would have to be broken and relevant agencies would be informed. A full outline of the risk assessment procedure can be found in the appendices (Appendix $\mathrm{H}$ ).

\subsubsection{Potential for Additional Burden}

It was recognised that the interviews may involve participants recalling potentially stressful and upsetting experiences, and that it was possible that some parents would be under ongoing burden due to the nature of their child's behavioural difficulties and/or other psychosocial stressors. All participants were provided with a debrief sheet (Appendix K) providing information about where to seek support or advice if needed and additional resources that were available. Participants were informed that details of their participation would not routinely be fed back to the CAMHS team (except in exceptional circumstances, as discussed above); unless they indicated that they would like this. Participants were also given the opportunity to provide feedback to the researcher about the process of taking part in the study.

\subsubsection{Reimbursement}

At the end of the research interview participants were given a ten pound high street voucher in recognition of their contribution to the study. Additionally it was highlighted that any travel expenses incurred would be refunded, but this was not necessary since interviews took place in participants' homes in order to reduce the inconvenience caused.

\subsubsection{Service User and Carer Input}

A number of non-statutory parent support organisations within the South London area were approached regarding inputting to the study at various 
points. Unfortunately none of the organisations approached chose to take part in the consultation process. However, the Co-ordinator for Service User \& Carer Involvement at the University of Surrey was able to provide some useful feedback regarding the accessibility of the recruitment and consent materials used in the study.

\subsection{Materials}

\subsubsection{Information and Consent Forms}

Separate information forms were used for participants and for referring professionals within the CAMHS teams (Appendices $E$ \& F). The professional information form contained an outline of the study, details of the inclusion and exclusion criteria, including diagnostic considerations and the procedure for identifying potential participants. Participant Information forms contained an outline of the study, information about what participation would involve, what to do if they had any queries or concerns and the necessary contact details. The terms 'conduct disorder' and 'oppositional defiant disorder' were not used in the participants information form since it was likely that some children would not have received a formal diagnosis.

\subsubsection{Participant Contact Form}

During the recruitment stage participants' contact details were initially recorded using the Participant Contact Form (Appendix I), which also included a brief risk assessment to be completed in conjunction with MHP who had gained verbal consent to ensure that inclusion and exclusion criteria were met and discuss the appropriateness of visiting the participants' home. At the point of interview, the researcher recorded some brief demographic information (such as age, gender, occupation, ethnicity and relationship to the child identified as having conduct problems) to help to contextualise the data and a diagrammatic genogram 
was constructed with each participant in order to gain a sense of the family relationships. At this stage participants were assigned a unique participant number so that this information could be stored separately from the contact details.

\subsubsection{Interview Schedule}

Interviews were conducted using a semi-structured interview schedule (Appendix J) which included additional optional prompts in line with the. suggested methodology for a study utilising an Interpretative Phenomenological Analysis (IPA) approach. By using this method the researcher was able to be curious and explorative and follow relevant lines of questioning as they unfolded during the interview.

The interview schedule consisted of an introductory question to ascertain the family composition and then seven further questions to explore the identified child's behavioural difficulties, including: the participant's (or third party's) main concerns, when the behaviour(s) were first identified as a problem; what (if any) ideas the participant had at the time about the origin of the behaviour(s) and what (if any) strategies they tried to implement to manage the behaviour(s); whether the behaviour(s) have changed over time; who else became involved in trying to support the family in managing the behaviour(s) and whether the participant thought that their ideas about the origin and nature of the behaviour(s) had changed over time.

The interview schedule was developed by the lead researcher with input from the academic and field supervisors.

\subsubsection{Debrief Information Form}

Participants were provided with a debrief form (Appendix $K$ ) at the end of the research interview which contained information about where to seek help or advice in case individuals felt worried or upset. The debrief form 
also contained information about relevant support services for parents and carers in the local area.

\subsection{Contextualising the Data}

Table 1. - Demographic Information

\begin{tabular}{|c|c|c|c|c|c|}
\hline Name* & $\begin{array}{l}\text { Gender/ } \\
\text { Age }\end{array}$ & Ethnicity & Occupation & $\begin{array}{l}\text { Relationship } \\
\text { to child }\end{array}$ & $\begin{array}{l}\text { Child Age/ } \\
\text { Gender (No. Of } \\
\text { siblings) }\end{array}$ \\
\hline Alison & $F, 48$ & White British & Shop-owner & Mother & $\begin{array}{l}10, F \\
(0)\end{array}$ \\
\hline Beatrice & $F, 34$ & $\begin{array}{l}\text { Black } \\
\text { British/Caribbean }\end{array}$ & $\begin{array}{l}\text { Student / } \\
\text { journalist }\end{array}$ & Mother & $\begin{array}{l}11, M \\
\text { (1) }\end{array}$ \\
\hline Connie & $F, 46$ & White British & $\begin{array}{l}\text { Full-time } \\
\text { mum }\end{array}$ & Mother & $\begin{array}{l}10, M \\
(3)\end{array}$ \\
\hline Diane & $F, 32$ & Black Caribbean & $\begin{array}{l}\text { Full-time } \\
\text { mum }\end{array}$ & Mother & $\begin{array}{l}9, M \\
(2)\end{array}$ \\
\hline Ellie & $F, 48$ & White British & $\begin{array}{l}\text { Child- } \\
\text { minder }\end{array}$ & Mother & $\begin{array}{l}13, M \\
(3)\end{array}$ \\
\hline Fiona & $F, 41$ & White European & $\begin{array}{l}\text { Own } \\
\text { cleaning } \\
\text { business. }\end{array}$ & Mother & $\begin{array}{l}12, \mathrm{M} \\
(2)\end{array}$ \\
\hline
\end{tabular}

*Names given are pseudonyms used to preserve participant confidentiality.

Although efforts were made to recruit parents of both genders, all of the final participants were mothers and this has been reflected in the results. Alison's partner also joined the discussion at times, but as he had not given consent to take part in the research his details have not been included. It is also important to note that five out of the six children who were identified 
as having conduct problems were male and so the majority of the research interviews captured the mother-son relationship. The participants' children had all been referred to CAMHS at some point for their behavioural difficulties; but only two of the families were currently receiving direct input. Four of the families had also received input through school from an educational psychologist, two families had received input from a Youth Justice programme and a non-statutory family support programme and one family had recently had input from the Multisystemic Therapy (MST) team.

Three of the identified children were currently in special educational provision for emotional and behavioural difficulties, one child was currently in mainstream education and one of the children was currently suspended from school and had been referred to a short-stay school. Two of the children had previously been home-schooled.

Two of the participants described themselves as single mothers, one family had both biological parents living at home and two participants had separated from their child's biological father and were in long-term relationships with new partners who were not living in the family home. Two participants reported a history of domestic violence from their previous partners.

\subsection{Data Analysis}

\subsubsection{Procedure}

Interviews were transcribed and analysed in line with the principles of Interpretative Phenomenological Analysis (IPA) as described by Smith et al. (2009). The first stage in this process was the verbatim transcription of audio recordings; this was done by listening to the recordings and typing transcripts by hand (as opposed to using a transcription service or 
software) as this allowed the researcher to become fully immersed in the data. At this stage personally identifiable details were omitted or altered to preserve anonymity and participants were given a pseudonym so that the data continued to represent a person and their lived experience, rather than potentially dehumanizing the participant by just assigning them a number. Since the main aim of data analysis in IPA is to interpret the content of the participant's account, transcripts do not generally contain a detailed account of the prosodic aspects of the recordings (such as exact length of pauses and all non-verbal utterances) which might be included in some other methodologies. Rather, IPA requires a semantic record of the interview, including notable non-verbal utterances, such as laughter and significant pauses and hesitations, which are represented in the transcript by bracketed text (Smith et al., 2009). In order to aid the later stages of coding, completed transcripts contained wide margins and space was left between turns in the conversation. Once the transcription stage had been completed, audio recordings were destroyed in line with the original protocol regarding data confidentiality.

The next stage was to read and re-read the transcripts in order to become immersed in the data. During this process some of the researcher's initial observations and reactions were recorded in the reflective log as part of the process of 'bracketing' off any strong reactions. This stage also allowed the researcher to develop an overview of the structure of the interview and an understanding of the shifting narrative, for example from a chronological account to a focus on specific incidences. It can also help to highlight the location of richer and more detailed sections of the interview, as well as any contradictions or paradoxes (Smith et al., 2009).

Next the researcher started the 'Initial noting' phase of analysis in which each line of text was subjected to close analysis. These notes are recorded in the right hand margin and represent three separate levels of analysis: 
Descriptive comments focus on the content of what the participant has said at 'face value'; Linguistic comments which explore the potential meaning of the specific use of language, such as hesitations and emphasis and finally Conceptual comments which aim to make more interpretative statements about the underlying meaning of the data. Ultimately, although IPA is primarily concerned with understanding participants' experiences from their perspective, the method of data analysis means that the final results represent an account of how the researcher 'thinks the participant is thinking' (Smith et al., 2009, p.80).

Once the initial noting was completed, the next stage for the researcher was to start to identify the emergent themes; these themes take the form of concise statements that aim to capture the 'essence' of the data. Whilst themes often make use of psychological terminology and aim to reach a higher level of abstraction than the initial noting, they should remain grounded in the participants' experience. Any connections between emergent themes were then identified so that any similar themes could be clustered together, and potentially grouped into a super-ordinate theme. An excerpt from one of the analysed transcripts can be found in the appendices (Appendix L).

Once this process was completed for the first transcript, it was repeated for each case until all of the transcripts were analysed in this way. During this process the researcher was able to start identifying recurring patterns as well as recognising new themes and unique experiences. The emergent themes from each transcript were then entered into a table in order to try and determine where there were similar patterns and convergences in the data which could assist in determining the final super-ordinate themes. However, themes which appeared to be unique to one individual transcript were not dismissed since these could also be conceptualised as representing an aspect of a higher-order theme which represented a 
common experience. Part of the process of determining the emergent themes can be found in the appendices (Appendix $N$ ).

\subsubsection{Validity and Reliability}

There has been considerable discussion regarding how the validity and reliability of qualitative research should be assessed (Meyrick, 2006) and although there is no one agreed set of criteria Yardley (2008) suggests four main principles.

The first principle 'sensitivity to context' refers to the extent to which the researcher demonstrates sensitivity to the socio-cultural context, the existing literature and the process of gathering data. In the current study, a substantive literature review of the aetiology and treatment of disruptive behaviour in childhood and the proposed role of parenting in the development and treatment of these difficulties as well as the possible interaction of parental attributions and help-seeking behaviour was undertaken in order to provide a context for the research question. The data was contextualised by describing the demographic and socio-cultural characteristics of the participants and their environment; the potential impact of these factors is explored further in the discussion. The potential impact of the data collection process on participants, including the role of the researcher was considered at length during the development of the research protocol and is considered further in the discussion. Finally sensitivity to the context of the data is demonstrated by the inclusion of verbatim extracts from the original transcripts so that the resulting themes results remain grounded in the participants' experience.

The second principle is the 'commitment and rigour' with which the research is carried out. In some senses the commitment of the researcher to the data collection and quality of the research process is synonymous with sensitivity to context. In the current study, care was taken to try and 
ensure that interviews were conducted in a manner that ensured that participants felt at ease and were comfortable with the process. This included conducting interviews in participants' homes so that they did not feel inconvenienced, ensuring that each participant had adequate time to review the information sheets prior to the interview, providing additional information about support services and seeking feedback at the end of each interview. In terms of demonstrating the rigour of the research process, efforts were taken during the selection and recruitment process to ensure that participants' represented an appropriate sample, i.e. were homogeneous in their experiences of having a child with conduct problems as described previously. The researcher had received teaching in the process of data analysis and regularly attended a qualitative research focus group to ensure that the method was being adhered to. Additionally, once the initial noting and emergent themes had been identified for the first transcript, these were taken to supervision to ensure that the themes accurately represented the data and that there were no important omissions.

The third principle that Yardley suggests is 'transparency and coherence'. This refers to how clearly the research has been described, the coherence of the argument and how closely these both fit with the principles of the chosen methodology, in this case IPA. In the current study, a reflective log was used to try and ensure transparency in the research process and effort was taken to carefully describe each stage of the research. Additionally the supervision process had an important role in ensuring adherence to the principles of IPA; as well as regular attendance at the qualitative research focus group.

Yardley's final principle is 'impact and importance', that is that research should convey something interesting, important or useful to the reader and that the findings should add something of worth to the existing literature. 
It is hoped that the current study will provide important information for clinicians and services about the processes that parents might utilise when trying to make sense of their children's behaviour. This will aid provision of information, support and advice at the appropriate points. In addition to attempting to disseminate the research via publication, the findings of the study will be presented to the CAMHS teams involved in the recruitment process.

\subsubsection{Researcher's Own Perspective}

It is not possible for a researcher to be completely objective when approaching any question, but the process of self-reflexivity or becoming aware of one's own preconceived ideas may help the researcher to temporarily put them aside, or 'bracket' them during the process of analysis (Ahern, 1999). As Rolls and Relf (2006) state: 'Reflexivity... involves an understanding and acknowledgement that researchers are part of the world they are studying, and that their values and interests may impinge on the research work (p.290).

Therefore it is important to be aware of the potential impact that the researcher's background, assumptions and values may have on the research process. Explaining one's own personal and professional context can also help the reader to better understand and situate these findings, as well as keeping a reflective log throughout the research process,

I am a female, White-British, Trainee Clinical Psychologist currently in the third year of doctoral training. Professionally my particular interest is working with individuals with complex and multiple difficulties, including severe and enduring mental health problems, diagnoses of personality disorder, substance misuse and forensic history. Currently I work with adults in a medium-secure psychiatric unit as well as with children with a range of needs in a Child and Adolescent Mental Health Service (CAMHS) 
and adolescents with oppositional and anti-social behaviour as part of a Multi-Systemic Therapy (MST) service.

This means that I have direct experience of working with individuals across the lifespan who have multiple and complex needs and may be currently displaying behaviour that is construed by others as 'challenging'. These experiences mean that I hold certain assumptions about the origins of these behaviours and the inherent difficulties that services face in engaging so-called 'anti-social' individuals and their families.

When I originally approached this subject area, I found myself taking a somewhat sceptical position with regards to the concept of labelling externalising behaviours in childhood as a diagnosable disorder. In general I would align myself with a 'relativist' position, which assumes that there are multiple views and perspectives and that individuals are influenced by their social and cultural environments. This perspective is by nature inherently critical of the reductionist 'positivist' approach of diagnosis that assumes there is an objective 'truth' or knowledge that can be discovered using scientific means.

As a Trainee Clinical Psychologist within the NHS I work within a system that relies heavily upon the nomenclature of diagnosis in order for individuals to receive services. My own experience of working with individuals who have been given a psychiatric diagnosis has been varied, for some the process has seemed helpful and normalising. They have described the process as akin to realising that they are 'not alone' and have described a sense of relief and hopefulness, since when they have discovered that there is an explanation for their difficulties, they have also discovered that there are treatments that can help. Arguably, this feeling of acceptance and understanding is one that is fostered by the therapeutic relationship and is not reliant on the concept of diagnosis. Additionally the 
stigma of 'mental illness' and some diagnoses in particular have poor longterm prognoses and evidence from personal recovery literature, has emphasised how this can serve to increase a sense of hopelessness (British Psychological Society, 2011). In approaching this area I wondered how this related to parents experiences of receiving an explanation for their children's difficulties.

I am also aware that my own cultural and educational background is likely to influence my ideas and beliefs about help-seeking and the ways in which individuals understand others' actions and behaviours. My own experiences of caring for a family member with multiple and complex health problems has given me some insight into the difficulties of tackling issues of stigma and navigating social and healthcare services. However, as a White British, educated woman I am aware of some of the advantages that this affords me. Additionally, my position as a professional and a researcher means that I hold a certain position of power in relation to the individuals I work with on a daily basis and the participants in this study.

Finally, in approaching this study I was aware that there was a potential for some tensions to arise as an artefact of holding a dual role as a researcher and a member of one of the CAMHS teams from which I was recruiting, since research could bring up criticisms of the service. This could potentially mean that $\mathrm{I}$ would feel aligned with my colleagues and defensive of these criticisms or else try and distance myself from the ways of working, or even find myself feeling alienated from colleagues. 


\section{Results}

In understanding the results of the interpretative phenomenological analysis, the research question of 'how do parents make sense of their children's behaviour over time?' was kept in mind as a frame of reference for understanding. The analysis revealed four master themes that seemed to encapsulate the commonalities across the participants' individual experiences; these were conceptualised as 'Looking for an answer' 'The emotional experience of being a parent', 'Trying to get help' and '... a long, long road...'

The master and subordinate themes are summarised in Table 2 and discussed in detail below. Many of the theme titles have been represented by quotes used by participants (as indicated by inverted commas) and verbatim quotes from the research interviews are used throughout to demonstrate the ways in which the results of the analysis are grounded in participants' experiences. Pseudonyms are used throughout to preserve anonymity.

\subsection{Looking for an Answer...}

Participants used a range of theoretical, social and cultural frameworks in their attempts to try and make sense of their children's behaviour. At times, the various explanations seemed to be at odds with one another; seemingly reflecting the difficult and complicated process that mothers were going through in trying to understand their child's internal world. Many of the participants commented on the difficulty of trying to make sense of their children's behaviour: 
Table 2. - Master Themes and Subordinate Themes

\begin{tabular}{|c|c|}
\hline Master Themes & Subordinate themes \\
\hline 3.1. Looking for an answer. & $\begin{array}{l}\text { '..watching a kettle boil...' } \\
\text { Loss and trauma } \\
\text { '...problems at school...' } \\
\text { '...it's like there's two of them...' } \\
\text { 'Would you call that normal?' }\end{array}$ \\
\hline $\begin{array}{l}\text { 3.2. The emotional experience of } \\
\text { being a parent. }\end{array}$ & $\begin{array}{l}\text { 'I feel like l'm... labelled...' } \\
\text { 'I couldn't cope' } \\
\text { 'I've tried everything!' } \\
\text { '..friends and family...' }\end{array}$ \\
\hline 3.3. Trying to get help. & $\begin{array}{l}\text { 'Asking for help is embarrassing' } \\
\text { '...listen to parents!' } \\
\text { '...pushed around from pillar to post' } \\
\text { 'They helped me to understand...' } \\
\text { Power and Authority }\end{array}$ \\
\hline 3.4. '... a long, long road...' & $\begin{array}{l}\text { Looking back... } \\
\text { Getting Stuck } \\
\text { '...growing up...' }\end{array}$ \\
\hline
\end{tabular}

\subsection{1. '... watching a kettle boil...'}

All of the participants talked about their children's behaviour as a result of them struggling to deal with difficult emotions; these emotions were often framed as 'anger' but were also associated with experiences of loss, confusion, sadness and frustration. Although the extent to which parents saw this as the main factor in the onset of their child's difficulties varied, some of the mothers, such as Beatrice made a very direct link: 
"...I could kind of understand why [the behaviour was occurring], because I understood that he was kind of going through a lot emotionally as well."

There was a sense that participants viewed their children as struggling to cope with a range of complex emotions, and 'bottling them up' until they were expressed as anger. Many of the mothers spoke about their children's aggressive behaviour being an 'explosion' or 'eruption' of emotions. Ellie used an analogy of a kettle boiling to describe this process:

"if [he] has got something playing on his mind, he doesn't talk about it, he bottles it up. [pause] Um... so a lot of the things I didn't find out until he would... literally... you could see it, it's like... [pause] watching a kettle boil."

Many of the mothers spoke about their children's reluctance to talk about these feelings and a sense of being unable to help them in the important task of learning to manage their emotions, as Fiona explained:

"...he wouldn't open up easily and he wouldn't open up to me. Cos he thinks if he will tell me things then I will be nagging him, and telling him again, he doesn't like when you sit him down and explain to him, he just, you know he really like doesn't like those conversations."

She went on to explain how she hoped the input from CAMHS might help her son to learn different ways of dealing with his feelings:

"... I want him to learn some tools of how to deal with his anger, because sometimes he holds so much things inside, and then when he blows..." 


\subsubsection{Loss and trauma}

A theme that came up for many of the participants was the impact of the breakdown of relationships within the family context. Some of the participants directly associated their children's emotional experience with the breakdown of the parental relationship and saw their children as having difficult conflicted feelings about these relationships, as Fiona explained:

"... [his father] will get at me through the children and I think that's why probably [he] has so many emotional problems because he's not dealing with all these things".

The impact of having witnessed conflict, including for some physical violence within the parental relationship was also identified by some participants as playing a significant role in their children's behaviour. Beatrice spoke about her son needing help in processing these feelings:

"there was a lot of things that ... [he] erm, needed to talk about or things that he had seen, or things that he's found quite distressing that he kind of kept to himself and that was kind of coming out in his behaviour."

Many of the children had only sporadic contact with their fathers following the breakdown of their parents' relationship and this was seen by many as a significant loss. Fiona spoke directly about her sense that her children needed to have a positive relationship with their father, despite her own feelings towards her ex-partner and her disappointment that this did not seem to be possible:

"...even though you know when the marriage doesn't work out, 1 think the father should be there for them and have... and you know have at least one weekend a month to spend with them, and that will make, you 
know their life much better. I think both of them, they need a father, that's what I think."

Some of the participants made direct comparisons between their children and their fathers. Connie described the difficult feelings that this evoked for her:

"I think he's like [his] little clone, he's more like his dad than all the others... and I don't know, I just... he kinda, when he sees his dad he's all smiles and it really upsets me because I just think like, he's never there for him, he never does anything... and yet [he's] got a lot of credit for him $y^{\prime}$ know and its harsh really."

\subsection{3. '...problems at school...'}

All of the mothers interviewed spoke about their children having particular difficulties with learning which contributed to behavioural problems at school. Alison spoke about her daughter's feelings of frustration in struggling with her literacy difficulties:

"...it's not so much, spelling words out, like talking, it's putting it on paper... it's really bad... I've told them about and they still haven't done a thing about it and I think she gets frustrated with that as well."

Common issues that arose were difficulties in the areas of concentration, impulsivity and hyperactivity, although it was noted that none of the children had received a diagnosis of Attention Deficit Hyperactivity Disorder (ADHD). Diane described the impact of these difficulties:

" $[\mathrm{He}]$ is very energetic and he finds it hard to sit still or to sit down and do any amount of work for any period of time, he's got to do some 
work for a little bit then he's got to do something else and then come back to it..."

Mothers also spoke about their children's developing awareness of themselves as 'different' from other children and feeling ostracised or isolated from their peers as a result. Several of the children had been removed from mainstream classes, meaning that they were also physically isolated from their peers. Connie talked about the emotional impact that this had on her son:

"[He] was more upset about, he couldn't play in the playground with the other children; he couldn't do sports with the other children, $y^{\prime}$ know he was kinda on his own in a room for two hours."

\subsection{4. '...it's like there's two of them...'}

When talking about their children, some of the participants used an analogy of sometimes feeling as though there were two different children. This seemed to represent a polarity in their views of their child and some difficulty in simultaneously holding in mind these two versions of their child into one, integrated person. As Ellie explains:

"And... it's... it's like there's two of them, and all it takes is a switch to flick from one to the other, does that make sense?"

In some of the interviews, this conflict between the two versions of the child was represented by the participants' descriptions of their child as being controlling, clever and manipulative on one hand:

"[He] is very clever; he knows how to work people, especially people like CAMHS. He can come across as a darling, and he'll come out of CAMHS 
and he'll say, 'see they don't want to see me again'. And he knows how to play them..." (Ellie)

Whilst on the other hand the view of their child as being vulnerable, having difficulties understanding other people and being unable to navigate interpersonal relationships.

"...he's not where he should be emotionally for his age, he never has been" (Ellie)

"... [he] is still at that stage where he's not sure, he's not that good at making friends..." (Ellie)

This was also represented in the discussions about the behaviour, with descriptions of the behaviour oscillating between being purposeful and directive:

"...he was just doing everything to make me upset." (Fiona)

Whilst on the other hand uncontrollable and without meaning:

"...then after this two seconds attack, like I call them, he just looks at it and he doesn't control himself when he does it and he just looks and says, 'oh I'm sorry, I'm sorry what I've done'." (Fiona)

At these times, participants seemed to be grappling with strong conflicting emotions towards their child, which seemed to oscillate along with their view of the behaviour. When participants made attributions that implied that the behaviour was intentional and purposeful, they spoke in terms of strong negative emotions (hate, frustration, anger); whereas when they 
framed the behaviour as uncontrollable, this seemed to allow them to maintain a softer, more nurturing approach.

\subsection{5. 'Would you call that normal?'}

At times participants seemed to be drawing upon ideas of what represents 'normal' versus 'abnormal' behaviour in understanding their children. These representations sometimes came from their own experiences of parenting their other children:

"Ermmm. Erm... he, considering he'd got like four other siblings, [he] didn't, [his sister] wasn't like it, the others weren't like it...". (Connie)

Participants' expectations of 'normal' behaviour also seemed to be driven by cultural and social expectations, for example of age-appropriate behaviour or gender roles:

"...would you call that normal? From a nine year old, because I don'tI Would a nine year old normally be that blunt?" (Ellie)

"But then, um... I still come to this, you know like... that's boys! Boys will be always boys..." (Fiona)

Participants also drew upon their knowledge of clinical representations of 'abnormal' or pathological behaviour in trying to understand the origins of their child's behaviour.

"Another one said something like 'oh I think she's got ODD' and then you start thinking, when they say what their kids are doing, then you start thinking, mmm yeah, she does do some of those things". 
"[He] does have a little bit of $O C D$, he is very... obsessive over things, but I think that's a little bit of a family trait". (Ellie)

In the cases when participants made specific references to a diagnosis of Oppositional Defiant Disorder (ODD), this was seen as a 'checklist' of behaviour that fitted with their experience but did not seem to add anything to their understanding of the origins of the behaviour. Only one mother, Diane had the experience of her child being given a formal diagnosis of ODD:

"Um, it was helpful to finally put a name to what the condition was, but like the help given to me wasn't really enough..."

But for her this did not seem to be an adequate explanation, and she returned her focus to her sense that her son was struggling with some complex emotions:

"I think probably if they'd um... gone a little bit deeper, then they could've gotten to say the root of why he is the way he is, because sometimes he opens up to me but he just opens up a little bit and then he'll close back down, so... I keep trying, and I try and I try but sometimes I can only get to that level where he's already taken me and then he pulls back."

\subsection{The emotional experience of being a parent}

Participants spoke in depth about the emotional impact of having a child with behavioural difficulties and their role as a mother.

\subsection{1. '... I feel like I'm... labelled...'}

Many parents spoke about the feelings of shame and embarrassment that they experienced due to their child's behaviour. Often this seemed to be 
related to experiences when somebody outside of the family had commented on their child's behaviour, or when external agencies had become involved.

"It was embarrassing because I was actually in the room at the time when it happened and because it's inside school you don't know whether you should let the school deal with it or whether you should step in and deal with it so it was... very embarrassing and.. sort of a view of things to come..." (Ellie)

There was a sense that their child's behaviour reflected on them as caregivers and I wondered about the impact this had on their ability to ask for help. Three of the mothers interviewed described being accused of neglect or abuse; these experiences seemed to have been particularly difficult, as Fiona explains:

"...that was horrible. That was horrible. When your own child, when he tells that you don't give him food enough. This all started because he was always late to school, so instead of explaining himself why he is late to school, he started blaming everything else around. And that was, oh that was horrible, you know just listening to someone when they tell you that [your son] is always dirty, and he, you know, and um... he's not... er, he's asking people for money because he doesn't have food at home and that I don't give him any food. That was [laughs] embarrassing really."

Particpants seemed to be particularly concerned about the stigma of being judged as 'bad parents', not just by external agencies, but by other parents and their local communities.

"I have to live here! You can't call the police two or three times a week! One it's embarrassing..." (Fiona) 
"... well if it was me listening to someone else saying it l'd think, my God, where's social services? Do you know what I mean? But being on the other end of it..." (Alison)

The way in which participants seemed to deal with these feelings was quite varied; often during the interviews participants would laugh when they described these experiences, and I wondered whether this was a way of defending against the difficult feelings that this evoked. For some, the feelings of shame and embarrassment were accompanied by expressions of anger and frustration, either towards their children or towards services. However, at other times this sense of shame seemed to have become internalised, such as in the following example, when Fiona spoke about blaming herself for her son's behaviour:

"And I was like in the middle of it, you know, like maybe I'm not doing this right, I'm not good enough so that was a really bad time."

\subsection{2. 'I couldn't cope'}

Many of the mothers interviewed spoke about periods of feeling overwhelmed by their child's difficulties.

"...because I really was at the point where I couldn't cope, I couldn't do anymore." (Ellie)

Many of the participants described feeling as though they were alone in their struggle, as Alison explains:

"Mm. Yeah. Sometimes, you do feel a bit like, on your own and you're pulling your hair out, and you think, erm... why?" (Alison) 
These experiences seemed to be associated with a sense that their children were making demands that they could not meet. Five of the mothers interviewed had separated from their child's father, and the pressure of being a single mum was a recurrent theme. Participants emphasised the multiple pressures in their family lives and feeling as though they did not have any time for themselves:

“...sometimes I feel really guilty, I don't give the right attention, but I think I give him enough attention. I need some time for myself as well, and they want me all the time, you know for them". (Ellie)

At these times it seemed as though some of the mothers found it difficult to access support for their own emotional needs, seeing them as secondary to their children's needs. Diane spoke about feeling as though her own life was 'on hold':

“...you can't do nothing, it's like you've just got to sit down and like wait for the phone call to say 'can you come and get [him] can you come and...' and it's like you're not really living any life, you're just like sitting there waiting and you're like 'okay, let's see what happens today'."

\subsection{3. 'I've tried everything!'}

During the interviews participants described some of the ways in which they had tried to manage their child's behaviour; there was a common experience of many of these strategies failing:

"We tried the naughty step, erm... [pause] we tried sending him to his room, tried taking things away, all these were things that had worked with the other two, never... never worked with [him]". (Ellie) 
In these descriptions it seemed that techniques and strategies were tried for a short time and then discarded and labelled as 'not working'.

"We've tried loads of different things, we've tried star charts, we've tried reports, we've tried aiming for things, we've tried taking things away. Erm, nothing really seems to work." (Alison)

I noticed that during the interviews participants rarely reflected on why the various techniques they had tried had been unsuccessful, and at times it seemed as though they seemed to be constantly searching for a single solution that was going to solve the problem once and for all.

"...the punishment doesn't really work, so they do work for a time, but it doesn't work over all." (Diane)

This search for a 'solution' seemed to mirror the quest for a definitive explanation for their child's behaviour. I wondered if this meant that participants found it difficult to conceptualise their children's difficulties as being multi-factorial. However, there were also some experiences of successful strategies, both in the home and in educational settings. Participants emphasised the importance of individual support, structure, routine, boundaries and consistency.

"...he really needed that sort of one to one, sitting down with him, that one to one support, I did notice that quite a bit". (Beatrice)

"...but then I'm not consistent with them. So I have to go back to the book again, and you know read it and put myself back on track with them." (Fiona) 


\subsection{4. '...friends and family...'}

Participants emphasised the importance of their relationships with family and friends in providing an important source of emotional and practical support:

"I've never really felt alone with him if I'm being honest. I don't know what'd it be like for somebody who didn't have absolutely anybody around 'em, it must be absolutely awful. I've always got friends, family, support around me." (Connie)

"I've got a network of really great friends, and y'know my partner and my mum, they were really supportive." (Beatrice)

The importance of talking to other parents who could empathise with the experience and challenges of having children with complex needs was echoed by several of the participants, who explained that they would share ideas about things that help:

"...you know like when you speak to your friends, cos I have got friends with kids with $A D H D$ and handicapped kids that have different problems and that, and erm they've said, you know, like erm with like the star charts and rewards and 'time out' and things like that..." (Alison)

"I've got some friends who've got children with special needs as well, so sometimes we just have a chat and compare notes and see what is working for this one and so, okay then I can try that the next time and see if it'll work for me and stuff like that so..." (Diane)

However, at times participants also spoke about the sense that although others were supportive, they did not fully understand their experience. Diane spoke about her parents' difficulty in understanding her child's 
behaviour, and there seemed to be some intergenerational conflict in how her child's difficulties were perceived:

"They don't understand why he doesn't listen because they think, in their time, when you talk to your children, they're supposed to listen and do what you say and they can't understand why it doesn't work for him."

As well as the breakdown of the parental relationship, many of the participants spoke about the impact of multiple family stressors, including illness and bereavement on their own and their children's emotional wellbeing:

"There's been a lot going on with the marriage breakup, my mum has Parkinson's, she has dementia, my Dad's registered blind, we've had... lost a lot of relatives over the last... we're getting to that age where, you know, I mean my uncles funeral next week, he's just 58 years of age, dies of lung, jaw and throat cancer and.... you get a lot of things going on in your life..." (Ellie)

\subsection{Trying to get help}

All of the participants interviewed had received input from multiple external agencies, including educational services, social services, CAMHS, health visitors, the Multisystemic Therapy (MST) service, the police and voluntary sector organisations.

Participants' experiences of seeking help for their child's difficulties were varied; all of the parents reported some helpful and unhelpful aspects of their experiences. Overwhelmingly though, there was a sense that participants had felt let down and frustrated by the lack of help that was 
available for them and their children, inconsistencies in the provision of services or poor communication.

\subsection{1. 'Asking for help is embarrassing...'}

Accessing support was described as a complicated process, many of the parents spoke about their early concerns regarding their children's behaviour initially being dismissed; in this extract Alison describes her first experience of going to CAMHS for support around managing her daughter's behaviour:

“...they just said, like she was a wilful child and they didn't really erm diagnose her with anything or say you know, like we could do this or do that."

Often referrals to CAMHS were prompted by third parties, following concerns at school or after an appointment for physical health treatments. This seemed to reflect a sense of shame about needing to access help due to behavioural difficulties, because of the meaning that this held, of being a 'bad parent' or not being able to cope. As Ellie explains:

"...asking for help is embarrassing. Because you and I both know I should be able to do it with my eyes shut."

In this excerpt Beatrice speaks about her frustration in trying to access help and the experience of stigma:

"...from my point of view it's like 'well, that's not helping me because I'm a parent here, struggling to keep my child in school and I feel like I'm kind of labelled in a sort of way, where, erm if they're giving a certain, if they're giving a certain problem then they belong to this group, or they belong in this sort of establishment..." 
Another common experience was the confusion in trying to navigate and understand the various different agencies involved. Fiona explained that she did not know where to go to get help:

"I don't know where to ask, if I was in [country of origin] I would know where to go and what to do, but here I don't know if there is something, you know to do the tests and you know..."

And Beatrice talked about her experience of being referred on to a voluntary sector organisation:

"I just feel like sometimes it's kind of been pushed, it's just been pushed around from pillar to post sort of thing."

\subsection{2. '...listen to parents!'}

Some of the most unhelpful experiences were characterised by parents not feeling listened to or understood by professionals, as Ellie explained:

"I think the hardest part for me was always feeling like I wasn't being listened to"

Some participants also described feeling as though professionals did not believe them. Beatrice described a difficult relationship with the headmaster at her son's school:

"...as if what I was kind of saying actually wasn't the truth, so I find, I found it very hard to have communication with the school, extremely hard and I don't feel like they were supportive." 
In contrast, when participants described positive experiences of engaging with services they spoke about feeling listened to and understood. A key aspect of this seemed to be when clinicians took a 'non-judgemental' stance.

"...it was like someone's actually listening to what we were saying and not just assuming that we were bad parents..." (Alison)

There were also some accounts of participants finding their experiences were 'normalised', as reflected by Fiona's description of receiving support from a parenting group via social services:

"...that was helpful because, you know she was just pointing things like, you know, what I'm doing right, what I'm doing wrong, you know explaining it as normal, as every parent is going through those stages..."

\subsection{3. '...pushed around from pillar to post.'}

Participants also reported feeling frustrated by the inconsistencies that they experienced when trying to access support. In the following extract Beatrice describes the lengths she went to in trying to get a response from CAMHS:

"... it got to the point where my mum would try, still no response, so then we went to my local MP and explained the situation, she called, there still wasn't, I don't feel... a good response, a positive response that we were looking for in terms of getting him seen every week."

Although later in the interview she also acknowledged the impact of limited resources on the support that is available: 
"I don't know if the support for parents is good enough. I understand, because now that I'm kind of on the other side of seeing how, how stressful it can be and how the, $y^{\prime}$ know the resources are often stretched, I understand from the other point of view, but from the parent's point, from a parent's point of view, erm l just think that there's not enough resources out there."

The long-term impact of these perceived inconsistencies on the relationship to services was described by Ellie when she explained how her son reacted to meeting the MST therapist for the first time:

"...he said 'but she'll be like everybody else' and I said 'what do you mean she'll be like everybody else?' He said 'she'll say she's coming, then when she's supposed to come, she'll cancel, then she'll cancel again' he said 'and then she'll disappear' but she didn't, and that was I think a big thing for [him]."

\subsection{4. 'They helped me to understand...'}

Several participants described input from external agencies as helping them to understand their child's difficulties in a new light, or adding to their existing understanding.

"It confirmed a lot, it confirmed a lot of my ideas of what, $y^{\prime}$ know, what I thought, and what a lot of people thought about why he was behaving in the way in which he was behaving." (Beatrice)

"All those sessions, they helped me to understand things..." (Fiona)

For some of the mothers, the input they received also helped them to take a different approach in dealing with their child's behaviour: 
"...she made you stop and think, what was it that [he] did that wound me up so quickly and to learn before I got to that point, to come out the room, to count to ten or $y^{\prime}$ know, make myself a cup of coffee or do something before I went back into the room, was a real help, because you don't actually see those triggers yourself. You just [pause]... you just see... you don't see the cause, you just see the battle and you're determined to win, does that make sense?" (Ellie)

\subsubsection{Power and Authority}

There were times when participants reported using external agencies to help to enforce parental authority. Both Alison and Ellie described contact with the Police:

"Well yeah, I mean we didn't just let her get away with it, we have taken her to the police station about four times now." (Alison)

“...the copper said to him 'next time you come in front of me, even if it's only for nicking a penny sweet, it'll be court in the morning, Feltham in the afternoon and it'll be a long time before you go back home' and that frightened the life out of him. And that's when he realised he had to start to... to toe the line and change as far as the police were concerned, he'd gotten away with as much as he was getting away with." (Ellie)

However, some participants also seem to have felt that their parental authority had been undermined and there was a sense of feeling disempowered, for example in their interactions with schools. In this excerpt Beatrice describes her experience of decisions being made about her son's future:

"I found it very hard to have communication with the school, extremely hard and I don't feel like they were supportive and I actually feel 
that, erm, part of the erm, process of deciding whether he should stay on and repeat the year or go onto high school early, I feel like the er headmaster took that, erm stance to... for him to go to high school early because it was kind of like, okay let's get him out as soon as we can so that we don't have to really deal with this because it's a bit much for us to deal with."

Diane also described an experience of disagreeing with the school about their approach but feeling unable to communicate her opinion:

"...it just doesn't make sense to me, so... But you see you can't really tell them that that's what should happen because everybody's got their own things working so you just got to accept whatever decision they make and just work with that."

The issue of perceived power in relationships was also reflected by Alison's frustration at needing to have her concerns about her daughter's behaviour validated by the school before they were taken seriously:

"Erm, for me it was annoying a bit in a way because I already knew and I'd tried to say things to them but, erm putting her on the IEP for her behaviour sort of proved my theory if you know what I mean."

\section{4. '... a long, long road...'}

The theme of the journey that participants had been through over time was prominent throughout the interviews; all of the mothers identified their child's difficulties as having spanned several years. Participants spoke about 'looking back' in time to try and determine the origins of their child's difficulties and 'looking forward' to try and sense what the future might hold. At times it seemed as though participants were attempting to process 
the meaning of their experiences as they spoke and were engaged in a process of trying to put the pieces of the puzzle together.

\subsubsection{Looking back}

During the interview participants were asked to describe when they first became concerned about their child's behaviour. Several of the participants described how they had dismissed their early concerns as just a phase' or being normative in terms of their child's developmental stage:

"I noticed it, but because l'd been there with the other one, I kind of thought 'oh, he'll grow out of it'" (Connie)

"...but at that time I thought it was like, as they say toddler tantrums and stuff like that, but then it just got worse and worse and worse, but then you thought 'oh, he's getting older, he will settle', he just didn't settle, he just kept getting worse, more demanding." (Diane)

"Yeah, I mean at first I thought it was just, you know [his brother] was like it so [he] was like it and it would be something that he'd um, grow out of". (Ellie)

Some participants also reflected on experiences during birth, pregnancy and early infancy which they had come to understand as early signs that their child was 'different':

"Yeah. I think really, really if I'm being honest, I think I've always known [he] was different, even from a baby..." (Connie) 
"So he was angry really, you know from, even when he was born if I gave him the milk bottle too late, he was screaming and he wouldn't take it, and that was like two, three months when he was really young." (Fiona)

\subsubsection{Getting Stuck}

There were several times when participants spoke about periods when they felt 'stuck' in their journey. Some of the mothers spoke about times when they started to anticipate 'bad behaviour' and there was almost a sense of 'dread' in their descriptions. This was reflected by Alison:

"I do get to the point, where sometimes I think, oh God, I know she's going to do something, when she's told off or when we've took something away from her, then you think, oh God, she's going to do something, she's going to smash something, or whatever. You know, you just get the feeling that you know she's going to retaliate in some way."

In these descriptions there was a sense that parents had 'lost control' and felt powerless. In this excerpt Ellie describes how she had lost confidence in being able to manage her son's behaviour:

"But it had been that long since I'd been in control... that I had lost the confidence to do what I knew I had to do."

\subsection{3. '...growing up...'}

Participants' reflections on what the future might hold for their children seemed to be related to both their child's developmental stage and the perceived efficacy of attempts to manage their child's behaviour so far. Having recently received input from the MST service which she found very helpful, Ellie described her hopes for a more positive future: 
....it's been emotionally draining but it's been worth it, because if you'd have asked me six months ago, where my little boy would be at sixteen I would've told you inside [prison]. Now I honestly believe, touch wood, if we can sort school out, and I think for the first time, I really think..."

Whilst Fiona reflected on some of the fears and worries she had about what the future might hold for her son:

"Yeah, I'm just scared he will grow up, and you know be involved in so many fights, and you know that will, it won't help him to do what he wants in his life."

For Diane, thinking about the future came with a sense of resignation as she reflected on her role as a parent:

"I'm at the stage now where I think there's nothing that probably anyone's going to do right that's going to get him to behave properly, it's all on him."

This statement seemed to reflect a sense of hopelessness and helplessness, as Diane described her son as the only person who could determine his destiny. I wondered if this was a result of her repeated experiences of 'failure' in trying to influence his behaviour. 


\section{Discussion}

The aim of the research was to add to the current understanding of the experiences of parents whose children have been identified as having behavioural difficulties, which can be understood within the diagnostic framework of 'Disruptive Behaviour Disorders' (Conduct Disorder and Oppositional Defiant Disorder): Specifically, this study aimed to explore the ways in which parents attempt to make sense of their children's behaviour and has focussed on mothers' experiences.

Previous research suggests that parental attributions regarding their children's behaviour are likely to influence parenting style, perceived selfefficacy and engagement with parenting programmes (Morrissey-Kane \& Prinz, 1999). Further barriers to engagement with support services have been suggested, including the impact of stigma and social exclusion (Kane et al., 2007).

The themes generated from the data are discussed below with reference to previous research findings and theoretical considerations. The strengths and potential limitations of the study will be considered, before discussing the clinical implications of the findings and directions for future research.

\subsection{Research Findings}

Four master themes emerged from the data, namely 'Looking for an answer', 'The emotional experience of being a parent', 'Trying to get help' and '... a long, long road...'

\subsubsection{Looking for an answer}

Participants used a variety of theoretical, social and cultural frameworks in their attempts to make sense of their children's behaviour. Mothers' explanations included viewing the behaviour as a result of their child 
struggling to deal with complex emotions, problems in interpersonal relationships and difficulties in the learning environment. Notably, the impact of loss and trauma within relationships played a fundamental role in mothers' understanding of their children's internal world. The impact of trauma has also been highlighted by Briggs et al. (2012) who found that $80 \%$ of children referred to child and adolescent mental health services had experienced at least one type of traumatic event, including traumatic loss, separation or bereavement, exposure to domestic violence, emotional abuse and neglect.

Participants frequently described their children as having problems with aspects of cognition, including impulse control, hyperactivity and social communication (e.g. understanding others' points of view and inferring negative intent in others' actions). These areas are frequently represented in the literature as factors which are often thought to contribute to the development of externalising behaviours (Farrington, 2005; Baker, 2008); although Gilmour et al. (2004) highlights that social communication in particular is an often overlooked area.

Participants' attributions appeared to oscillate, from viewing their children's behaviour as 'intentional and directive' on one end of the spectrum to 'uncontrollable' on the other. Mothers' descriptions of their children were also conflicting, with children described as 'manipulative' on one hand and 'vulnerable' on the other. These shifting perspectives appeared to be associated with strong emotional responses, with participants finding it difficult to integrate the conflicting viewpoints. This is consistent with previous research which suggests that parental attributions which include appraisals of behaviour as child-centred, directive and made with negative intent are likely to be followed by feelings of anger and harsh, inconsistent parental responses (Snarr et al., 2009). Appraisals of the behaviour as 'uncontrollable' are less likely to evoke such powerful 
negative affect; but may still be associated with feelings of frustration and low self-efficacy (Saltmarsh, 2005).

However, much of the existing literature relies on parents making causality and responsibility appraisals about hypothetical situations which are unlikely to capture the oscillating nature of emotional conflict which parents experience. In the current study the qualitative nature of the data adds an additional dimension to understanding parents' (specifically mothers') emotional experiences. This finding is particularly salient when considering the important role of attachment and parental affect regulation in influencing the development of externalising behaviours, as highlighted by Keiley (2002), Lyons-Ruth (1996) and Scaramella and Leve (2004).

\subsubsection{The emotional experience of being a parent}

Parents' own emotional wellbeing appeared to play an important role in how equipped they felt to manage their children's behaviour; the mothers interviewed described feeling overwhelmed and emphasised the multiple pressures in their family lives. Five of the mothers had separated from their children's father, often in the context of violence and conflict in the relationship. This echoes the issues of loss and trauma highlighted by the previous theme and many of the participants described the emotional impact of this loss on their own wellbeing as well as the added pressures of being a single parent. The impact of violence and conflict within the parental relationship upon the subsequent mother-son dyad has been highlighted by Hill (2002) as an important area for consideration when conceptualising individual case-formulations. Dekleyn et al. (1998) also draw attention to the importance of considering the marital context and father-son attachment.

All of the participants were living in social housing and three of the participants were reliant on state-benefits for all or part of their income. 
Although financial pressures were not a prominent theme during the interviews, the impact of these multiple stressors over the life course is highlighted in longitudinal studies (Murrey at al., 2010).

The role of relationships was central in understanding participants' experiences. Parents used family and peer networks as sources of emotional and practical support and there was an emphasis placed on the importance of speaking to people who shared similar experiences. This is consistent with previous findings into the ways in which parents utilise informal support networks (Keller \& McDade, 2000; Redmond et al., 2002).

\subsubsection{Trying to get help}

In some cases support from external agencies was framed as being helpful in aiding understanding, normalising parents' experiences and improving confidence in addressing challenging behaviours. However help-seeking was also associated with feelings of shame and stigma, and external agencies were often experienced as invalidating, inconsistent and disempowering. For some, these experiences seemed almost to be echoing the existing experiences of loss and abandonment in their personal relationships. One participant (Ellie) vividly described the impact of this on her son, who came to expect to be let down and rejected by the professionals who came to help. Moretti et al. (1997) and Keiley (2002) highlight the important role of systemic interventions, such as Functional Family Therapy (FFT) and Multisystemic Therapy (MST) in keeping in mind this attachment-focus to engagement when working with multi-stressed families.

The potential for negative experiences of services to act as a barrier to future engagement has been discussed previously by Kerkorian (2006). Participants also reported difficulties in accessing services in the first place, and confusion regarding the multiple agencies involved. It has previously been shown that families of children with conduct disorders are often in 
contact with multiple agencies and parents report several barriers to accessing services (Shivram et al., 2009), highlighting the importance of effective co-ordination in these circumstances. Ford et al. (2007) also raise the issue of identification of mental health difficulties in children by health, education and social services and the importance of effective co-ordination between agencies.

\subsection{5. '... a long, long road...'}

Participants' understanding of their own role in the development and maintenance of their children's behaviour and their hopes and expectations for the future appeared to be influenced by the perceived effectiveness of strategies employed to try and manage their children's behaviour. This would add support to the idea that parental attributions regarding their children's behaviour and their own feelings of self-efficacy are shaped over time by their experience of parenting a child with behavioural problems (Wilson et al., 2006). The current study also suggests that these beliefs are likely to be influenced by a range of personal, social and cultural factors, including pre-existing ideas about what constitutes 'normal behaviour', previous experiences of parenting, positive and negative experiences of engaging with services, access to informal support networks and the wider family context.

The evidence regarding the overall impact that parents' existing attributions may have on engagement with services is mixed (Peters et al, 2005) and it remains unclear as to whether addressing parental attributions is necessary as a separate component, or whether existing interventions are already sufficient in this area (Sanders et al., 2004). However there remains a group for whom the basic parent-training interventions are not sufficient (Scott \& Dadds, 2009) and in the current study participants described some of the most helpful interventions as those which took into account their own emotional needs and utilised systemic theory and practices to inform the intervention. 


\subsection{Strengths and Limitations}

The strengths of using a qualitative design lie in the ideographic approach which allows an in-depth exploration of participants' experiences. In the current study participants were recruited due to their shared experiences of parenting children with behavioural difficulties. This has the potential to provide services. with useful insights into how parents make sense of their children's behaviour. Information and resources can then be targeted in a way which makes sense to parents and helps to add to their existing understanding in a useful and non-blaming way.

Parents of children with conduct problems are often viewed as being 'difficult to engage' and it is likely that professionals may hold certain assumptions that are likely to impact upon the development of the therapeutic relationship. This study has the potential to provide useful insights into parents' experiences of engaging with services so ways to overcome potential barriers can be found.

Guidelines for ensuring validity and reliability were adhered to throughout the research process, as discussed in the methodology section. Verbal feedback of participants' experiences of the research process was obtained at the end of each interview; however it might have been helpful to have provided participants with an opportunity to provide anonymous feedback about the interview process after some time had elapsed so that they had time to reflect on the process and may have felt more able to give negative feedback. It might also have been useful to carry out a pilot interview; however this was not carried out due to difficulties identifying a suitable candidate and time constraints.

In seeking to explore the experiences of a homogenous group, parents were recruited through tier two and three Child and Adolescent Mental Health Services, however parents had received several different types of intervention, which is likely to have played a part in the differences in 
individual experiences. However, the aim was not to investigate parents' experiences of engaging in a particular type of intervention, but to gain a wider understanding of the ways in which parents understand their children's behaviours, which may or may not include the input they receive from external agencies. Many of the parents had additional stressors which they viewed as playing a part in the development of their child's behavioural difficulties. However, it is precisely the experiences of these parents whose engagement with services has not been 'straightforward' which is likely to be of particular interest to clinical psychologists in specialist services when considering the factors which may impact upon engagement.

Participants volunteered to take part in the research; in this respect it is possible that those who took part in the research were those parents who felt more comfortable engaging with the research process or had a particular personal investment in sharing their experiences (such as grievances with external agencies), and therefore represent the experiences of a particular group.

It is also important to acknowledge the potential impact that the researcher's cultural and educational background and role as a Mental Health Professional within CAMHS may have had on the extent to which participants felt able to express their viewpoints openly. It is likely that participants may have had concerns about being judged by the researcher. This was reflected by one of the participants during the debrief interview, when she expressed that she had been worried about "saying the right thing" at the start of the interview. However, every care was taken to try and ensure that participants felt comfortable during the process, including assuring participants that their views would not be fed back to the professionals involved in their care.

It is noted that the linguistic framework used during the interview to discuss parents experience could be criticised for being problem saturated, 
for example the interview included questions about parents' 'concerns' and their children's 'behavioural problems' may have influenced the way in which participants framed their experiences.

The study included participants from a White British, White European and Black Caribbean backgrounds. It would have been valuable to gain perspectives from individuals from a wider range of social and cultural backgrounds. Additionally all of the views represented were from mothers, who were predominantly talking about their sons; it would have been interesting to gain more insight into fathers' experiences and to explore further the impact of gender on parental beliefs about behaviour.

\subsection{Clinical Implications}

Within a qualitative framework the aim is not to 'generalise' findings to the wider population, but rather the concept of 'transferability' is used in order to provide clinically useful insights into participants' experiences. The current study is able to add to the current understanding of the needs of parents of children with conduct problems, who are likely to be facing multiple pressures in their personal and family lives.

\subsubsection{Improving Access}

Participants reported considerable difficulties accessing services and navigating the multiple agencies involved in their children's care. These issues were highlighted in the Department of Health funded paper 'Child Mental Health is Everybody's Business' (Ford et al., 2007) which suggested targeted training in child mental health difficulties for those in health and education services. Clearly there is more work to be done in ensuring parents have access to the necessary support services, including early intervention programmes which provide targeted support to vulnerable groups. 


\subsubsection{Signposting to Additional Support Services}

The mothers interviewed spoke about multiple pressures and stressors in their family lives, which emphasises the importance of recognising parents' needs (Kane at al., 2007) and helping parents to access additional support services as needed, for example by signposting to housing, education and adult mental health services.

\subsubsection{Promoting Engagement}

Participants' experiences of engaging with services were varied; the findings highlight the importance of a collaborative, non-judgemental stance so that parents feel listened to and understood. Most of the mothers had not received a formal diagnosis for their children's difficulties which may reflect hesitance on the part of clinicians in diagnosing a behavioural disorder in cases where there are a multitude of complex needs. For those parents who did discuss a diagnosis of Oppositional Defiant Disorder, they described the diagnosis as a 'checklist' of behaviours that did little to enhance their understanding of the origin of their children's difficulties. Participants used a range of concepts and ideas in their attempts to understand their children's difficulties. This would support a collaborative, formulation-based approach which makes use of these existing frameworks to help parents develop an integrative and individualised framework with which to understand their children's difficulties and explains the rationale for targeted interventions.

Particpants reported difficulties in implementing parenting strategies in the home, which were quickly dismissed as being ineffective. This highlights the importance of not delivering information about behavioural strategies in too shallow a manner, which might assume a certain prior knowledge. Two of the mothers reported particularly benefitting from individual support in carrying out these strategies at home, for example in ensuring consistency. 


\subsubsection{Recognising Loss and Trauma}

The current study highlighted the important role of loss and trauma in the development of externalising behaviours. This draws attention to the need for an in-depth and thorough assessment, including paying particular attention to issues around domestic violence, parental conflict and significant losses within the family. This finding also adds further support to systemic interventions which pay particular attention to issues around attachment and loss, such as MST and FFT. There are also important implications to consider for service delivery; several parents reported being referred for multiple, brief interventions which were framed as being ineffective and are likely to have added to the feelings of failure and rejection in the midst of a stressful family context. This highlights the need for services to consider the role of attachment and loss in influencing engagement and be pro-active in 'stepping-up' care at the appropriate points, rather than run the risk of perpetuating this negative cycle.

\subsection{Future research}

The current study highlights several areas that would benefit from further investigation. Mothers' explanatory models regarding their children's behaviour appeared to favour a formulation-driven approach which takes into account a range of individual and systemic factors. It would be helpful to directly compare the experiences of parents who received information delivered in this way, to those who received information regarding their children's difficulties informed by a diagnostic framework.

Additionally the current study highlights the need for further attention to be paid into the link between externalising behaviours and early experiences of trauma and loss, so that suitable interventions can be targeted at the families for whom this is particularly relevant. Additionally it would be useful to explore parents' experiences of being parented (i.e. 
their own early attachment relationships) and how this compares to their experiences of engaging with professionals to add further discussion around the possible role that services may play in perpetuating unhelpful cycles of relating.

\subsection{Final Reflections}

This study highlights the complex task of trying to make sense of childhood behavioural difficulties and the importance of frequently re-examining assumptions about the basis of these behaviours.

I greatly appreciated the openness with which participants shared their experiences; often reflecting on highly personal and emotional experiences and the difficulties they have faced in trying to seek support for themselves and their children. For me, this experience has given me a greater understanding of parents' experiences which I believe will help me to keep in mind the importance of a collaborative, non-judgemental stance when working with parents who may feel disempowered by engaging with mental health services.

Throughout the process of data analysis I tried to remain aware of preexisting knowledge and assumptions, and was careful to try and 'bracket' these thoughts to one side to be re-examined later. I found that I was surprised at the extent of the thoughtfulness with which parents attempted to make sense of their children's internal world. Upon reflection I think that the assumptions I had about parents' ability to reflect on these issues had been influenced by the existing literature which can often frame parents as 'difficult to engage'. Much of the existing literature describes parents and their children in a very clinical fashion that does not adequately capture the emotional conflict that parents experience in trying to understand their children. For me, this highlights the importance of 
qualitative research in ensuring an individual's emotional experiences do not get lost amongst the clinical descriptions of 'disordered' groups.

I was also particularly moved by the tremendous tenacity which parents displayed in trying to access help for their children. Parents remained open to engaging with services despite facing multiple barriers and negative experiences which for me, highlights the importance of trying to hold the individual's 'journey' in mind each time a new referral comes through the door. 


\section{References}

Ahern, K.J. (1999). Ten tips for reflexive bracketing. Qualitative Health Research, 9, 407-411.

American Psychiatric Association (2000). Diagnostic and Statistical Manual of Mental Disorders, $4^{\text {th }}$ Ed. - Text Revision. Washington DC: American Psychiatric Association.

American Psychiatric Association (2012). DSM-5 Development: Proposed Revisions: Disruptive, impulse control, and conduct disorders: 002 Conduct Disorder. Retrieved 12 July 2012 from www.dsm5.org/ proposedrevision/pages/proposedrevision.aspx?rid $=370$

Angold, A., Costello, J. \& Alaattin, E. (1999). Comorbidity. Journal of Child Psychology and Psychiatry, 40(1), 57-87.

Audit Commission for Local Authorities and the National Health Service in England and Wales (1999). Children in Mind: Child and adolescent mental health services. London: Audit Commission.

Baker, K. (2008). Conduct disorders in children and adolescents. Paediatrics and Child Health, 19(2), 73-78.

Bassarath, L. (2001). Conduct Disorder: A biopsychosocial review. Canadian Journal of Psychiatry, 46, 609-616.

Bornovalova, M.A., Hicks, B.M., lacona, W.G. \& McGue, M. (2010). Familial transmission and heritability of childhood disruptive disorders. The American Journal of Psychiatry, 167(9), 1066-1074. 
Briggs, E.C., Fairbank, J.A., Greeson, J.K.P., Layne, C.M., Steinberg, A.M., Amaya-Jackson, L.M., et al. (2012). Links between child and adolescent trauma exposure and service use histories in a national clinic referred sample. [Electronic Version]. Psychological Trauma: Theory, Research, Practice and Policy, 4(2), No pagination specified.

British Psychological Society (2011). Good Practice Guidelines on the use of psychological formulation. Leicester: BPS

Broadhead, M.A., Hockaday, A., Zahra, M., Francis, P.J. \& Crichton, C. (2009). Scallywags - an evaluation of a service targeting conduct disorders at school and at home. Educational Psychology in Practice, 25(2), 167-179.

Canino, G. \& Alegira, M. (2008). Psychiatric diagnosis - is it universal or relative to culture? Journal of Child Psychology and Psychiatry, $49(3), 237-250$.

Carr, A. (2009). The effectiveness of family therapy and systemic interventions for child-focused problems. Journal of Family Therapy, 31, 3-45.

Chronis, A.M., Lahey, B.B., Pelham Jr., W.E., Williams, S.H., Baumann, B.L., Kipp, H., et al. (2007). Maternal depression and early positive parenting predict future conduct problems in young children with attention-deficit/hyperactivity disorder. Developmental Psychology, $43(1), 70-82$.

Costello, E.J. \& Angold, A. (2001). Bad behaviour: an historical perspective on disorders of conduct. In Hill, J. \& Maughan, B. (Eds.) Conduct 
disorders in childhood and adolescence. Cambridge: Cambridge University Press.

CYP IAPT (2012). Children and young people's project. Retrieved 11 July 2012 from www.iapt.nhs.uk/cyp-iapt/

DeKleyn, M., Speltz., M.L. \& Greenberg, M.T. (1998). Fathering and early onset conduct problems: Positive and negative parenting, fatherson attachment, and the marital context. Clinical Child and Family Psychology Review, 1(1), 3-21.

Department of Health (2009). New Horizons: A Shared Vision for Mental Health. London: Department of Health.

Farrington, D.P. (2005). Childhood origins of antisocial behaviour. Clinical Psychology and Psychotherapy, 12, 177-190.

Finch, A.J., Nelson, W.M. \& Hart, K.J. (2006). Conduct disorder: Description, prevelance, and etiology. In Nelson, W.M., Finch, A.J. \& Hart, K.J. (Eds.) Conduct Disorders: A practitioner's guide to comparative treatments. New York: Springer Publishing Co.

Ford, T., Hamilton, H., Meltzer, H. \& Goodman, R. (2007). Child mental health is everybody's business: The prevalence of contact with public sector services by type of disorder among british school children in a three-year period. Child and Adolescent Mental Health, 12(1), 13-20.

Frick, P.J., Lahey, B.B., Loeber, R., Stouthamer-Loeber, M., Christ, M.A.G. \& Hanson. (1992). Journal of Consulting and Clinical Psychology, 60(1), 49-55. 
Garder, R. (2009, 13 March) Hoodies, louts, scum': how media demonises teenagers. The Independent. Retrieved 14 July 2012 from www.independent.co.uk/news/uk/home-news/hoodies-loutsscum-how-media-demonises-teenagers-1643964.html

Gergen, K.J., Lightfoot, C. \& Sydow, L. (2004). Social construction: Vistas in clinical child and adolescent psychology. Journal of Clinical Child and Adolescent Psychology, 33(2), 389-399.

Gilmour, J., Hill, B., Place, M. \& Skuse, D.H. (2004). Social communication deficits in conduct disorder: A clinical and community survey. Journal of Child Psychology and Psychiatry, 45(5), 967-978.

Grusec, J.E., Rudy, D. \& Martini, T. (1997). Parenting cognitions and child outcomes: An overview and implications for children's internalization of values. In Grusec, J.E. \& Kuczynski, L. (Eds.) Parenting and children's internalization of values. New York: John Wiley \& Sons, Inc.

Harwood, V. (2005). Diagnosing 'disorderly' children: A critique of behaviour disorder discourses. Abingdon, Oxfordshire: Routledge.

Hendrick, H. (2006). Histories of youth crime and Justice. In Goldson, B. \& Muncie, J. (Eds) Youth crime and justice. London: Sage Publications Ltd.

Hill, J. (2002). Biological, psychological and social processes in the conduct disorders. Journal of Child Psychology and Psychiatry, 43(1), 133164. 
Kane, G.A., Wood, V.A. \& Barlow, J. (2007). Parenting programmes: a systematic review and synthesis of qualitative research. Child: Care, health and development, 33(6), 784-793.

Keenan, K., Loeber, R. \& Green, S. (1999). Conduct disorder in girls: A review of the literature. Clinical Child and Family Psychology Review, 2(1), 3-19.

Keiley, M. (2002). Attachment and affect regulation: A framework for family treatment of conduct disorder. Family Process, 41(3), 477493.

Keller, J. \& McDade, K. (2000). Attitudes of low-income parents toward seeking help with parenting: Implications for practice. Child Welfare, 79(3), 285-312.

Kerkorian, D. (2006). Seeking help a second time: Parents'/caregivers' characterizations of previous experiences with mental health services for their children and perceptions of barriers to future use. American Journal of Orthopsychiatry, 76(2), 161-166.

Lahey, B.B., Loeber, R., Quay, H.C., Frick, P.J. \& Grimm, J. (1992). Oppositional defiant and conduct disorders: Issues to be resolved for DSM-IV. Journal of the American Academy of Child \& Adolescent Psychiatry, 31(3), 539-546.

Loeber, R., Burker, J. \& Pardini, D. (2009). Perspectives on oppositional defiant disorder, conduct disorder and psychopathic features. Journal of Chid Psychology and Psychiatry, 50, 131-142 
Lyons-Ruth, K. (1996). Attachment relationships among children with aggressive behaviour problems: The role of disorganized early attachment patterns. Journal of Consulting and Clinical Psychology, $64(1), 64-73$.

Mah, J.W.T. \& Johnson, C. (2008). Parental social cognitions: Considerations in the acceptability of and engagement in behavioural parent training. Clinical Child and Psychology Review, 11(2), 218-236.

Mallett, C.A. (2006). Behaviourally-based disorders: the historical construction of youths' most prevalent psychiatric diagnoses. History of Psychiatry, 17(4), 437-460.

Maniadaki, K., Sonuga-Barke, E., Kakouros, E. \& Karaba, R. (2006). AD/HD symptoms and conduct problems: Similarities and differences in maternal perceptions. Journal of Child and Family Studies, 15(4), 463-477.

Marmorstein, N.R. \& Icano, W. (2004). Major depression and conduct disorder in youth: Associations with parental psychopathology and parent-child conflict. Journal of Child Psychology and Psychiatry, $45(2), 377-386$.

Maughan, B., Rowe, R., Messer, J., Goodman, R. \& Meltzer, H. (2004). Conduct disorder and oppositional defiant disorder in a national sample: developmental epidemiology. Journal of Child Psychology and Psychiatry, 45(3), 609-621.

Meier, M.H., Slutske, W.S., Heath, A.C. \& Martin, N.C. (2011). Sex differences in the genetic and environmental influences on 
childhood conduct disorder and adult antisocial behaviour. Journal of Abnormal Psychology, 120(2), 377-388.

Meyrick, J. (2006). What is good qualitative research? A first step towards a comprehensive approach to judging rigour/quality. Journal of Health Psychology, 11(5), 799-808.

Miller, J. \& McClelland, L. (2006) Social inequalities formulation: Mad, bad and dangerous to know. In Johnston, L. \& Dallos, R. (Eds.) Formulation in Psychology and Psychotherapy: Making sense of people's problems. London: Routledge.

Miller, S. A. (1995). Parents' attributions for their children's behavior. Child Development, 66, 1557-1584.

Moffitt, T.E. (2003). Life-course-persistent and adolescence-limited antisocial behavior: A 10-year research review and a research agenda. In Lahey, B.B., Moffitt, T.E. \& Caspi; A. (Eds.) Causes of conduct disorder and juvenile delinquency. New York: The Guildford Press.

Moretti, M.M., Emmrys, C., Grizenko, N., Holland, R., Moore, K., Shamsie, J. \& Hamilton, H. (1997). The treatment of conduct disorder: perspectives from across Canada. Canadian Journal of Psychiatry, $42,637-648$

Morrissey-Kane, E. \& Prinz, R.J. (1999). Engagement in child and adolescent treatment: The Role of parental cognitions and attributions. Clinical Child and Family Psychology Review, 2(3), 183-198. 
Murray, J. \& Farrington, D.P. (2010). Risk factors for conduct disorder and Delinquency: Key findings from longitudinal studies. The Canadian Journal of Psychiatry, 55(10), 633-642.

National Institute for Health and Clinical Excellence (2006). Conduct disorder in children - parent-training/education programmes. London: National Institute for Health and Clinical Excellence.

Nix, R.L., Bierman, K.L. \& McMahon, R.J. (2009). How attendance and quality of participation affect treatment response to parent management training. Journal of Consulting and Clinical Psychology, $79(3), 429-438$.

Pearce, M.J., Jones, S.M., Schwab-Stone, M.E. \& Ruchkin, V. (2003). The protective effects of religiousness and parent involvement on the development of conduct problems among youth exposed to violence. Child Development, 74(6), 1682-1696.

Peters, S., Calam, R. \& Herrington, R. (2005). Maternal attributions and expressed emotion as predictors of attendance at parent management training. Journal of Child Psychology and Psychiatry, 46(4), 436-448.

Puckering, C. (2009). NICE guidelines on parenting programmes for children with conduct disorder. Child and Adolescent Mental Health, 14(2), 58-61.

Redmond, C., Spoth, R. \& Trudeau, L. (2002). Family and community level predictors of parent support seeking. Journal of Community Psychology, 30(2), 153-171. 
Renk, K. (2008). Disorders of conduct in young children: Developmental considerations, diagnoses, and other characteristics. Developmental Review, 28, 316-341.

Richters, J.E. \& Cicchetti, D. (1993). Mark Twain meets DSM-III-R: Conduct disorder, development, and the concept of harmful dysfunction. Development and Psychopathology, 5(1), 5-29.

Roberts, R.E., \& Roberts, C.R. (2007). Ethnicity and risk of psychiatric disorder among adolescents. Research in Human Development, 41, 89-117.

Rolls, L. \& Relf, M. (2006). Bracketing interviews: Addressing methodological challenges in qualitative interviewing in bereavement and palliative care. Mortality, 11(3), 286-305.

Sainsbury Centre for Mental Health. (2009). The chance of a lifetime: preventing early conduct problems and reducing crime. London: Sainsbury Centre for Mental Health.

Saltmarsh, R., McDougall, S. \& Downey, J. (2005). Attributions about child behaviour: Comparing attributions made by parents of children diagnosed with ADHD and those made by parents of children with behavioural difficulties. Educational and Child Psychology, 22(4), 108-126.

Sanders, M.R., Markie-Dadds, C., Tully., L.A. \& Bor, W. (2000). The triple-p positive parenting program: A comparison of enhanced, standard and self-directed behavioural family intervention for parents of children with early onset conduct problems. Journal of Consulting and Clinical Psychology, 68, 624-640. 
Sanders, M.R., Pidgeon, A.M., Gravestock, F., Connors, M.D., Brown, S. \& Young, R.W. (2004). Does parental attributional retraining and anger management enhance the effects of the triple p-positive parenting programme with parents at risk of child maltreatment? Behaviour Therapy, 35, 513-535.

Scaramella, L.V. \& Leve, L.D. (2004). Clarifying parent-child reciprocities during early childhood: The early childhood coercion model. Clinical Child and Family Psychology Review, 7(2), 89-107.

Scott, S. \& Dadds, M.R. (2009). Practitioner Review: When parent training doesn't work: Theory-driven clinical strategies. Journal of Child Psychology and Psychiatry, 50(12), 1441-1450.

Scott, S., Spender, Q., Doolan, M., Jacobs, B. \& Aspland, H. (2001). Multicentre controlled trial of parenting groups for childhood antisocial behaviour in clinical practice. British Medical Journal, 323, 1-7.

Shinebourne, P. (2011). The theoretical underpinnings of Interpretative Phenomenological Analysis (IPA). Existential Analysis, 22(1), 16-31.

Shivram, R., Bankart, J., Meltzer, H., Ford, T., Vostanis, P. \& Goodman, R. (2009). Service utilisation by children with conduct disorders: Findings from the 2004 Great Britain mental health survey. European Child and Adolescent Psychiatry, 18, 555-563.

Smith, J.A., Flowers, P. \& Larkin, M. (2009). Interpretative Phenomenological Analysis: Theory, method and research. London: Sage Publications 
Smith, J.A. \& Osborn, M. (2003) Interpretative Phenomenological Analysis. In Smith, J.A. (Ed) Qualitative psychology: A practical guide to research methods. London: Sage Publications.

Snarr, J.D., Smith Slep, A.M. \& Grande, V.P. (2009). Validation of a new selfreport measure of parental attributions. Psychological Assessment, 21(3), 390-401.

Stepp, S.D., Burke, J.D., Hipwell, A.E. \& Loeber, R. (2012). Trajectories of attention deficit hyperactivity disorder and oppositional defiant disorder symptoms as precursors of borderline personality disorder symptoms in adolescent girls. Journal of Abnormal Child Psychology, $40(1), 7-20$.

Trouble shooters scheme to tackle 'troubled families'. (2011, 15 December). $B B C$ News. Retrieved 11 July 2012 from www.bbc.co.uk/ news/uk-politics-16187500.

Wakefield, J.C., Pottick, K.J. \& Kirk, S.A. (2002). Should the DSM-IV diagnostic criteria for conduct disorder consider social context? The American Journal of Psychiatry, 159(3), 380-386.

Walton, A. \& Flouri, E. (2010). Contextual risk, maternal parenting and adolescent externalizing behaviour problems: the role of emotion regulation. Child: Care, health and development, 36(2), 275-284.

Webster-Stratton, C., \& Hammond, M. (1990). Predictors of treatment outcome in parent training for families with conduct problem children. Behaviour Therapy, 21, 319-337. 
Webster-Stratton, C., \& Reid, M.J. (2010). The incredible years parents, teachers and children training series: A multifaceted treatment approach for young children with conduct problems. In J. Weisz \& A. Kazdin (Eds.) Evidence based psychotherapies for children and adolescents ( $2^{\text {nd }}$ ed.) New York: Guilford Publications.

Willig, C. (2008). Introducing qualitative methods in psychology ( $2^{\text {nd }} \mathrm{Ed}$ ). Buckingham: Open University Press.

Wilson, C., Gardner, F., Burton, J. \& Leung, S. (2006). Maternal attributions and young children's conduct problems: A longitudinal study. Infant and Child Development, 15, 109-121.

Yardley, L. (2008). Demonstrating validity in qualitative psychology. In Smith, J.A. (Ed). Qualitative Psychology: A Practical Guide to Methods ( $2^{\text {nd }}$ Ed). London: Sage. 


\section{APPENDICES}

\section{APPENDIX A - OUTCOME LETTER FROM NHS RESEARCH ETHICS}

\section{COMMITTEE}

19 September 2011
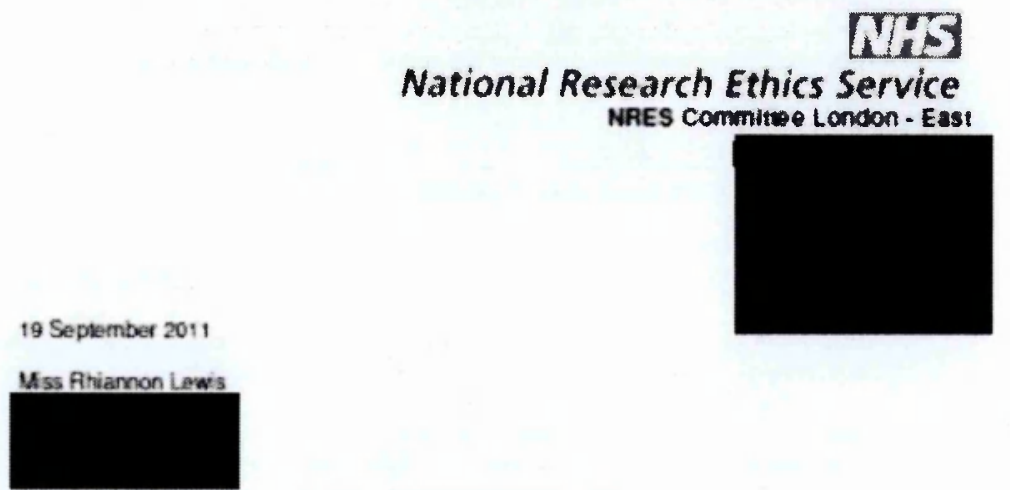

Dear Miss Lewis

Sudy tot

Understunding Conduct Disorder: The wrys in which purents' utie mpt to mule anse of their childen's beheriour.

REC relerence:

11201395

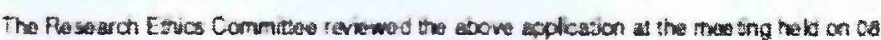
September 201\%. Them rou tar mandry wo a suss the study.

\section{Ethical opinton}

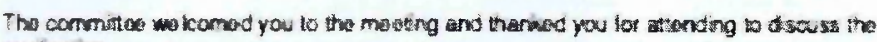
apotestion

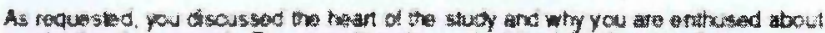

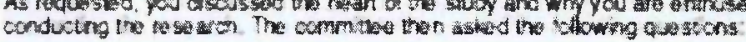

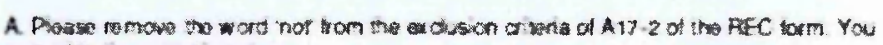
acread to the mondment

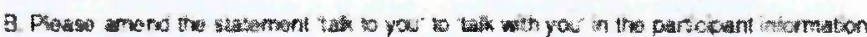

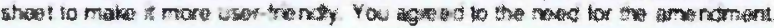

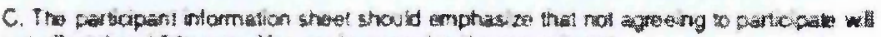

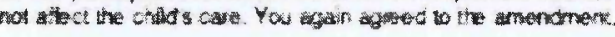

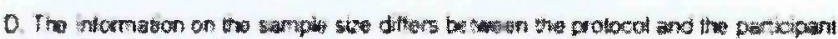

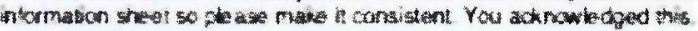

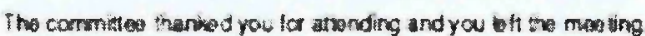

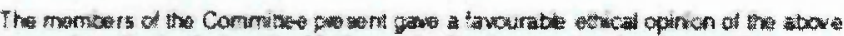

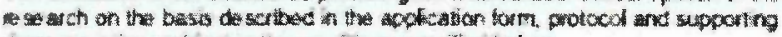
documentation, suopect wo the cond trems spectied betow. 
Ethical review of rege arch sites

\section{Nhs Stes}

The levourable coinish apples to all NHS ales teking part in the study, subject to managament permission being abtained from the WHSHSC FaD office prot to the start of the study (sese "Gondtions of the tevorrable opinion" below).

\section{Conditions of the favourable opinion}

The favcurable opinion is subject to the following conditions being met pribr to the stem of the sludy.

Manegameni cemission or acoroval must be colinad Irom each host orgenisation crioc to

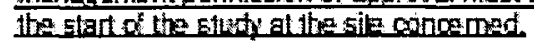

Menagenent pemission ("RsD approwal) shouid be sought from ai HitS organisations irvoved in the study in accordance with wis s research governance amangementa.

Guidanoe on appling for NHS pexmission tor tesearch is Evelably in the Integrabd Research Appucation Systam or at hilpimwe rdforum,nhs.uk.

Where a NHS oggariselians role in the study is frited to idendfying end referning potential pertopante to research sites (panticipend identifietion centre). Guidance shouto be saught from the AsD office on the information it requires to give permission for this acowty.

For non-NHS sites, site manegenend pemission shoud be oblaned in acoordance with the pocedires of the relevent host ogganisation.

Sponsors ane not required to nolity the Committe of approvals from host organisations

Other conditions specified by the REC

\section{Pafticioant Intometion Shat:}

i. Plasa amend the phrase 'we will talk to you' to we will telk with you'.

i. Prease emphesize that disagreaing to perticipate will not aflact the childts cere.

iii. Phease include a subhesded paragraph for Why Hawe I been inviled to take pert? and a separate gub-hnadad paragraph on conplaints proxedres. Pheage refar to the NRES websita for guidanos on the format and content of such.

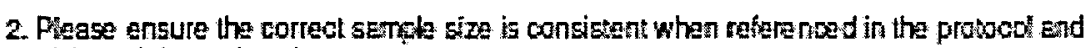
participent intormetica shoet.

3. Piease re move the nord 'not' from the exclusion crivgia in A17-2 ot the AEC form.

It is responsibility of the sponsor to engure that all the cond tions are complied with before the atart of the study or its initiation at a particular sife (Eg applicable).

You should notily the REC in writing once all conditions have been met (except tor site approv als from host organisations) and provide copies of any revised documentation with updated version numbers. Confirmation should also be provided to hast organisations together with relevant documentation 
Approwed documents

The documents teveswed and approved at the meeting ware:

\begin{tabular}{|c|c|c|}
\hline Document & Version & Dare \\
\hline Coverrg Letor & & 04 August 20:1 \\
\hline Evisenos of ireuranos of romantif & & 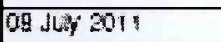 \\
\hline GFCrersuant nlcmalon Stragts & 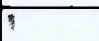 & 0日: A.just $20: 1$ \\
\hline 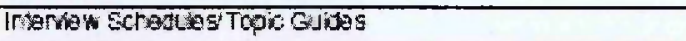 & 1 & 08 August 2011 \\
\hline ITwaspalch Cy & & 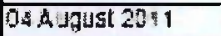 \\
\hline Otter Cy' ter sudant-Finianron Lews & & 04 Aug̣ust 20:1 \\
\hline 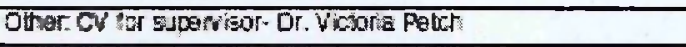 & & 04 August 20:1 \\
\hline Otrer appendx E-patcipen tebrel shoel & 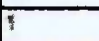 & OQ August 251 \\
\hline Other acpendx C-Paricipant contact steat & 1 & 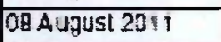 \\
\hline 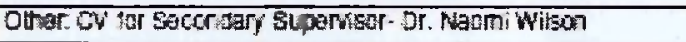 & & O4 August $20 \% 1$ \\
\hline 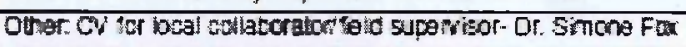 & & 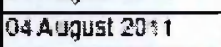 \\
\hline Paticpart Consant fom: sppendix F & 9 & 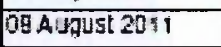 \\
\hline 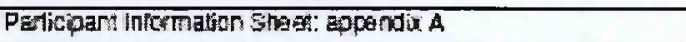 & 1 & 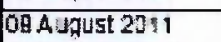 \\
\hline Prdasol & 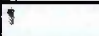 & \\
\hline FEC acpliaslior: & 1 & DQ AUDUSt 20:1 \\
\hline Febress or oftar sciantic crifque repon & & 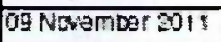 \\
\hline
\end{tabular}

\section{Membership of the Committee}

The members of the Ethics Commitze who were prosent at the ragang are listed on the ateched shoel.

\section{Staternent of compliance}

The Comoritee is constituted in accordence with the Govemanos Arrangements for

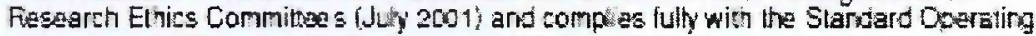
Propedura 5 for Pesearon Ethics Commitaes in the UK.

\section{After ethical review}

\section{Pigportira requiremants}

The aneched documen 'After etrical revizw - guidenoe tor researchers" givas detaiked guidanos on raporting requin ments for studies with a tawourable opinion, inchuding:

- Nobtying substantial amandmerns

- Adong new sives and investipators

- Notication ol seriols braches of the protocol

- Progress and sedety opots

- Nostying the end of the study

The NRES website Elso provides guidande on the ge ipgics, which is updated in the ight of changes in ragerting requiramenss or proosduras.

Feadpack 
Yow are inv to give your view of the service that you have received from the National

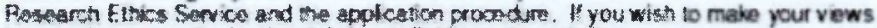

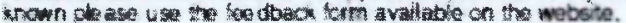

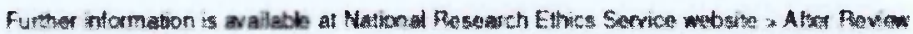
$11 / 201395$

Please quote this number on all correspondence

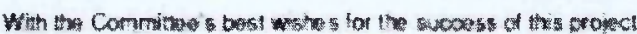

Yours snaray

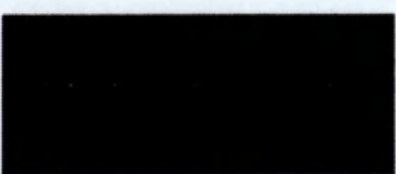

Endosures: List of names and protessions of mernturs we present at the werte and those who subritted with comments

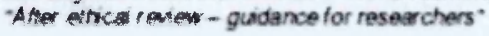

Cacy to: 


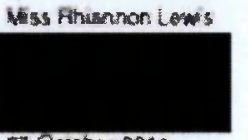

27 octorer 201

Dea hats Lew

Full tithe of study:

AEC referesce number:
Understanding Condict Otsorde: The ways in which parents' nempt to make of their childeren's bohaviour.
11 Lo1305

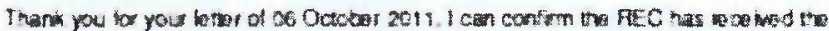

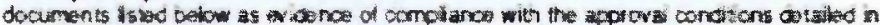

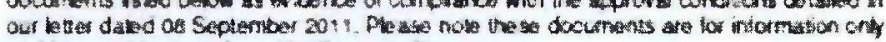
and have now been wewed ty the commat

\section{Documents received}

The documerits ace cived were as follows

\begin{tabular}{|c|c|c|}
\hline Docamars & | Venuen & Late \\
\hline Cowarth Let & & $x$ batron 2019 \\
\hline Partiopant nformation Snav: & $\sqrt{2}$ & F canom $\times 1$ \\
\hline
\end{tabular}

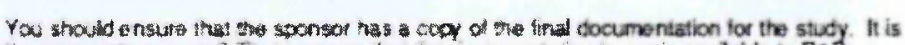

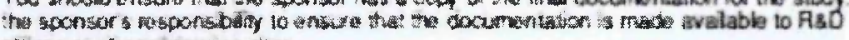

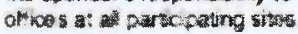

\section{5} Penes quol thil number on all correspondence

\section{Youts whoeret}

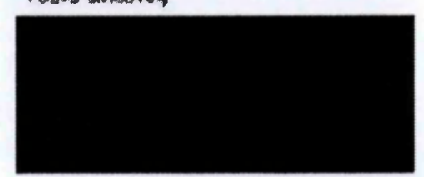

Aopy sx 


\section{APPENDIX C - NHS R\&D APPROVAL}

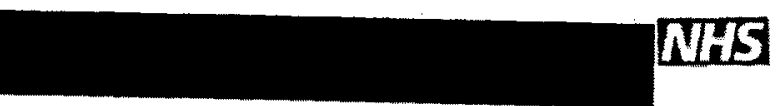

Resenrch and Development

Miste Rhiannan Lewie

Trtine Cinical Psyctologist

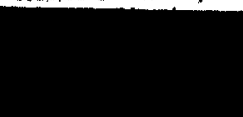

13 December 2011

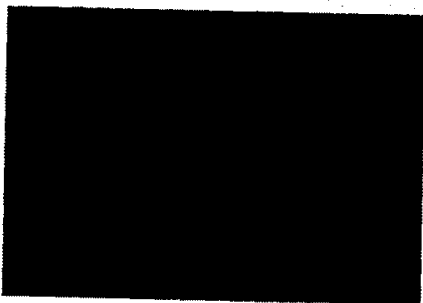

Doar Miss Lewis.

Research Tlte: Understanding Conduct Disorder: The ways in whleh parent's to make sense of their chlldren's behaviour.

Princlpal Inveatigator. Mass Rhiannon Lewis

Prolect roforance: PF 606

Sponsof: University of Surrey

Folbwing various discussion your sludy has now been awarded resoanch approval. Please remember to quote the above project relerence number on any tuture correspondenco relating to this study.

Plesse note that, in addition to ensuring that the dignily, safety and wellboing of particlpants ate ghen priority at all limes by the research team, host site approval is subjact to the following conditions:

In addition to ensurng that the dignty, aatety and woll.being of partichants ane oiven protity al all times by the research team, you need to ensura the following:

- The Princtial Investigator (PI) must ensure compliance with the resoarch protocol and advise the host of any change(s) (eg. patient recrutment or fundimg) by following the agreed procedures for notifeation of amendments. Falkure to comply may rasul in Inumediats withdrawal of host sits approval.

- Under the torms of the Rescarch Govemance Frameund the PI is obliged to report any adverse events to the Research Office, as well as the REC, in line with the protoco and sponsor requirements. Adverse evants must also be reported in accordance with the Trust Accidentincident Reporting Procadures.

- The PI must ensure appropriate procodures are in place to action urgent salefy neasures.

- The PI must ensure the maintenance of a Tral Master Fite (TMF).

Terms and ecoeditions of Apgrowal, serion I.1 I112201! 
- The PI must ansure that all named stafl are compliant with the Data Protection Act, Human Trasus Act 2005. Mental Capacity Act 2005 and all other statutory guidance and legistation (where applicabie)

- The PI must comply with the Trus's research auditing and montoring processes. All investigators involved in ongoing research may be subject to a Trust audit and moy be sent an interim project review form to facilhato monitorng of research activity.

- The PI must report any cases of suspected research miscronduct and fraud to the Research Onice.

- The PI must provide an annual repont to the Research Office for all research invoiving NHS patients. Trust and resources The PI must also notity the Research Otfice of any presentations of such restarch at scientific or professional meatings or on the event of papers being pubtished and any direct or indirect impacts on patient care. This is vita to ensure the quality and output of the research for your project and the Trust as a whole.

- Paltent contact Oniy trained or supervised rasearchers holding a TrustNHS contract (honorary or substantive) will be alkowed to make contact with patients.

- Intormed consent is abtaned by the lead of traned researcher according to the requiraments of the Reseranch Ethics Committea. The onginas signed consent form should be kept on file Informed consent will be monitored by the Trust at intervals and you wit be resaured to provide relevant information.

- Closure form: On sompletion of your project a closure form wal be sent 10 you (according to the and date specified on the R \& D database), which meors to be retumed to the Research Office.

- All research carried out within

Trust must be in accordance with the princoles sel out in the Department of Healhis Research Govemance Framewtork for Hesith and Social Care 2005 (2 ${ }^{\text {no }}$ edition).

Falure to comply with the condikions and regulations oullined abowe constitutes research misconduct and the Research Office will take approporlate action immed uately.

Please noto. howaver, that this list is by no means exhaustive and zamains subject to change in response to now relevant statutory policy and guidance. If you nave any queries regarding the above points please conlact RACI Co-ordinator, on

Yours sigcerely,

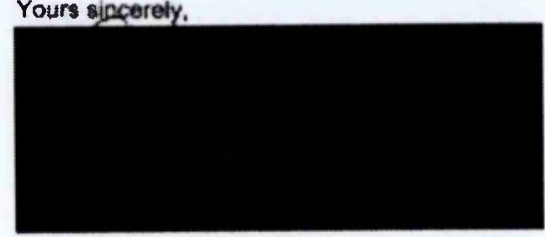

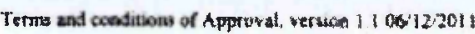


APPENDIX D - APPROVAL FROM UNIVERSITY OF SURREY'S FACULTY OF ARTS AND HUMAN SCIENCES ETHICS COMMITTEE

\section{SURR UNREY}

Dr

Chair: Faculty of Arts and Human Sciences Ethics Committee

Faculty of Arts and Human Sciences

University of Surrey

Guildford, Surrey GU2 7XH UK

T: $+44(0) 1483689445$

$\mathrm{F}:+44(0) 1483689550$

www.surrey.ac.uk

Rhiannon Lewis,

Trainee Clinical Psychologist

School of Psychology

University of Surrey

$10^{\text {th }}$ January 2012

Dear Rhiannon

Reference: 690-PSY-11 (FEO/NHS)

Title of Project: Understanding Conduct Disorder: The ways in which parents attempt to make sense of their children's behaviour

Thank you for your submission of the above proposal.

The Faculty of Arts and Human Sciences Ethics Committee has now given a favourable ethical opinion.

If there are any significant changes to your proposal which require further scrutiny, please contact the Faculty Ethics Committee before proceeding with your Project.

Yours sincerely

Dr

Chair 
APPENDIX E - PARTICIPANT INFORMATION FORM

Participant Information Sheet

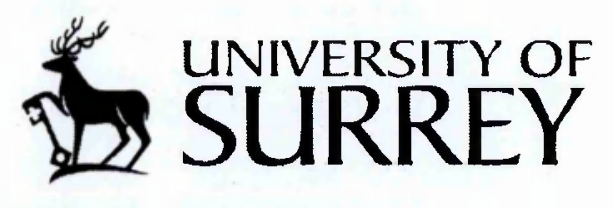

\section{Understanding Your Child's Behaviour}

My name is Rhiannon Lewis and I am a Trainee Clinical Psychologist at the University of Surrey. As part of my training to become a Clinical Psychologist, I am required to carry out some research. I would like to invite you to take part in my research into childhood behavioural disorders. To help you decide if you would like to do this, please read this information sheet so that you know what you will be asked to do.

\section{The research}

I am interested in parents' experiences of their child's behavioural difficulties, including any ideas that parents might have about why the behaviour(s) started. I hope that this research will help services to provide advice and information that is helpful in order to support families.

This study has received a favourable opinion from the NHS London - East Research Ethics Committee and the Ethics Committee of the University of Surrey's Faculty of Arts and Human Sciences.

Why have I been invited to take part?

I am hoping to talk with up to twelve parents whose children have been identified as having some behavioural difficulties by a Mental Health Professional at the Child and Adolescent Mental Health Service (CAMHS).

Do I have to take part? 
No, it is entirely up to you whether you take part in the research or not and your decision will not have any effect on your child's care.

\section{What will I be asked to do?}

I will ask you to spend some time talking with me either at the CAMHS office or at your home. I will ask you some questions about when you first started noticing your child's behavioural difficulties and what you thought about them at the time.

There are no right or wrong answers; I am just interested in hearing about your experiences. I will talk with you for up to an hour, but it may be less. During the time we are talking I will record our conversation. When the conversation has finished I will type out everything that we have said and the audio recording will be destroyed. I will use a made up name in the typed version so that no-one will be able to tell that it is you. If during the interview you say something that makes me worried for your own or someone else's safety then I would have to discuss this with my supervisor who is a psychologist and maybe someone at the CAMHS.

It is okay if you want to stop the conversation at any time, just let me know. Some people find talking about their experiences quite helpful, but for others it can be upsetting. If you do get upset during the conversation please let me know. If I think you are upset or worried during the conversation I will stop it.

You do not have to take part in this research. It is totally your choice if you take part in this research project or not, and your decision will not have any effect on any support you may be receiving from the CAMHS team. If you do want to take part I will ask you to read and sign a consent form.

You will receive a $£ 10$ High Street Voucher as a reimbursement for your time and effort, plus a refund of any travel expenses incurred. 


\section{Writing up the research}

All information that is gathered as part of this project will remain anonymous, unless you tell me something which causes me concern about your own or someone else's safety. Quotes from the interview may be used when the project is written up, but these will be made anonymous, so that no-one will be able to identify you from anything you say.

\section{Your rights}

If you decide that you would like to take part in this research it does not mean that you cannot change your mind later. You will not need to say why you have changed your mind. I will give you some information about who you can speak to if you feel upset or worried after the interview.

\section{What if there is a problem?}

If you have any concerns about any aspect of the research study, then you can contact one of my Supervisors. Their names are Dr. and Dr. at the University of Surrey. Both of their contact details are given below.

\section{What do I do next?}

If you have any questions about taking part in this research then please contact me on or via email If I am not able to answer the phone straight away then please leave a message and your contact details and I will get back to you as soon as possible.

Thank you

Rhiannon Lewis, Trainee Clinical Psychologist

Supervised by: 
APPENDIX F - PROFESSIONALS' INFORMATION FORM

\section{Information Sheet for CAMHS Team members}

\section{Understanding Conduct Disorder - The ways in which parents' attempt to make sense of their child's behaviour}

My name is Rhiannon Lewis and I am a Trainee Clinical Psychologist at the University of Surrey. I am carrying out a research project to explore the experiences of parents whose children have been identified as having behavioural difficulties, specifically conduct problems (i.e. oppositional and/or anti-social behaviour).

I hope that this research will help services to provide advice and information that is helpful and accessible in order to best support families.

This study has received a favourable opinion from the NHS London - East Research Ethics Committee and the Ethics Committee of the University of Surrey's Faculty of Arts and Human Sciences.

\section{What will participation involve?}

I will interview participants either at the CAMHS office or at their home. I will be asking them questions about when they first started becoming concerned about their child's behavioural difficulties and whether they have any ideas about what might have been contributing to the behaviour(s). The interview will last for around an hour and I will be recording the conversation. If during the interview the participant says something that would cause me concern for their own or someone else's safety then I would discuss this with my supervisor and if necessary a relevant person within the CAMHS team. Apart from these exceptional circumstances, all information gained during the interview will remain confidential and will be made anonymous prior to being included in the final study. 
It is important that participants know that their decision whether or not to participate is totally voluntary and will not impact in any way upon any support they may be receiving from the CAMHS team. If they do decide to take part they will need to read and sign a consent form.

Participants will receive a $£ 10$ High Street Voucher as a reimbursement for their time and effort, plus a refund of any travel expenses incurred.

Participants can choose to withdraw their information after the interview at any time (up until the point that the research is submitted to the University for assessment). I will provide participants with information about who they can speak to if they feel upset or worried after the interview.

\section{Who is eligible to take part?}

Any parent of a child aged 8-13 who has been identified as having significant behavioural problems, specifically conduct problems or oppositional behaviour as defined by the DSM-IV criteria for conduct disorder or oppositional defiant disorder (see below). The child does not need to have received a formal diagnosis.

The behaviour must not be attributable to another childhood developmental disorder (such as Autism or a Learning Disability) or mood disorder.

\section{DSM-IV criteria for Oppositional Defiant Disorder:}

Oppositional Defiant Disorder is a pattern of negativistic, hostile, and defiant behaviour lasting at least six months, during which four (or more) of the following are present:

1. Often loses temper.

2. Often argues with adults.

3. Often actively defies or refuses to comply with adults' requests or rules.

4. Often deliberately annoys people.

5. Often blames others for his or her mistakes or misbehaviour.

6. Is often touchy or easily annoyed by others.

7. Is often angry and resentful.

8. Is often spiteful or vindictive.

The behaviour must occur more frequently than is typically observed in individuals of comparable age and developmental level and must be causing significant problems in school and in relationships with family and friends. 


\section{DSM-IV criteria for Conduct Disorder:}

Conduct disorder is a repetitive and persistent pattern of behaviour in which the basic rights of others, or major rules and values of society are violated, as shown by the presence of three (or more) of the following behaviour patterns in the past 12 months, with at least one behaviour pattern present in the past six months:

Aggression to people and animals:

1. Often bullies, threatens, or intimidates others.

2. Often initiates physical fights.

3. Has used a weapon that can cause serious physical harm to others (for example, a bat, brick, broken bottle, knife, gun).

4. Has been physically cruel to people.

5. Has been physically cruel to animals.

6. Has stolen while confronting a victim (for example, mugging, purse snatching, extortion, armed robbery.

7. Has forced someone into sexual activity.

\section{Destruction of property:}

8. Has deliberately engaged in fire setting with the intention of causing serious damage.

9. Has deliberately destroyed others' property (other than by fire setting).

\section{Deceitfulness or theft:}

10. Has broken into someone else's house, building, or car.

11. Often lies to obtain goods or favours or to avoid obligations (in other words, "cons" others)

12. Has stolen items of nontrivial value without confronting a victim (for example, shoplifting, but without breaking and entering; forgery).

Serious violations of rules:

13. Often stays out at night despite parental prohibitions, beginning before age 13 years

14. Has run away from home overnight at least twice while living in parental or parental surrogate home (or once without returning for a lengthy period)

15. Is often truant from school, beginning before age 13 years

\section{Who might not be eligible?}

I want to try and make the research experience as helpful and useful as possible to parents, and limit any possible distress caused.

As such families identified as having any of the following risk issues should be excluded from taking part in the research study: 
- Currently involved in child custody or child protection proceedings.

- Are having significant difficulties coping with a major life stressor, such as recent bereavement or significant loss, serious mental or physical illness that required hospitalisation or homelessness in the last six months.

- Major risk issues identified within the family, such as domestic violence, abuse or neglect.

What do I do if I am working with someone who might be interested in participating?

Please provide them with a 'Participant Information Form' and ask if they would be interested in taking part. If they agree to be contacted further about the research, please fill in the attached contact form, including risk assessment and pass to me.

If you have any questions about the research then you can contact me on or

Thank you

Name of researcher:

Rhiannon Lewis, Trainee Clinical Psychologist

Supervised by: 
APPENDIX G - CONTACT FORM

Understanding Conduct Disorder - The ways in which parents attempt to make sense of their child's behaviour

Participant Contact Details (to be completed by the referring professional)

Name:

Sex: $M$ / F (delete as

appropriate)

Address:

Tel No:

Relationship to young person identified as having behavioural difficulties:

Age of young person (must be aged 8-13):

Sex: $M / F$

\section{RISK AND VULNERABILITY ISSUES}

Do you consider a home visit for research purposes feasible?

Is the child / young person safe at home?

Is it safe to visit the family home?

Are there any other risk issues that I need to be aware of?

If yes, expand.....

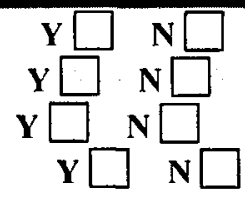

Has the young person / family displayed any of the following behaviours?

\begin{tabular}{|l|l|}
\hline$\square$ Verbally abusive behaviour & $\begin{array}{l}\square \text { Unpredicatability due to substance } \\
\text { misuse }\end{array}$ \\
\hline$\square$ Violent offences / behaviour & $\begin{array}{l}\square \text { Unpredictability due to mental health } \\
\text { issues }\end{array}$ \\
\hline$\square$ Verbal abuse / threats towards staff & $\begin{array}{l}\square \text { Sexual offences / sexually } \\
\text { innappropriate behaviour }\end{array}$ \\
\hline$\square$ Physical violence towards staff & $\square$ Self-harm / attempted suicide \\
\hline$\square$ Racist / homophobic abuse or other hate & $\square$ Other \\
\hline crime & \\
\hline \begin{tabular}{l} 
Please give details \\
\hline
\end{tabular}
\end{tabular}


- Do the Family have any pets? $\mathbf{Y} \square \mathrm{N}$

If Yes please describe what pets and how many

- Is the Neighbourhood safe at night? $\mathrm{Y} \square \mathrm{N} \square$

If NO please describe

Has the research been discussed with the individual named above?

$\mathbf{Y} \square$ $\mathbf{N} \square$

Have they consented to being contacted by the researcher? 
Participant Information (to be completed by the researcher)

Unique Participant Number

Age:

Sex:

Relationship to young person:

Ethnicity:

Genogram depicting close family relationships: 


\section{APPENDIX H - RISK ASSESSMENT}

\section{Risk assessment}

\section{Phvsical}

Risk will be managed for the participants and researcher by following the guidelines below:

- A risk assessment will be completed by a relevant healthcare professional to assess whether there are any significant risk issues within the family environment (see Appendices).

- Interviews will only be carried out during usual working hours, ie. Monday to Friday, 9am to $5 \mathrm{pm}$

- The researcher will follow the lone-working guidelines within the NHS trust and will carry out an assessment of the environment when entering participants homes, including ensuring a safe exit route.

- The researcher will let an identified professional within the CAMHS/MST service know when entering participants' homes and inform them of the expected end time for interviews.

\section{Emotional}

Risk will be managed for participants by following the guidelines below:

- Participants who are assessed as being at risk of emotional distress due to recent siginifcant life events will be excluded from the research study.

- Informed consent will be gained from each participant

- Participants will be informed of their right to withdraw and of their right to stop the interview at any time

- Participants will be informed that they can let the researcher know if they feel distressed during the interview

- The researcher will stop the interview if they become worried about the wellbeing of the participant.

- Participants will be de-briefed at the end of the interview, and they will be given information about who they should talk to if they feel distressed afterwards (see Appendices).

Risk will be managed for the researcher by following the guidelines below:

- The researcher will make use of regular supervision to discuss the emotional impact of the interviews 
Confidentiality

All information regarding personal details will be kept confidential to the individual participant and dealt with according to the Data Protection Act. The content of the interviews will be anonmyised, however, participants will be informed that anything that they say that gives the researcher cause for concern regarding the participant or another's safety will be discussed with the research supervisor prior to being discussed with the CAMHS or other relevant parties as is deemed necessary.

\section{Thanking participants for their participation}

Much thought has gone into determining a suitable way of thanking participants for their participation in this project. £10 was deemed to be a suitable amount of money, being a relatively low value and vouchers have been considered more suitable than cash. 
APPENDIX I - PARTICIPANT CONSENT FORM

Participant Consent Form

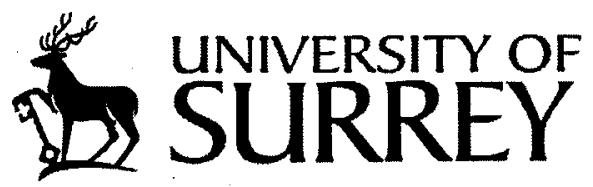

\section{Understanding Your Child's Behaviour}

Name of Researcher - Rhiannon Lewis, Trainee Clinical psychologist at the University of Surrey.

- I agree to being interviewed for the research project to explore parent's experiences of having a child with behavioural difficulties.

- I have read and understood the Information Sheet .

- I understand that my decision to take part in this project is entirely voluntary. I understand that whether I decide to take part in the research or not, will have no effect on any support I may be receiving from the CAMHS team.

- I have been given information by the researcher about what the project is about, where and why it is being done, and how long it is likely to take.

- I have been given information by the researcher of what I will be expected to do. I have been told about any possible emotional distress which taking part in the project may cause, and have been offered support should this happen.

- I have been given the opportunity to ask the researcher questions about any part of the project and have understood the answers to all of the questions I have asked.

- I will tell the researcher immediately if I become upset or worried by any questions that I am asked during the interview, or if I have any subsequent concerns.

- I understand that all personal data is held and processed in the strictest confidence, and in accordance with the Data Protection Act (1998). I have been informed that audio recordings will be destroyed once the study has been completed and that written transcripts will have any personally identifiable information omitted and/or removed to ensure anonymity.

- I am happy for the researcher to write about what I say during the interview and publish this as long as this information remains 
anonymous. I understand that quotes from the interviews may be used, but these will be made anonymous.

- I understand that I can change my mind about participating in the study at any time (up to the point that the research is submitted for assessment) and I don't have to give a reason for wanting to do this.

- I understand that as reimbursement for my time I will receive a $£ 10$ High Street voucher following the interview.

- I have read and understood everything written above and have chosen to consent to participating in this study. I have been given enough time to think about this and agree to comply with the instructions and restrictions of the project.

Name of participant (BLOCK CAPITALS)

Signed

Date

Name of researcher/person taking consent (BLOCK CAPITALS)

Signed

Date

Rhiannon Lewis,

Trainee Clinical Psychologist, University of Surrey.

Tel: Email: 
APPENDIX J - INTERVIEW SCHEDULE

Understandina conduct Disorder: The wavs in which parents attempt to make sense of their children's behaviour.

Interview Schedule

Introduction

- Explain rationale and procedure.

- Check participant has signed consent form.

- Ask if any questions.

Interview Schedule (including additional prompts to be used as required)

I am going to be asking you some questions about what has been like to be a parent of a child with behavioural difficulties. There are no right or wrong answers, I am just interested in hearing about your experiences, so please try and answer as honestly as possible.

1. Please could you start by telling me a little bit about who is in your family?

- Who is in the household?

- What are their names, ages, relationships to one another?

- Who in the family has been identified as having behavioural difficulties?

2. Can you describe for me the main concerns you have about your son/daughter's behaviour?

- If you don't have particular concerns, has someone else (within or outside the family) expressed concerns about his/her behaviour?

- What are the aspects of his/her behaviour that they have expressed concern about?

- How do you feel about this?

3. When/how did you first become concerned about your son/daughter's behaviour?

- Was there a specific incident that alerted you? 
- Did someone else (within or outside the family) raise the initial concerns?

4. Did you have any ideas (at the time) about why this might have been happening?

- Who did you speak to about your concerns at the time?

- Were you able to access any information about what was happening? If so, was the information helpful/unhelpful?

- Did you do anything in particular to try and manage the behaviour? If so, was there anything that helped or made it worse?

5. Has there been times when the behaviour has changed in some way, i.e. become better or worse?

- If so, do you have any ideas about why this was?

- Did your strategies to try and manage the behaviour change at all?

- Did you worry about being able to manage your child's behaviour?

- Did you feel like you needed more help in managing your child's behaviour?

6. Did anyone else become involved in helping you to manage your child's behaviour? (e.g. school, youth workers, other family support networks?)

- What have been your experiences of this?

- How have you found them? Helpful / unhelpful?

7. At what point did the CAMHS team become involved?

- What have been your experiences of this?

- How have you found them? Helpful / unhelpful?

- Has the input from the CAMHS team helped you to understand your child's behaviour? In what way? If so, how have your ideas about the behaviour changed as a result of the input from the CAMHS team? 
8. Looking back, do you think your ideas about why the behaviour was occurring have changed at all over time?

- If so, why do you think this was?

\section{Debrief}

- Thank you very much for your time. That is the end of the interview.

- Do you have any questions?

- How are you feeling?

- Give de-brief sheet. 


\section{Participant Debrief Sheet}

\section{Understanding Your Child's Behaviour}

Thank you for agreeing to talk to me about your experiences and taking part in my research.

Please let me know if you feel upset or worried after the interview

If anything that was talked about has upset or worried you and you don't feel like you want to talk to the researcher or someone at the CAMHS team, you might

find the following organisations helpful:

\section{General Information and Support}

Family Lives: parenting advice and support charity. Website www. familylives.org.uk Confidential Parentline: 08088002222

Parents Advice Centre: help and support for parents.

Website: www.parentsadvicecentre.org

Parents Helpline: 08088010722

Samaritans: 08457909090

\section{Specialist Information and Support}


National Parent Partnership: information advice and support for parents of children with Special Educational Needs.

Website: www.parentpartnership.org.uk

Gingerbread: advice and practical support for single parents.

Website: www.gingerbread.org.uk Helpline: 08088020925

Positive Parent Action: for parents of children with disabilities or additional needs in the borough of Wandsworth.

Website: www.positiveparentaction.org.uk Tel: 02089475260

If you continue to feel upset or worried and think you might need further support you should contact your GP who can refer you to a relevant professional if needed. 


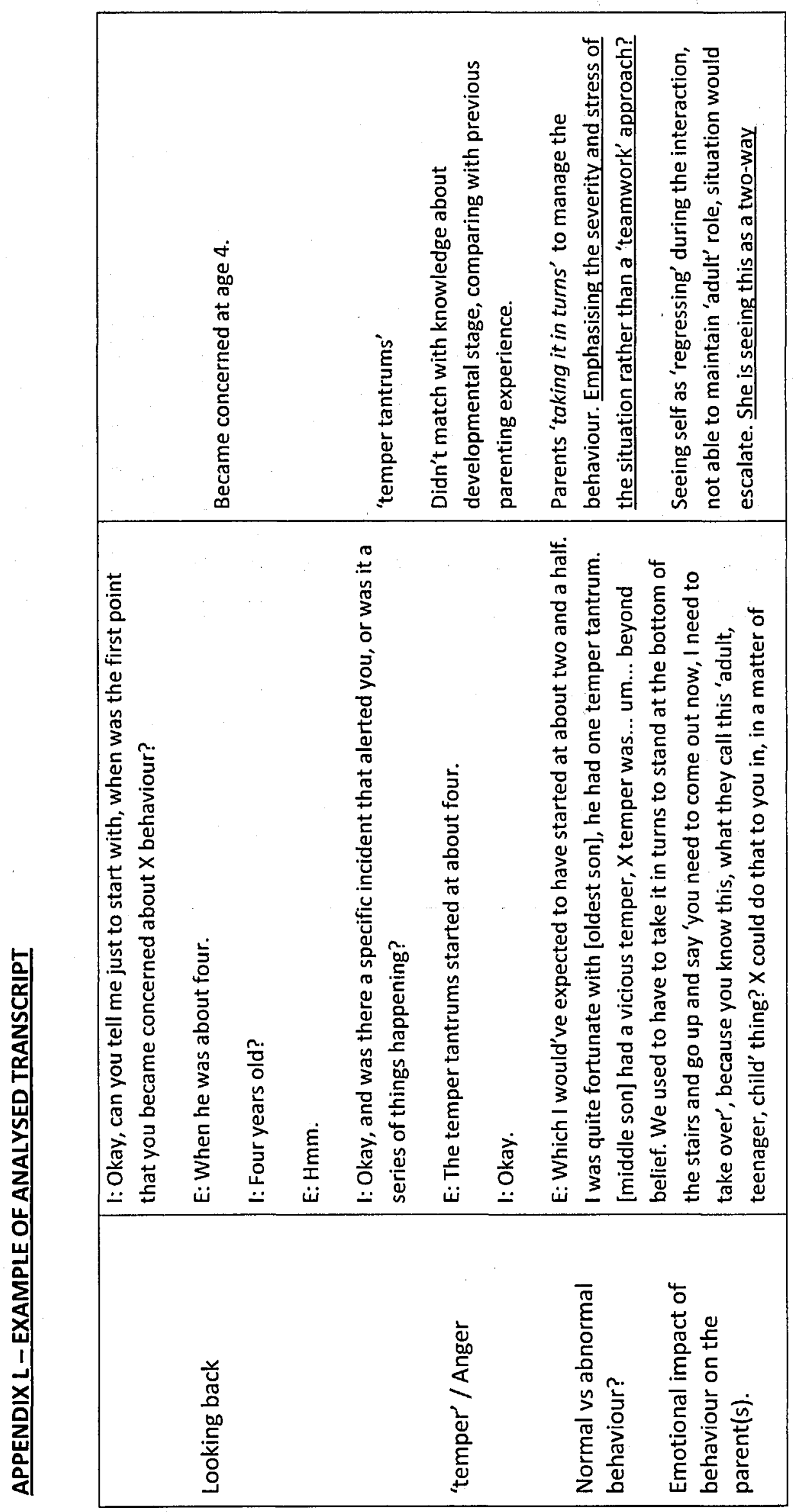




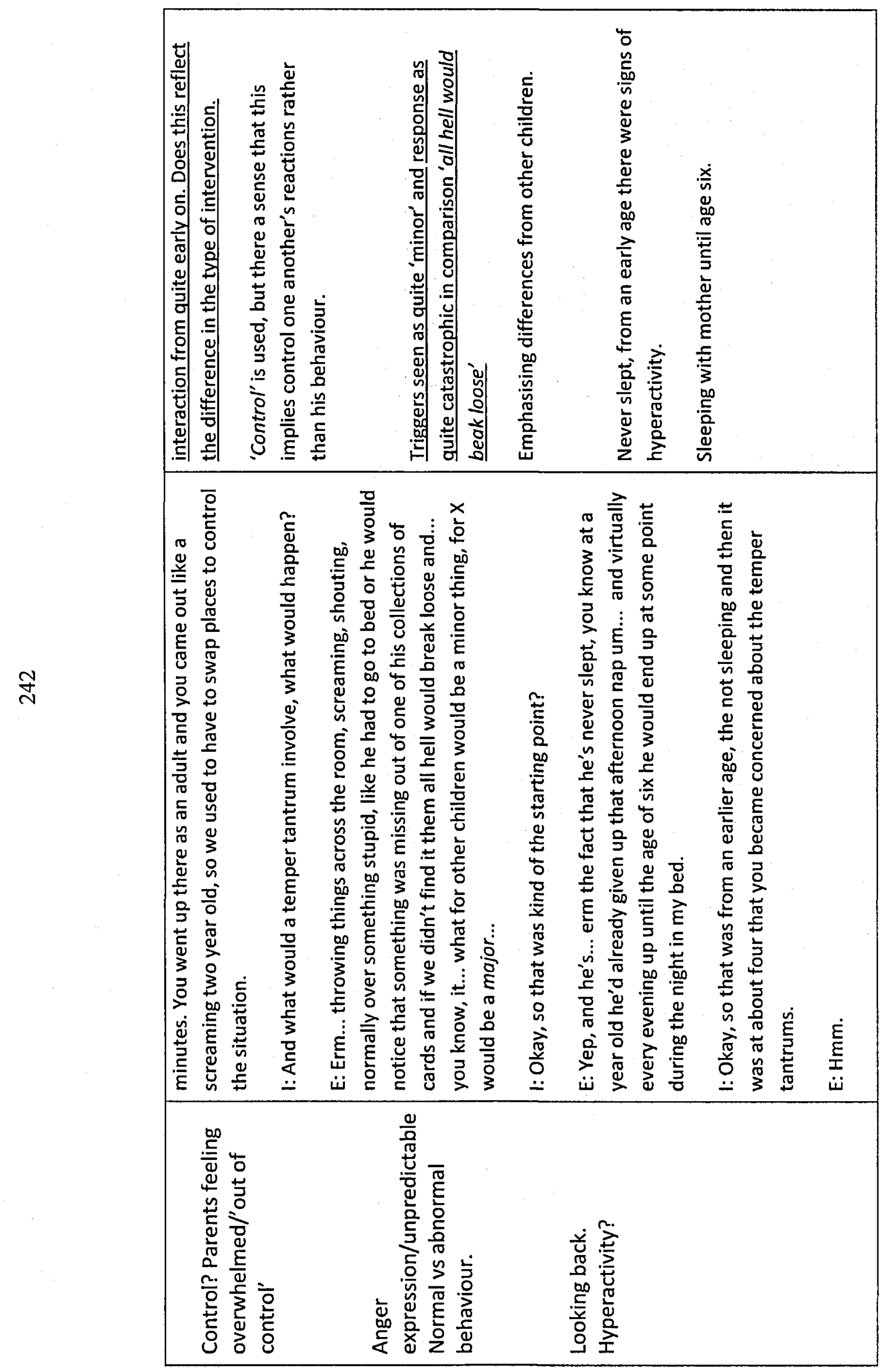




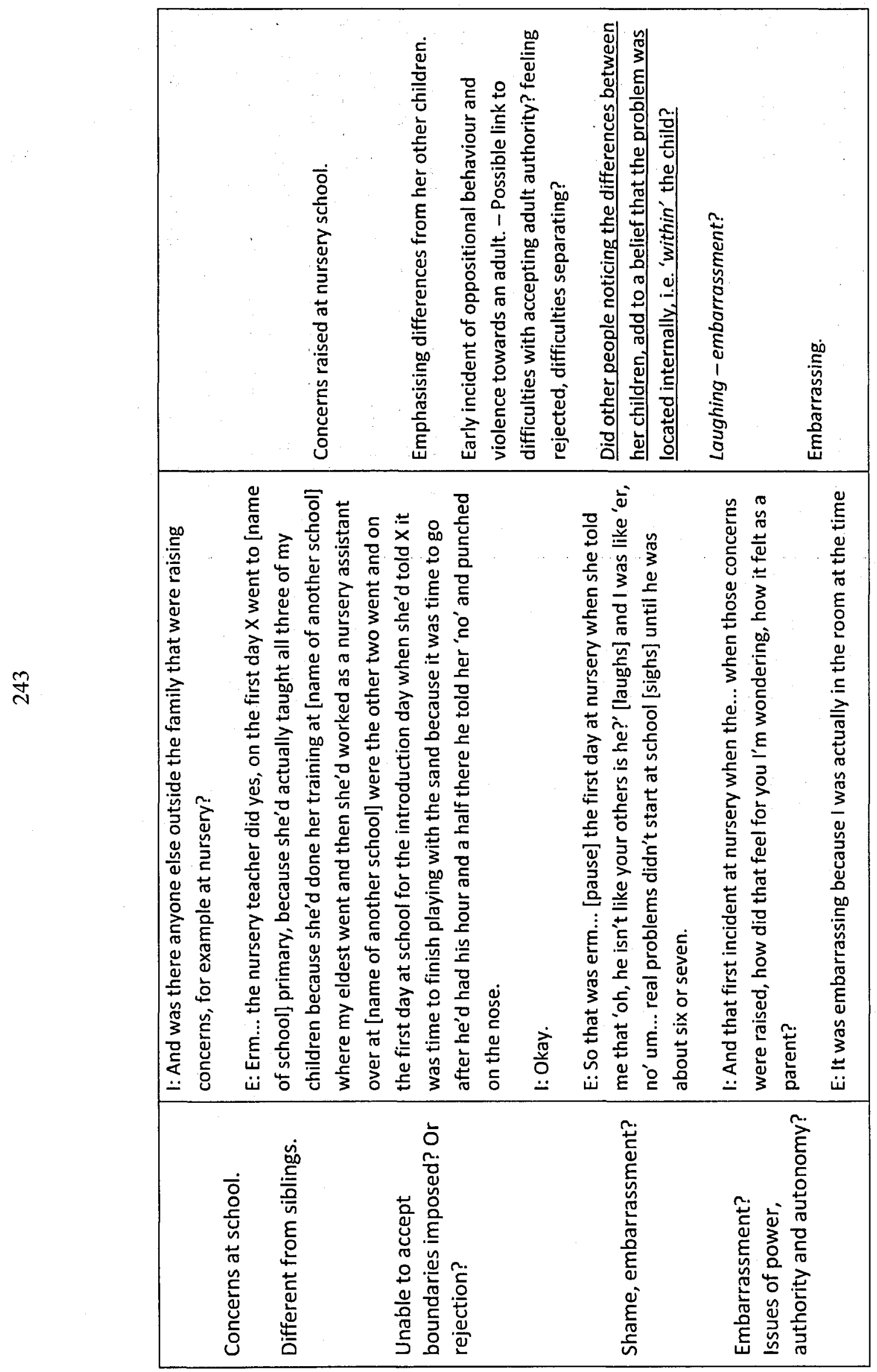




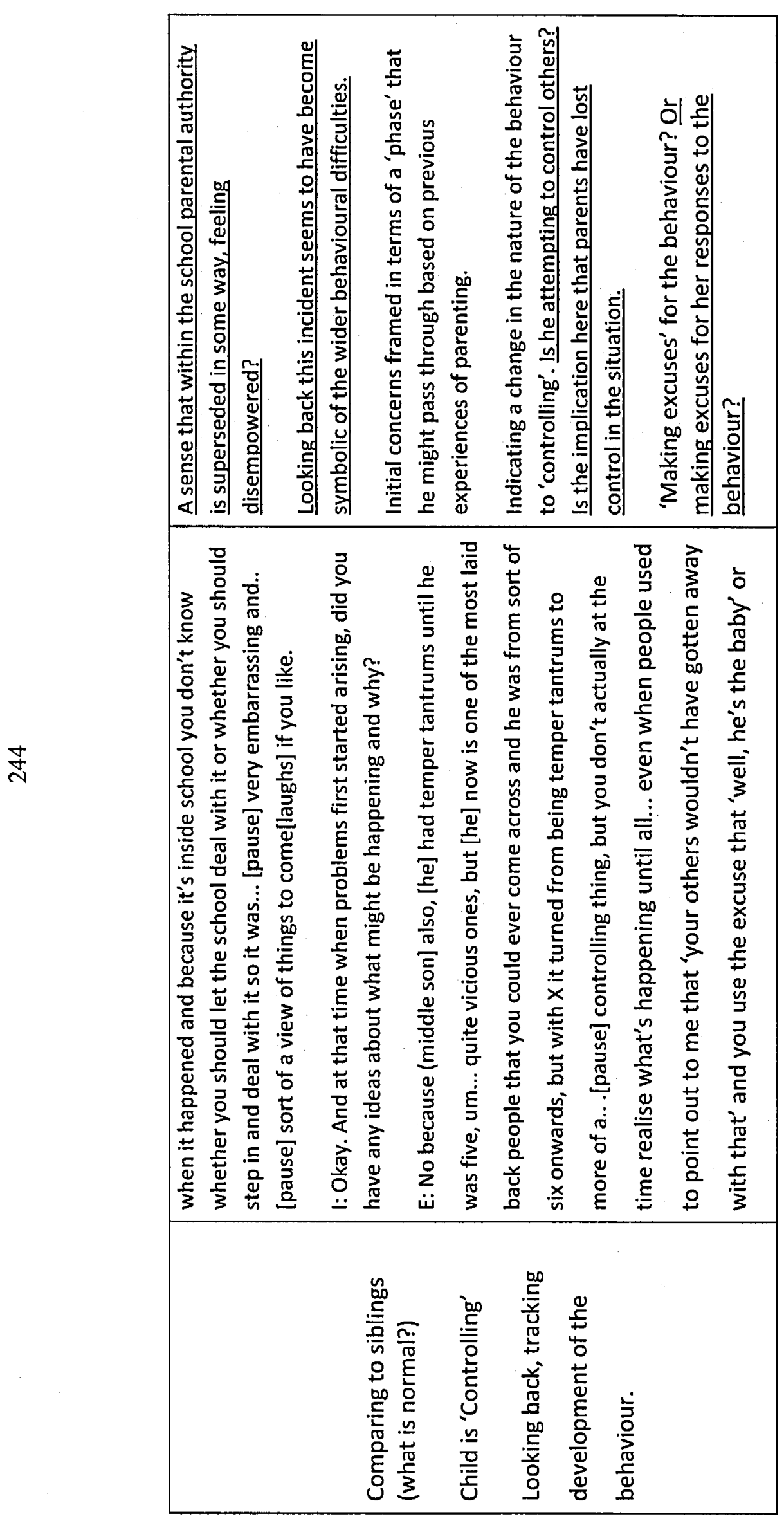




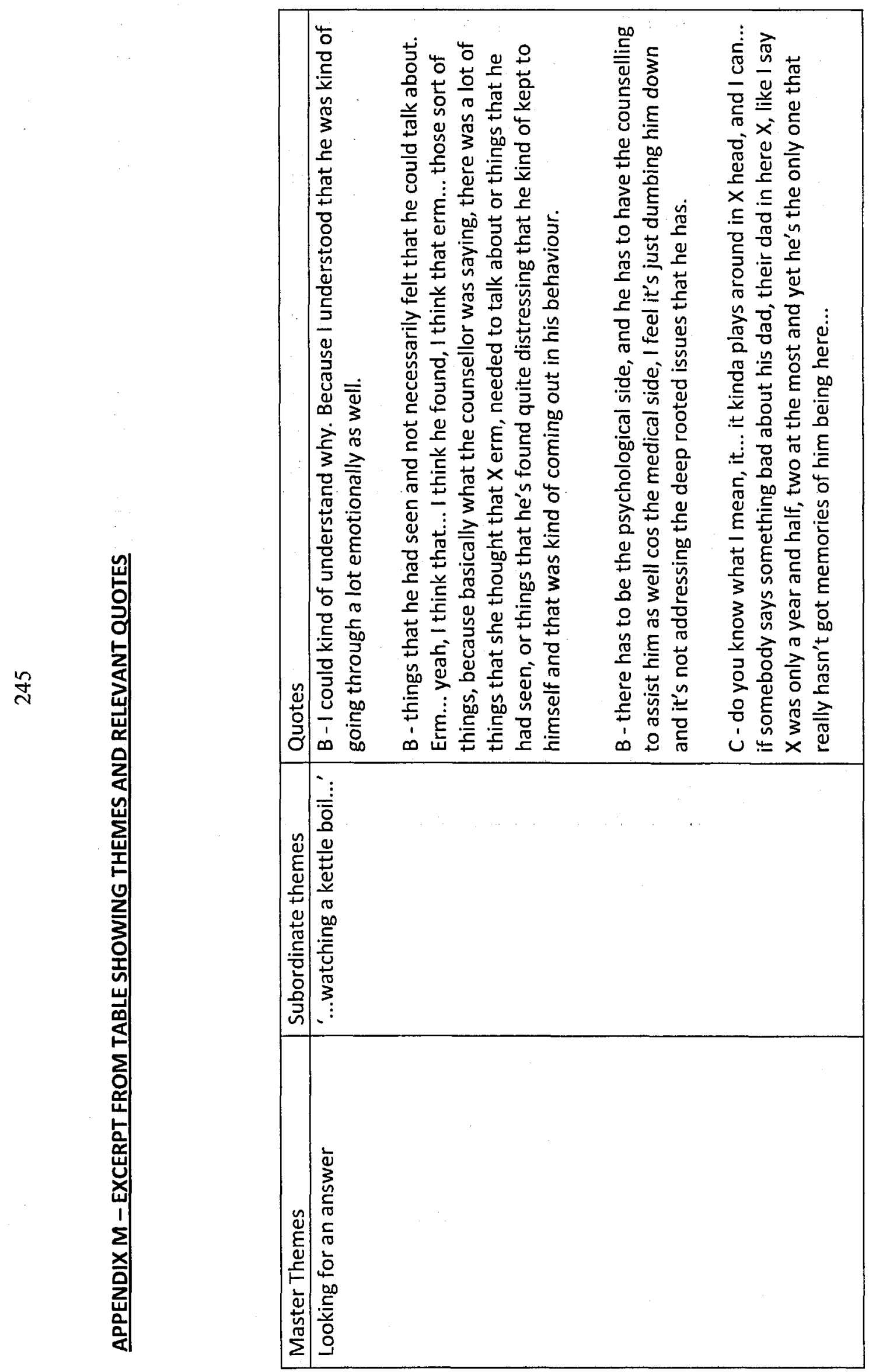




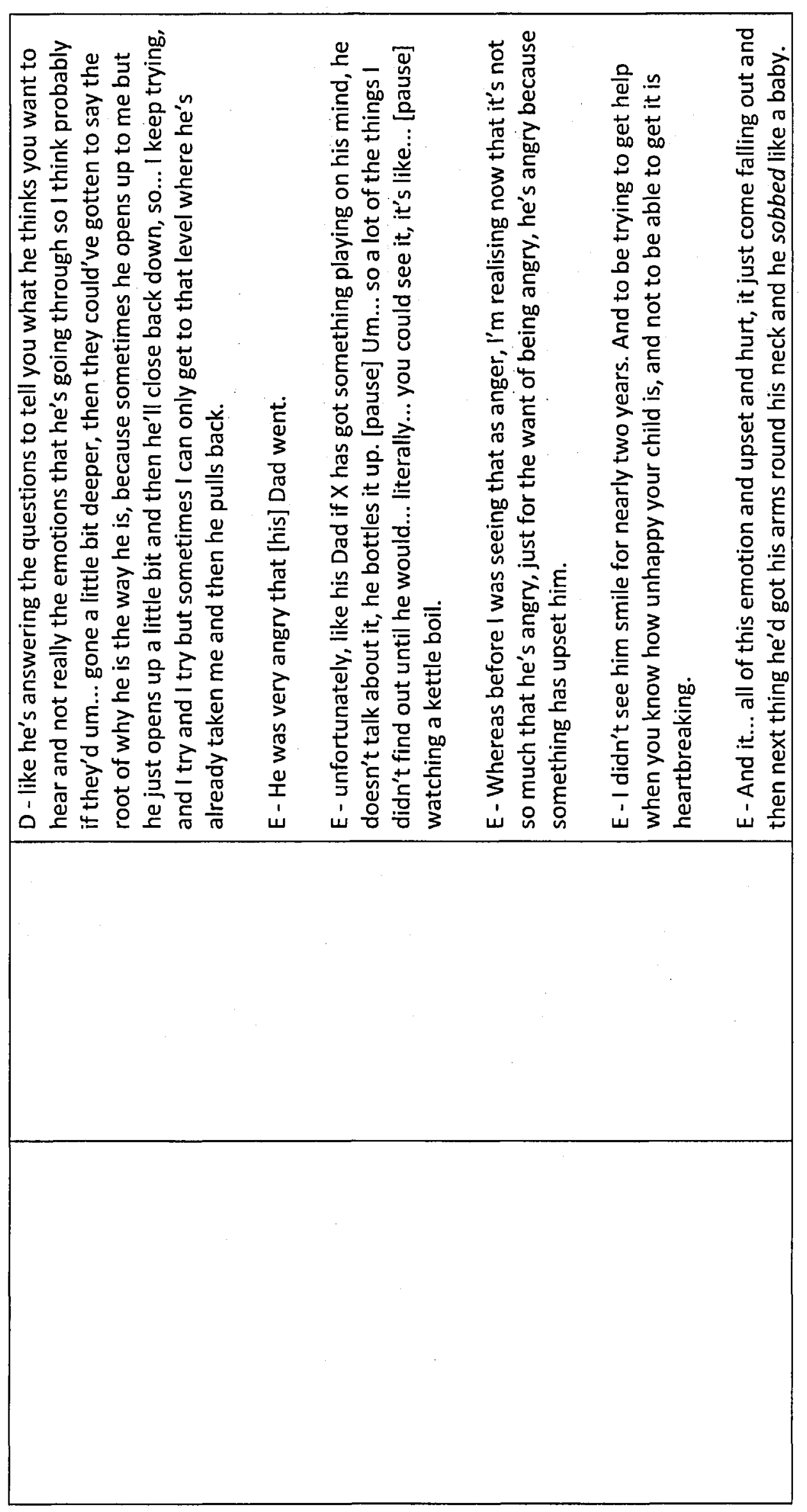




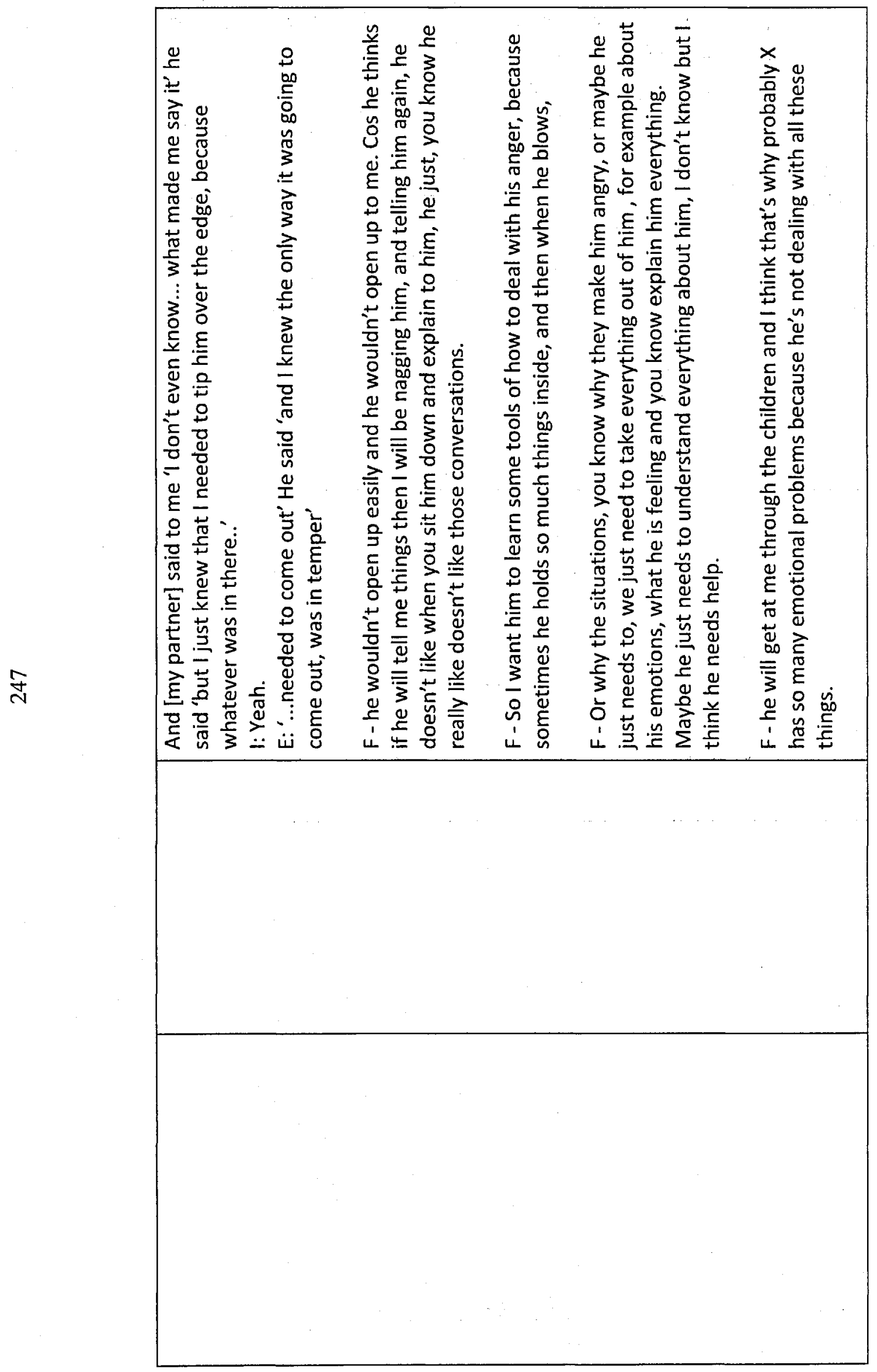




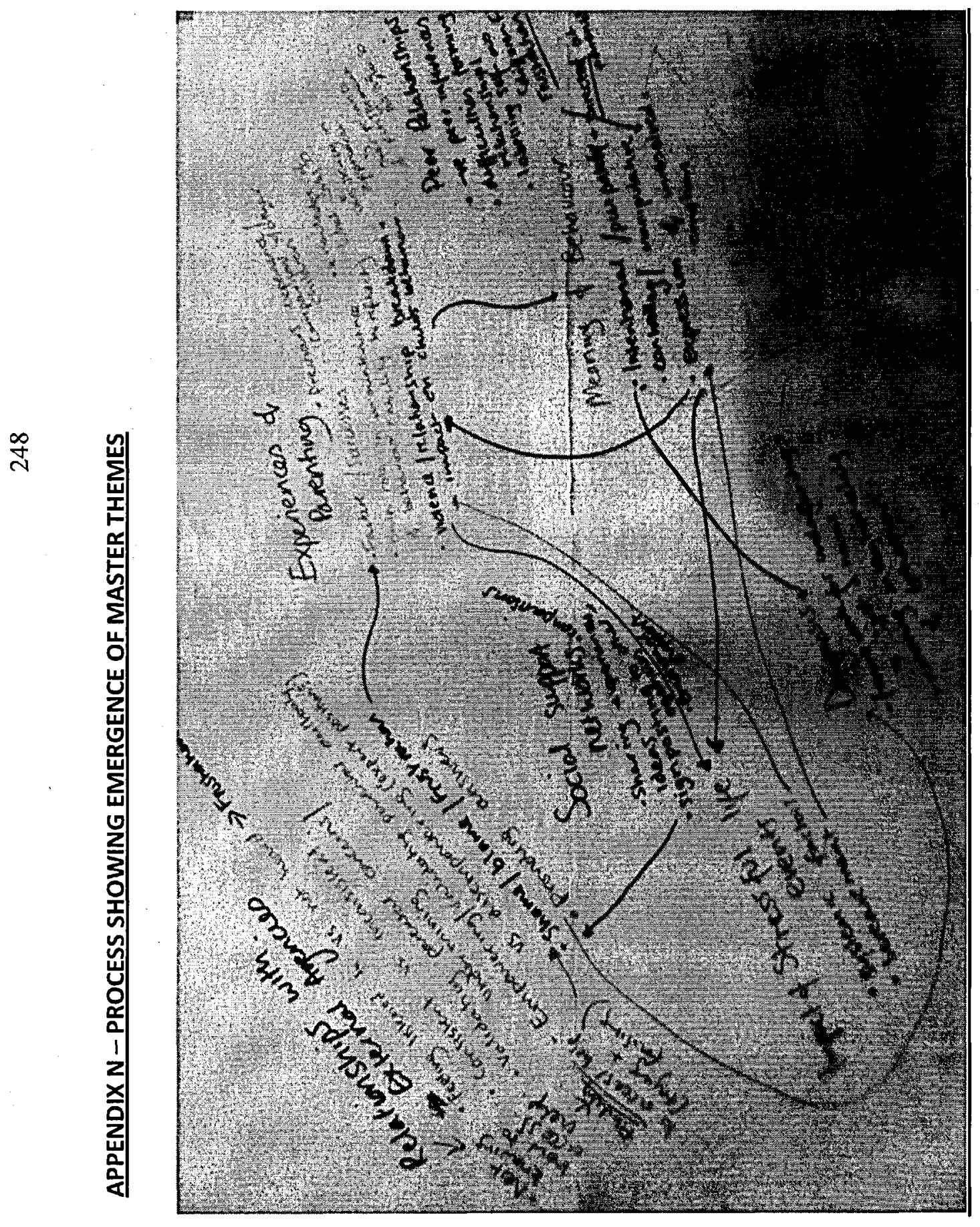




\section{Research Log}

\begin{tabular}{|c|c|c|}
\hline 1 & Formulating and testing hypotheses and research questions & $\checkmark$ \\
\hline 2 & $\begin{array}{l}\text { Carrying out a structured literature search using information technology and } \\
\text { literature search tools }\end{array}$ & $\checkmark$ \\
\hline 3 & Critically reviewing relevant literature and evaluating research methods & $\checkmark$ \\
\hline 4 & Formulating specific research questions & $\checkmark$ \\
\hline 5 & Writing brief research proposals & $\checkmark$ \\
\hline 6 & Writing detailed research proposals/protocols & $\checkmark$ \\
\hline 7 & $\begin{array}{l}\text { Considering issues related to ethical practice in research, including issues of } \\
\text { diversity, and structuring plans accordingly }\end{array}$ & $\checkmark$ \\
\hline 8 & Obtaining approval from a research ethics committee & $\checkmark$ \\
\hline 9 & Obtaining appropriate supervision for research & $\sqrt{ }$ \\
\hline 10 & Obtaining appropriate collaboration for research & $\checkmark$ \\
\hline 11 & Collecting data from research participants & $\checkmark$ \\
\hline 12 & Choosing appropriate design for research questions & $\checkmark$ \\
\hline 13 & Writing patient information and consent forms & $\checkmark$ \\
\hline 14 & Devising and administering questionnaires & $\checkmark$ \\
\hline 15 & Negotiating access to study participants in applied NHS settings & $\checkmark$ \\
\hline 16 & Setting up a data file & $\checkmark$ \\
\hline 17 & Conducting statistical data analysis using SPSS & $\checkmark$ \\
\hline 18 & Choosing appropriate statistical analyses & $\checkmark$ \\
\hline 19 & Preparing quantitative data for analysis & $\checkmark$ \\
\hline 20 & Choosing appropriate quantitative data analysis & $\sqrt{ }$ \\
\hline 21 & Summarising results in figures and tables & $\checkmark$ \\
\hline 22 & Conducting semi-structured interviews & $\checkmark$ \\
\hline 23 & Transcribing and analysing interview data using qualitative methods & $\sqrt{ }$ \\
\hline 24 & Choosing appropriate qualitative analyses & $\checkmark$ \\
\hline 25 & Interpreting results from quantitative and qualitative data analysis & $\checkmark$ \\
\hline 26 & Presenting research findings in a variety of contexts & $\checkmark$ \\
\hline 27 & Producing a written report on a research project & $\checkmark$ \\
\hline 28 & Defending own research decisions and analyses & $\checkmark$ \\
\hline 29 & $\begin{array}{l}\text { Submitting research reports for publication in peer-reviewed journals or edited } \\
\text { book }\end{array}$ & $\mathbf{X}$ \\
\hline 30 & Applying research findings to clinical practice & $\checkmark$ \\
\hline
\end{tabular}

